\title{
STUDIES OF MUCOSAL IMMUNE REGULATION \\ IN CELIAC DISEASE AND TYPE 1 DIABETES
}

\section{ANNE LAHDENPERÄ}

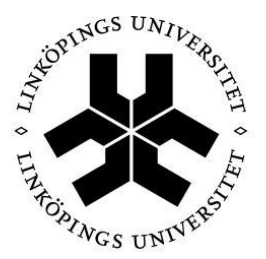

\section{Linköping University \\ FACULTY OF HEALTH SCIENCES}

Division of Paediatrics

Department of Clinical and Experimental Medicine

Faculty of Health Sciences, Linköping University, Sweden 
() Anne Lahdenperä, 2014

ISBN: 978-91-7519-286-4.

ISSN: 0345-0082.

Paper I, II and III has been printed with permission from the publisher.

During the course of the research underlying this thesis, Anne Lahdenperä was enrolled in Forum Scientium, a multidisciplinary doctoral programme at Linköping University, Sweden.

Printed in Sweden by LiU-Tryck, Linköping, Sweden, 2014. 
To my family 


\section{SUPERVISORS}

Johnny Ludvigsson, Professor Emeritus

Division of Paediatrics, Department of Clinical and Experimental Medicine, Faculty of Health Sciences, Linköping University, Linköping, Sweden.

Outi Vaarala, Professor

Institute of Clinical Medicine, University of Helsinki, Helsinki, Finland.

Translational Science, Innovative Medicine/Respiratory, Inflammatory and Autoimmune

Diseases, AstraZeneca.

Rosaura Casas, Associate Professor

Division of Paediatrics, Department of Clinical and Experimental Medicine, Faculty of Health Sciences, Linköping University, Linköping, Sweden.

\section{OPPONENT}

Eva Sverremark-Ekström, Professor

The Wenner-Gren Institute, Department of Molecular Biosciences, Stockholm University, Stockholm, Sweden.

\section{COMMITTEE BOARD}

Marie-Louise Hammarström, Professor

Immunology, Department of Clinical Microbiology, Umeå University, Umeå, Sweden.

Jonas Wetterö, Associate Professor

Autoimmunity and Immune Regulation Unit (AIR)/Rheumatology, Department of Clinical and Experimental Medicine, Faculty of Health Sciences, Linköping University, Linköping, Sweden.

Torbjörn Ledin, Professor

Oto-Rhino-Laryngology, Department of Clinical and Experimental Medicine, Faculty of Health Sciences, Linköping University, Linköping, Sweden. 


\section{CONTENTS}

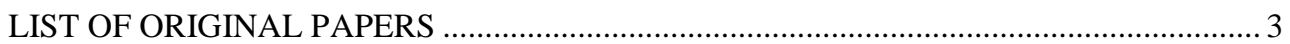

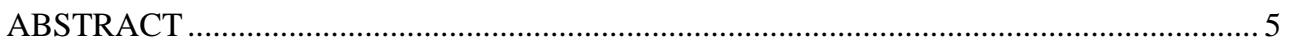

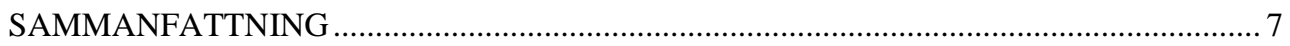

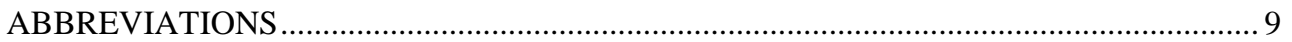

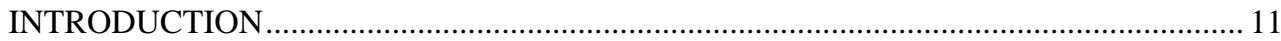

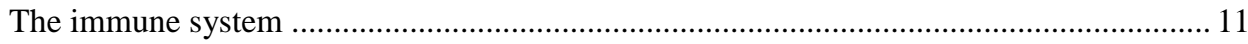

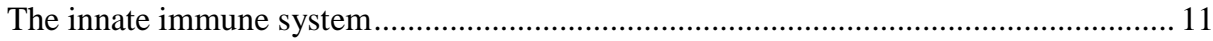

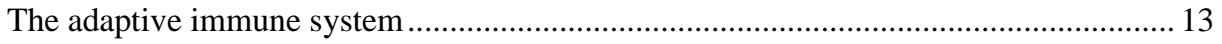

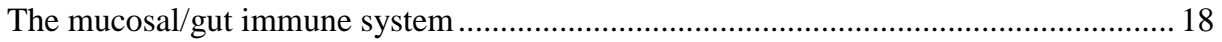

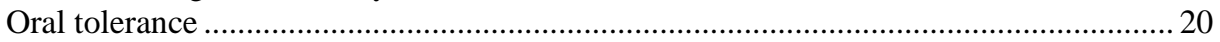

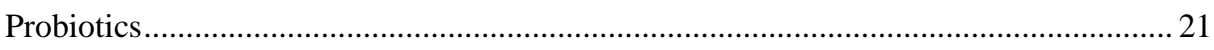

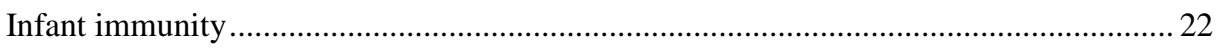

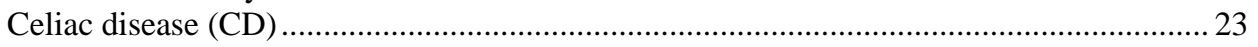

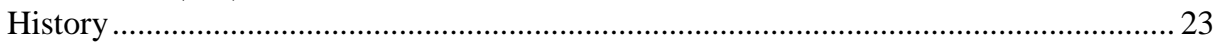

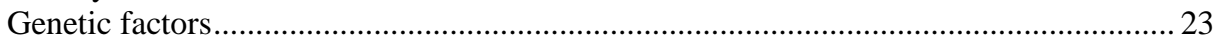

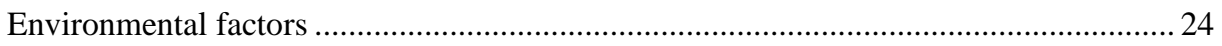

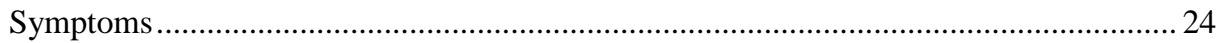

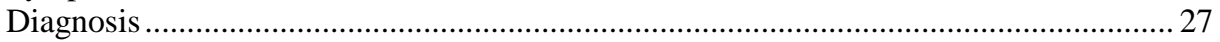

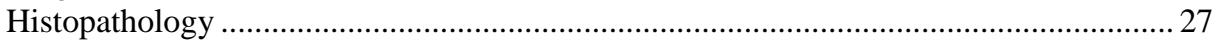

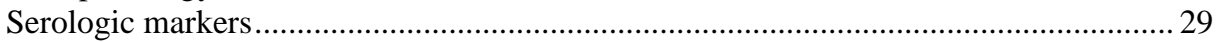

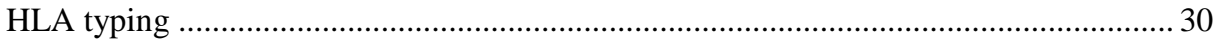

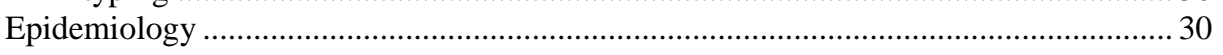

Development of CD/(Molecular) Pathogenesis ....................................................... 31

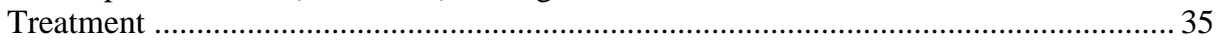

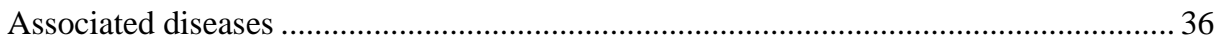

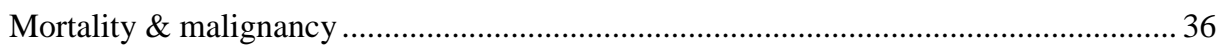

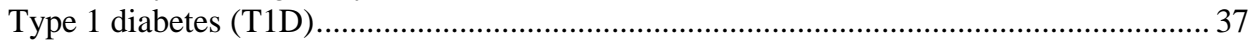

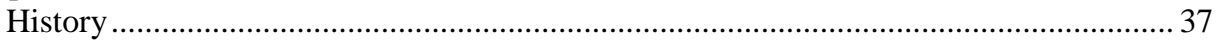

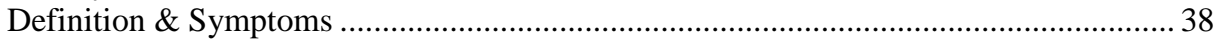

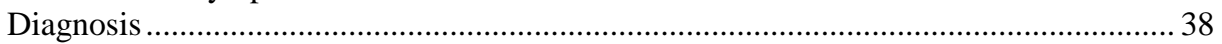

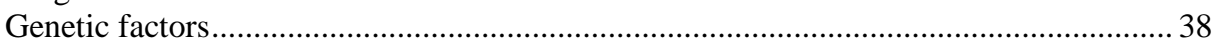

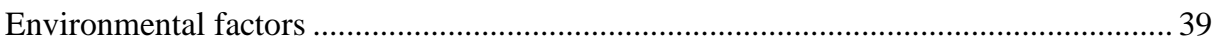

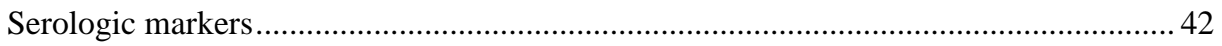

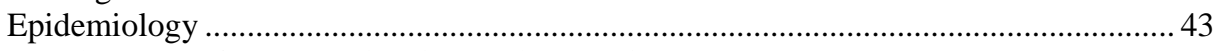

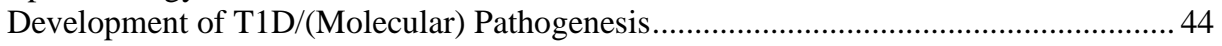

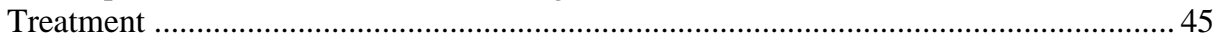

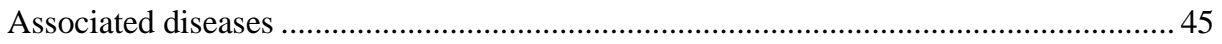

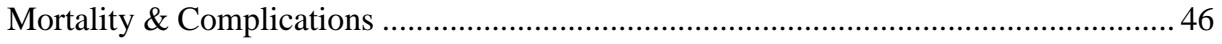

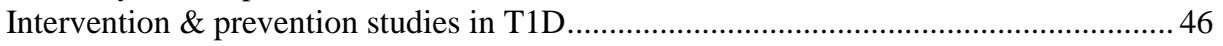

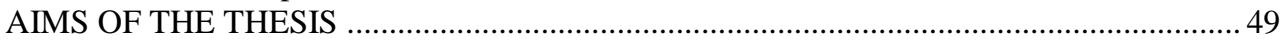

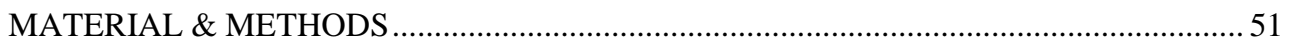

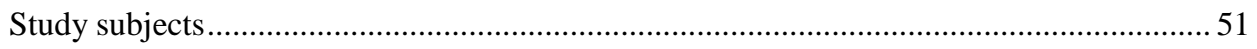

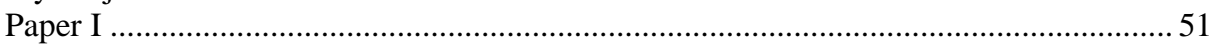

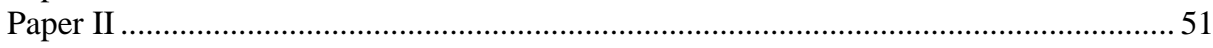

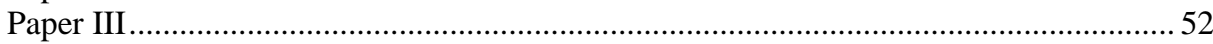

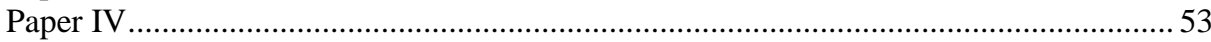

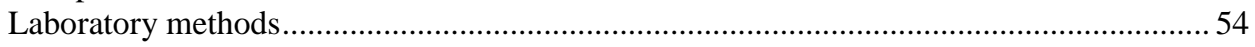




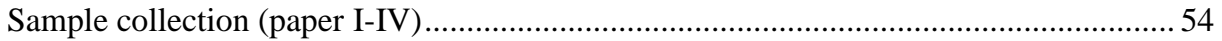

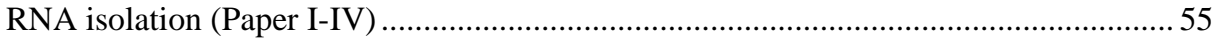

Real-time polymerase chain reaction (PCR)-array analyses (Paper I, III and IV)...........56

Quantitative real time reverse transcription (RT)-PCR analyses (Paper II and III) ..........59

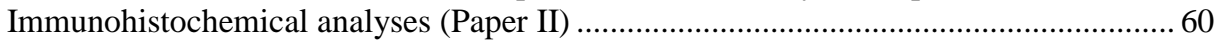

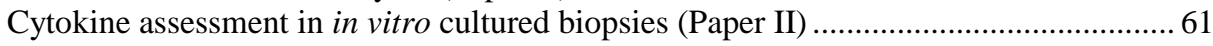

Analyses of apoptotic markers in IL-17 treated Caco-2 cells (Paper II) .......................... 61

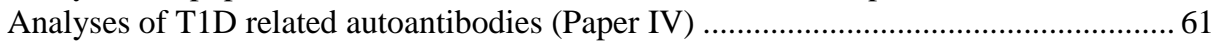

Whole blood cultures in vitro stimulated with LPS or LTA (Paper IV) ............................62 62

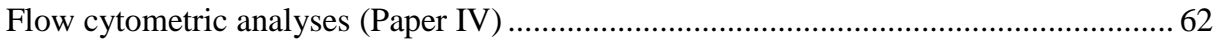

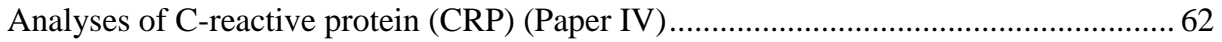

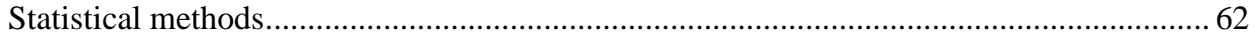

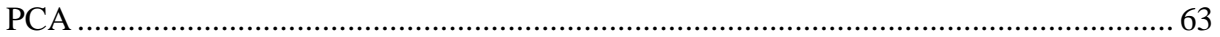

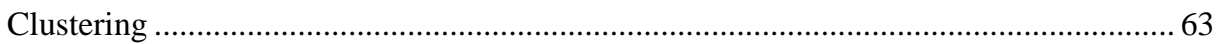

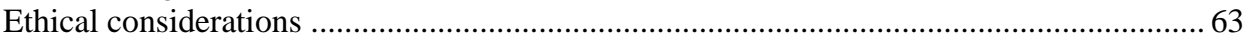

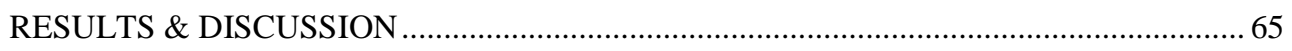

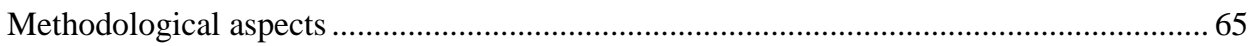

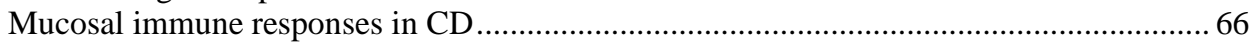

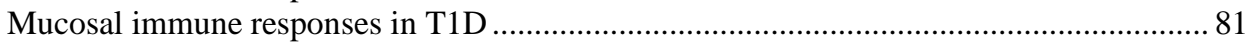

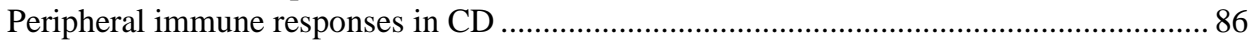

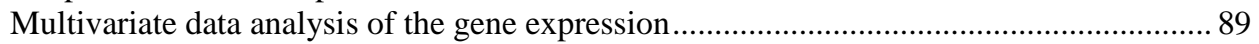

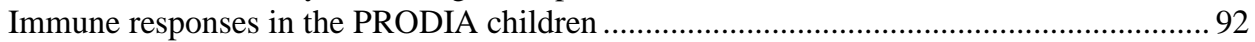

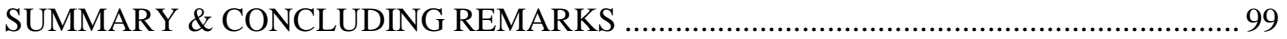

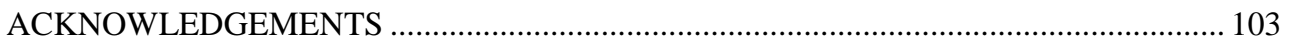

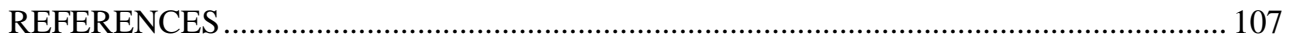




\section{LIST OF ORIGINAL PAPERS}

This thesis is based on the following papers, which will be referred to in the text by their roman numerals.

\section{Paper I}

ANNE I. LAHDENPERÄ, Johnny Ludvigsson, Karin Fälth-Magnusson, Lotta Högberg \& Outi Vaarala.

The effect of gluten-free diet on Th1-Th2-Th3-associated intestinal immune responses in celiac disease.

Scandinavian Journal of Gastroenterology, 2011; 46: 538-549.

Paper II

ANNE I. LAHDENPERÄ, Veera Hölttä, Terhi Ruohtula, Harri M. Salo, Laura Orivuori, Mia Westerholm-Ormio, Erkki Savilahti, Karin Fälth-Magnusson, Lotta Högberg, Johnny Ludvigsson, Outi Vaarala.

Up-regulation of small intestinal IL-17 immunity in untreated celiac disease but not in potential celiac disease or in type 1 diabetes.

Clinical Experimental Immunology, 2012; 167: 226-34.

Paper III

ANNE I. LAHDENPERÄ, Karin Fälth-Magnusson, Lotta Högberg, Johnny Ludvigsson, Outi Vaarala. Expression pattern of Th17 signalling pathway and mucosal inflammation in celiac disease.

Scandinavian Journal of Gastroenterology, 2014; 49:145-56.

\section{Paper IV}

ANNE I. LAHDENPERÄ, Martin Ljungberg, Anna Lundberg, Riitta Korpela, Rosaura Casas, Johnny Ludvigsson, Outi Vaarala.

Probiotics and innate immune response in infants.

In manuscript. 


\section{ABSTRACT}

Background: Celiac disease (CD) and type 1 diabetes (T1D) are two chronic autoimmune diseases with increasing incidence worldwide. A combination of genetic, environmental and immunological factors is considered to be involved in development of the diseases, even though the exact disease mechanisms still are unknown. CD and T1D are both believed to be associated with type 1 like immune responses. However, there is limited knowledge about the complex network of intestinal and peripheral immune responses associated with the diseases.

Aims: The aim of this thesis was to explore intestinal and peripheral immune responses in children at different stages of CD and in children with T1D. Further, we studied peripheral immune responses in children at risk for T1D supplemented with probiotics during their first 6 months of life (PRODIA study).

Results \& Discussion: Children with untreated CD had up-regulated T-helper (Th)1, T-cytotoxic (Tc)1, Th17 and T-regulatory (Treg) responses, but down-regulated Th2 and Th3 responses in the small intestine. The type 1 response (Th1 and Tc1) seemed to remain elevated in CD children under gluten free diet (GFD)-treatment and thus seemed to be related to the disease itself rather than the gluten intake. The Th2, Th3, Th17 and Treg responses seemed to be gluten dependent, since they normalized upon GFD-treatment. The alterations in the intestinal biopsies did not seem to correlate with the alterations seen in the blood Children with potential CD had diminished levels of the Th17 cytokine IL-17, whereas children with untreated CD had elevated levels of IL17 , indicating that IL-17 immunity develops in the late phase of $\mathrm{CD}$ when villous atrophy has developed. Furthermore, stimulation of intestinal epithelial cells with IL-17 induced anti-apoptotic mechanisms. The low intestinal expression of Th1, Th17 and Treg markers was normal in children with T1D, whereas children with T1D and CD had the same pattern as children with untreated CD: high intestinal secretion of pro-inflammatory and Th17 cytokines. The immune responses in children with T1D were generally influenced by the degree of villous atrophy.

As expected, the number of children in the PRODIA study developing T1D related autoantibodies during their first two years of life was low. No difference in the autoantibody emergence was seen between infants given probiotics compared to placebo. In the probiotic group, the number of circulating CD58+ monocytes was lower at 6 months of age. At 12 months of age the number of circulating CCR5+ monocytes was lower in the probiotic group, whereas the spontaneous expression of TLR9 on PBMCs was higher.

Conclusion: Most of the intestinal T-cell associated immune alterations were generally gluten dependent, since they normalized on a GFD treatment, but the type 1 response seemed to be related to the disease itself, since it was still seen in GFD treated individuals. IL-17 immunity seemed to be induced in the late stage of $C D$, when villous atrophy has developed and it seemed to be involved in protection from tissue damage in the inflamed intestinal mucosa. The intestinal immune responses were generally not reflected in peripheral blood.

Probiotic supplementation in infancy modulated the activation stage and stimulation response of monocytes. Thus, early exposure to microbes seemed to influence the function of the innate immune system in later life. 


\section{SAMMANFATTNING}

Bakgrund: Celiaki och typ 1 diabetes (T1D) är två kroniska autoimmuna sjukdomar med ökande förekomst världen över. En kombination av genetiska, miljömässiga och immunologiska faktorer är av betydelse för sjukdomsutvecklingen, även om den exakta mekanismen är okänd. Celiaki och T1D antas vara associerade med typ 1 lika immunsvar. Det finns dock begränsad kunskap om det komplexa nätverket av immunsvar i tarm och i blod associerade med sjukdomarna.

Syfte: Syftet med studien var att undersöka immunsvar i tarmen och i blodet hos barn med celiaki, med eller utan glutenfri kost, samt hos barn med T1D. Därtill att undersöka perifera immunsvar i blodet hos barn med risk för T1D, som fått probiotika under deras första levnadshalvår (PRODIA studien).

Resultat \& Diskussion: Barn med obehandlad celiaki hade uppreglerade T-hjälpar (Th) 1, Tcytotoxiska (Tc) 1, Th17 och T-regulatoriska (Treg) immunsvar i tunntarmen, men nedreglerade Th2 och Th3 svar. Typ 1 svaren (Th1 och Tc1) verkade förbli förhöjda hos barn som behandlats med glutenfri kost och verkade därför vara relaterade till sjukdomen i sig snarare än till intaget av gluten. Th2, Th3, Th17 och Treg svaren verkade vara beroende av glutenintag eftersom de normaliserades av glutenfri kost. Förändringarna i tarmbiopsierna verkade inte korrelera med förändringarna i blodet. Barn med potentiell celiaki hade nedreglerade nivåer av Th17 cytokinen IL-17, medan barn med obehandlad celiaki hade förhöjda nivåer av IL-17. Detta tyder på att IL-17 immuniteten uppkom sent i celiakiutveckligen när tarmskadan hade uppkommit. Därtill hade stimulering av tarmepitelceller med IL-17 påskyndat celldöd. Barn med T1D hade lågt uttryck av Th1, Th17 och Treg markörer, medan barn med både T1D och celiaki hade hög sekretion av proinflammatoriska och Th17 cytokiner i tarmen liksom barn med obehandlad celiaki. Immunsvaren hos barn med T1D influerades generellt sett av graden av villös atrofi.

Som förväntat var antalet barn i PRODIA-studien som utvecklade T1D relaterade autoantikroppar under sina första två levnadsår lågt. Det var inga skillnader i förekomst av autoantikroppar mellan barn som fick probiotika jämfört med placebo. I probiotika gruppen var antalet cirkulerande CD58+ monocyter lägre vid 6 månaders ålder. Vid 12 månaders ålder var antalet cirkulerande CCR5+ monocyter lägre i probiotika gruppen, medan det spontana uttrycket av TLR9 på PBMC var förhöjt.

Slutsats: Majoriteten av de T-cell associerade immun förändringarna i tarmen var gluten beroende, eftersom de normaliserades vid behandling med glutenfri kost, men de Typ 1 relaterade svaren verkade dock vara relaterade till sjukdomen i sig, eftersom de bibehölls hos individer behandlade med glutenfri kost. IL-17 immuniteten verkade induceras sent i sjukdomsutvecklingen vid celiaki, när tarmskadan hade uppkommit och verkade vara involverad i skydd mot vävnadsskada i den inflammerade tarmslemhinnan. Immunsvaren i tarmen avspeglade generallt sett inte immunsvaren i perifert blod.

Tillförsel av probiotika till spädbarn påverkade aktiveringsnivån och stimuleringssvaren hos monocyterna. Tidig exponering för mikroorganismer verkade påverka funktionen hos det medfödda immunförsvaret senare i livet. 


\section{ABBREVIATIONS}

\begin{tabular}{|c|c|}
\hline AGA & Anti-gliadin antibodies \\
\hline APC & Antigen presenting cell \\
\hline BCR & B-cell receptor \\
\hline CCR & Chemokine receptor \\
\hline $\mathrm{CD}$ & Celiac disease \\
\hline CRP & C-reactive protein \\
\hline CTLA-4 & Cytotoxic T lymphocyte associated antigen 4 \\
\hline DC & Dendritic cell \\
\hline $\mathrm{DH}$ & Dermatitis herpetiformis \\
\hline EMA & Endomysium antibodies \\
\hline FSC & Forward scatter \\
\hline Foxp3 & Forkhead box P3 \\
\hline GALT & Gut-associated lymphoid tissue \\
\hline GFD & Gluten free-diet \\
\hline HLA & Human leukocyte antigen \\
\hline ICOS & Inducible co-stimulator \\
\hline IEL & Intraepithelial lymphocytes \\
\hline IFN & Interferon \\
\hline $\operatorname{Ig}$ & Immunoglobulin \\
\hline IL & Interleukin \\
\hline INS & Insulin gene \\
\hline IRAK & IL-1 receptor associated kinase \\
\hline iTregs & Inducible $\mathrm{T}$ regulatory cells \\
\hline LAB & Lactic acid bacteria \\
\hline LADA & Latent autoimmune diabetes of adults. \\
\hline LP & Lamina propria \\
\hline LPS & Lipopolysaccharide \\
\hline LTA & Lipoteichoic acid \\
\hline MALT & Mucosa associated lymphoid tissue \\
\hline $\mathrm{M}$ cells & Microfold cells \\
\hline MLN & Mesenteric lymph node \\
\hline
\end{tabular}




\begin{tabular}{|c|c|}
\hline MMP & Matrix metalloproteinase \\
\hline MODY & Maturity onset diabetes of the young \\
\hline mRNA & Messenger ribonucleic acid \\
\hline MyD88 & Myeloid differentiation primary response gene \\
\hline $\mathrm{nF} \kappa \mathrm{B}$ & Nuclear factor kappa $b$ \\
\hline nTreg & Natural T regulatory cells \\
\hline NK cell & Natural killer cell \\
\hline NKT & Natural killer T cell \\
\hline NOD & Non-obese diabetic \\
\hline PAMP & Pathogen-associated molecular patterns \\
\hline PBMC & Peripheral blood mononuclear cell \\
\hline PCR & Polymerase chain reaction \\
\hline PP & Peyer's patches \\
\hline PRR & Pattern recognition receptor \\
\hline PTPN22 & Protein tyrosine phosphatase, non-receptor type 22 \\
\hline RT & Reverse transcriptase \\
\hline SIgA & Secretory immunoglobulin A \\
\hline SSC & Side scatter \\
\hline STAT & Signal transducers and activators of transcription \\
\hline T1D & Type 1 diabetes \\
\hline Tc & Cytotoxic T-cell \\
\hline TCR & T-cell receptor \\
\hline Tfh & Follicular T-helper cells \\
\hline TGA & Transglutaminase antibodies \\
\hline TGF & Transforming growth factor \\
\hline Th & T-helper cell \\
\hline TIRAP & Toll-interleukin receptor domain containing adaptor protein \\
\hline TLR & Toll-like receptor \\
\hline TNF & Tumour necrosis factor \\
\hline TRAF & Tumor necrosis factor receptor-associated factor \\
\hline Treg & Regulatory $\mathrm{T}$ cell \\
\hline tTG & Tissue transglutaminase \\
\hline
\end{tabular}




\section{INTRODUCTION}

\section{The immune system}

The most important feature of the immune system is its ability to distinguish between self and dangerous non-self, protecting our body against threats, such as microbial infections and tumors. The immune system consists of two parts; the innate and the adaptive immune responses, which co-operates to maintain immune homeostasis.

\section{The innate immune system}

The innate immune system provides an immediate non-specific response towards microbial infections, which is similar at every encounter with the pathogen [1]. This first line of defence consists of several interacting systems e.g. mechanical barriers such as skin and mucosal membranes, physiological barriers like low $\mathrm{pH}$ and biochemical barriers comprising antimicrobial peptides and NO. Additionally, it comprises other elements like the complement system and effector cells. The cell defence consists of macrophages, mast cells, neutrophils, eosinophils, dendritic cells (DCs), natural killer (NK) cells, natural killer T (NKT) cells and $\gamma \delta$ T cells. The effector cells recognize distinct pathogen patterns, leading to clearing the infection by means of phagocytosis or by secreting inflammatory mediators.

The pathogen patterns detected by the innate immune system are evolutionary conserved structures, present in large groups of microorganisms, e.g. bacteria, viruses, parasites and fungi, referred to as pathogen-associated molecular patterns (PAMPs) [2]. The best-known PAMPs are lipopolysaccharide (LPS), peptidoglycan, lipoteichoic acid (LTA), mannans, bacterial DNA, double-stranded RNA and glucans. These PAMPs are recognized by pattern recognition receptors (PRRs) including among others toll-like receptors (TLRs), NOD-like receptor (NLR), $\beta$-glucan receptors and mannan-binding lectins, which are present on various cells of the innate immune system. On recognition of PAMPs, the PRRs trigger signalling pathways that result in the induction of transcription of a variety of immune response genes, such as antimicrobial peptides and inflammatory cytokines. 
Gram positive bacteria, such as lactobacilli and bifidobacteria, express peptidoglycan and lipoteichoic acid (LTA) on their cell surface, whereas Gram negative bacteria express lipopolysaccharide (LPS) also called endotoxin. Bacterial peptidoglycan binds to the PRR nucleotidebinding oligomerization domain (NOD)2, LTA binds to TLR2 and LPS binds to TLR4 on cells of the innate immune system, e.g. macrophages and DCs. Binding of a TLR by its ligand (e.g. LTA to TLR2) initiates down-stream cellular signaling cascades resulting in strain specific cytokine and chemokine responses, but also transcription of genes important for controlling of infections. The down-stream effects of TLR activation depends on the inflammatory status of the mucosal microenvironment [3].

Activation of TLR2 by its ligand (LTA) leads to recruitment of toll-interleukin receptor domain containing adaptor protein (TIRAP) and myeloid differentiation primary response gene (MyD88), which results in activation of nuclear factor kappa $\mathrm{b}$ (NFkB) and production of cytokines and chemokines [3](Figure 1). Activation of TLR4 by its ligand (LPS) leads to recruitment of MyD88, phosphorylation of IL-1 receptor-associated kinase (IRAK) and tumor necrosis factor receptor-associated factor 6 (TRAF6), which results in production of NFkB and IFN- $\beta$ [3]. 

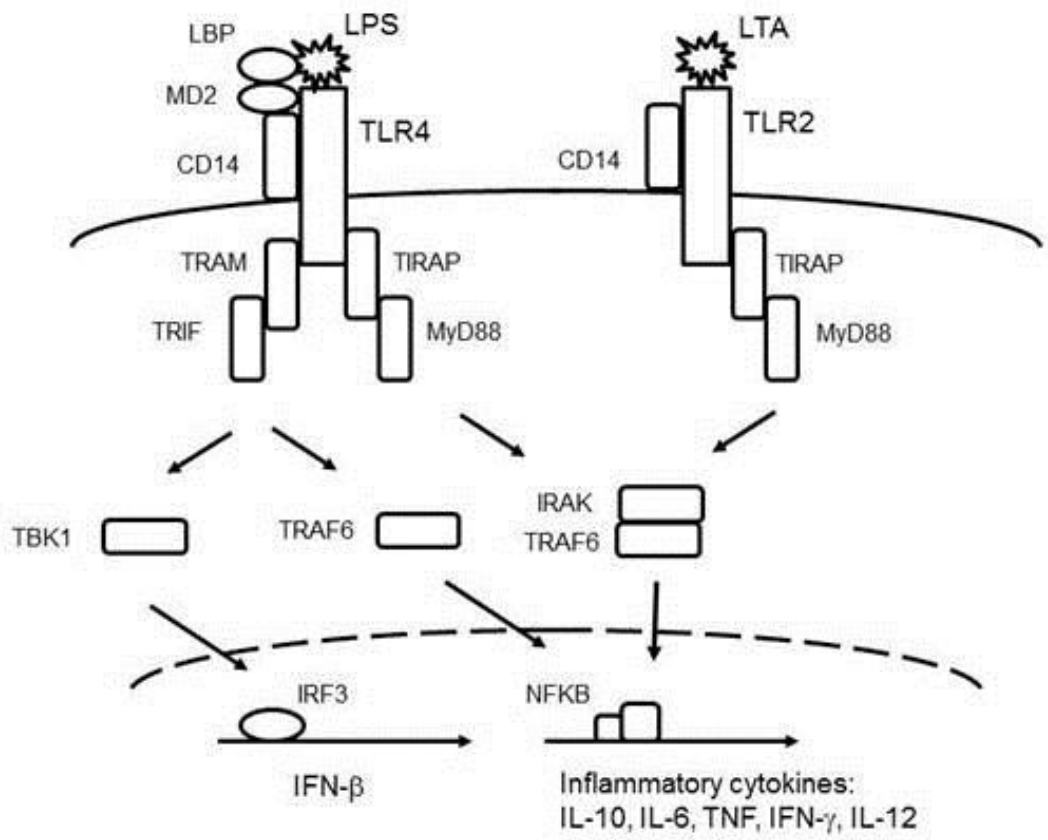

Figure 1. LPS and LTA induced TLR2 and TLR4 signaling pathways. The figure is modified from [4].

\section{The adaptive immune system}

The adaptive immune system is the second line of defence and provides a specific immune response to a specific pathogen. The adaptive response is slower than the innate one, but unlike the innate response it improves after each exposure to the stimulus. Adaptive immune responses are generated in the secondary lymphoid tissues, i.e. lymph nodes, spleen and mucosa-associated lymphoid tissue (MALT). The cell defence is constituted by T-cells and Bcells, which upon activation, proliferate and differentiate into effector cells. The T and B-cells are mainly secreting cytokines and antibodies, respectively. The T cells are subdivided into CD4+ T helper (Th) cells and CD8+ cytotoxic T (Tc) cells, while activated B cells differentiate into plasma cells, which can further differentiate into long-lived memory cells.

\section{T cells}

T-cells undergo a series of selection and maturation processes in the thymus [5]. During positive selection only $\mathrm{T}$-cells expressing a $\mathrm{T}$ cell receptor (TCR) reacting with low affinity with self-peptide-major histocompatibility complex (MHC) (human leukocyte antigen (HLA)) 
complexes receive a "survival signal" and differentiate further. Most T-cells, with no or low affinity for self-peptide-MHC (HLA) complexes, die by neglect. For T-cells expressing a TCR reacting with high affinity for self-peptide-MHC (HLA) complexes several outcomes are possible. Most of these cells are subjected to negative selection, where the main mechanism is clonal deletion. However, regulatory T cells (Tregs) are thought to be induced by high affinity self-peptide-MHC (HLA) interactions in the thymus.

The effector T cells, the Th and Tc cells, develop into different phenotypes, mainly depending on the cytokine milieu. Thus, naïve T cells also called Th0 cells, which mainly produce interleukin (IL)-2, become Th1, Th2, Th17 or inducible T regulatory cells (iTregs) upon activation (Figure 2). IL-12 promotes interferon (IFN)- $\gamma$ production and Th1 development, whereas IL-4 promotes Th2 development (reviewed in [6-8]). Transforming growth factor (TGF)- $\beta$, together with IL-1 $\beta$, IL-6, IL-23 are important for development of Th17 cells, however TGF- $\beta$ is also important for development of iTregs. There are several subpopulations of Tregs present in humans; both the natural Tregs (nTregs) which develop in the thymus, but also the iTregs which develop from naïve Th cells in the periphery. The most common iTregs are Th3 and Tr1 cells.

T cells are functionally subdivided by the pattern of cytokines they produce. The Th1 cells, involved in cell-mediated inflammatory reactions and defence against intracellular pathogens, are characterized by the production of IFN- $\gamma$ and IL-2 and the expression of the transcription factors T-box transcription factor (T-bet) and signal transducer and activator of transcription (STAT)1 and STAT4 [6-8]. The Th2 cells, which are involved in immunoglobulin (Ig)E antibody production and allergic responses, are on the other hand characterized by the production of IL-4, IL-5 and IL-13 and the expression of the transcription factor GATA-3 and STAT6 [6-8]. The Th17 cells, which are involved in protection against bacteria and fungi at mucosal surfaces and in autoimmunity and inflammation, are characterized by the production of IL-17, IL-21 and IL-22 and the expression of RAR-related orphan receptor (ROR) $\gamma$ and STAT3 [6, 8]. Regulatory T cells (Treg), both inducible and natural Tregs, are involved in regulation of the immune system and are essential for preserving tolerance. Both the nTregs and the iTregs Th3 are characterized by the production of IL-10 and TGF- $\beta$, the expression of the transcription factors Forkhead box P3 (FoxP3) and STAT5, and also by the expression of CD25 $[6,8,9]$. The Tr1 cells, another population of the inducible Tregs, do on the other hand 
not express FOXP3 or produce TGF- $\beta$ [9]. Lately, additional subpopulations of Th cells have been discovered e.g. IL-9 producing Th9 cells, IL-22 producing Th22 cells and IL-21 producing follicular Th cells (Tfh) cells (reviewed in $[10,11]$ ).

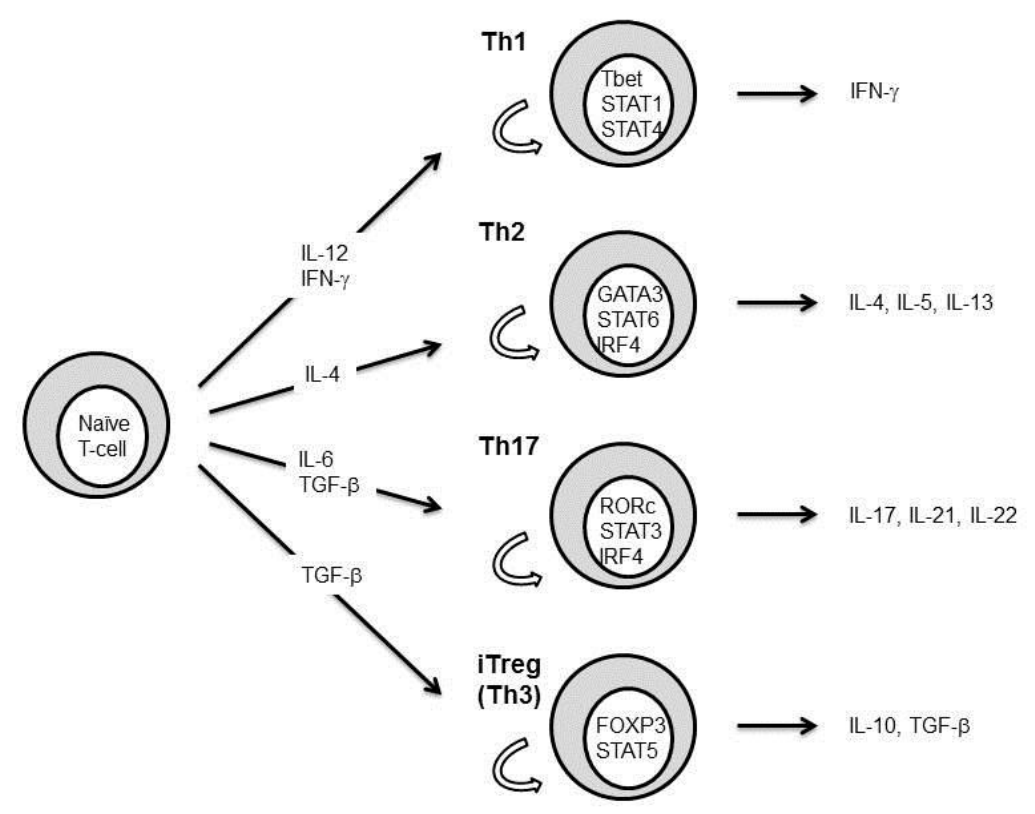

Figure 2. Th-cell differentiation. The figure is modified from [8].

Similarly as for the naïve Th0 cells, cytotoxic T precursor cells develop into Tc1 or Tc2 cells upon activation, which depends of the local cytokine milieu [7]. However, Tc cells need a higher cytokine dose than Th cells in order to differentiate. The Tc1 cells are induced by and produce type 1 cytokines (IFN- $\gamma$, IL-2) whereas the Tc2 cells are induced by and produce type 2 cytokines (IL-4 and IL-5).

\section{T cell receptors}

T cells carry on their cell surface so called TCRs. In humans, as the TCR consists of either $\alpha \beta$ - or $\gamma \delta$-chains, T cells are $\alpha \beta$ TCR positive or $\gamma \delta$ TCR positive, respectively [1]. Approximately $90-95 \%$ of the circulating T cells in humans are $\alpha \beta$ TCR positive, whereas the remaining $\sim 5-10 \%$ are $\gamma \delta$ TCR positive. In the normal intestine, approximately $10 \%$ of the 
intra epithelial lymphocyte (IEL)s are $\gamma \delta$ TCR positive [12], while they are rare in the lamina propria (LP). The majority of the normal intestinal LP T-cells are $\alpha \beta$ positive, whereas only $1 \%$ are positive for $\gamma \delta$.

\section{The immunological synapse}

The activation of T cells by antigen presenting cells (APCs), in the immunological synapse, is a central event in adaptive immunity (Figure 3). Through the TCR they recognize antigens presented by MHC molecules on APCs, called HLA in humans. The TCR is activated by the first signal through the interaction of the TCR, CD4/8 and HLA [1]. The second signal, also called the co-stimulatory signal, is $e . g$. achieved from the interaction of CD28 with CD80/CD86 (or CD40-CD40 ligand and LFA-1/ICAM-1) on the APCs. The CD3 complex, which is associated with the TCR, is responsible for the transmission of the activation signal into the cell. A third signal, most often composed of cytokines produced by the APC, induce different pathways of differentiation of the effector T cells, which in turn induce different effector responses. Enrichment of the molecules involved in the immunological synapse is essential for a successful T-cell activation. Signalling by TCR and HLA alone in the absence of co-stimulatory signals, leads to anergy or apoptosis. These responses are defence mechanisms against activation of the immune system when danger signals are lacking, as danger signals are known to up-regulate CD80/86. T cells can also be deactivated via the interaction of the inhibitory molecule cytotoxic T lymphocyte associated antigen (CTLA)-4 with CD80/86 on the APCs. 


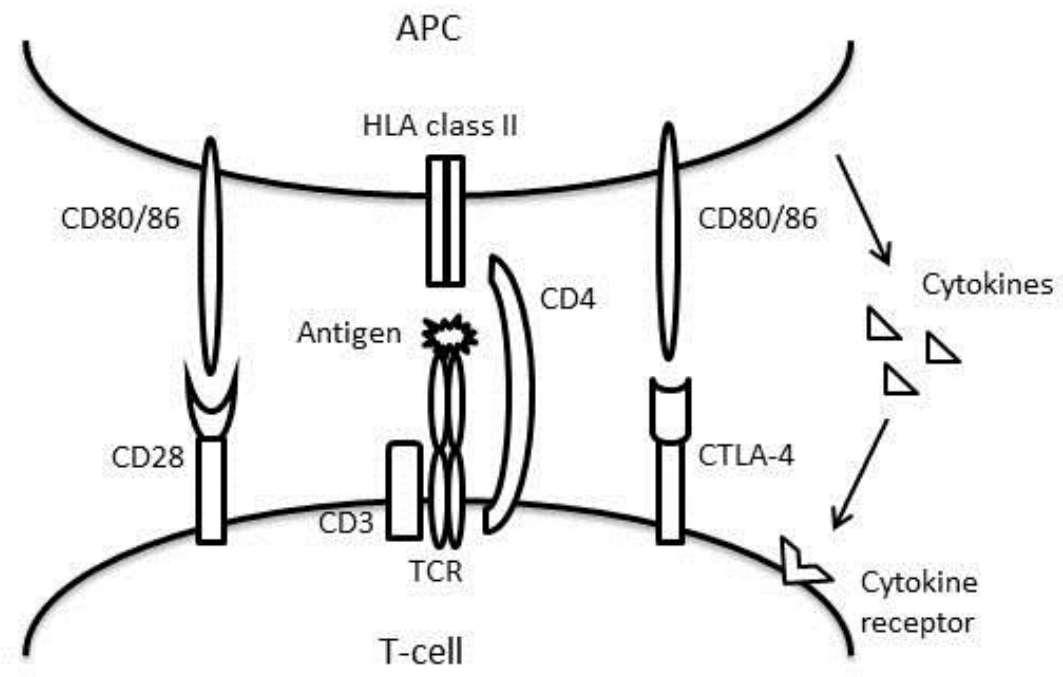

Figure 3. The immunological synapse.

Th cells recognize exogenous antigens presented by HLA class II molecules, present on professional APCs such as DCs, macrophages and B-cells, and they mediate help to other cells by secreting cytokines. The Tc cells recognize endogenous antigens presented by HLA class I molecules, present on all human cells. The Tc cells kill e.g. infected cells via perforin or granzyme or by Fas-Fas ligand interaction.

\section{B cells}

The B cells produce immunoglobulins (Igs) which can be bound to the cells and function as B cells receptors (BCRs), which recognize antigen, B cells can also secrete the Igs, which then are called antibodies and are subdivided into the isoptypes $\operatorname{IgM}, \operatorname{IgD}, \operatorname{IgA}, \operatorname{IgG}$ and $\operatorname{IgE}$. $\operatorname{IgA}$ is the predominant antibody isotype in humans. The IgA and IgG antibodies can be further divided into the subclasses, $\operatorname{IgA} 1$ and $\operatorname{IgA} 2$ and $\operatorname{IgG} 1, \operatorname{IgG} 2, \operatorname{IgG} 3$ and $\operatorname{IgG} 4$, respectively. At mucosal surfaces IgA is the most important antibody, which mainly is present as dimers. Before the B cells are activated they express $\operatorname{IgM}$ and $\operatorname{IgD}$, but after maturation they switch to $\operatorname{IgA}, \operatorname{IgG}$ and IgE [1], depending on the local cytokine milieu [13]. Switching to IgA is for instance stimulated by TGF- $\beta$. About $15-40 \%$ of mononuclear cells in the normal small intestinal lamina propria (LP) are B cells. The humoral immune response in the gut-associated 
lymphoid tissue (GALT) is dominated by the production of secretory $\operatorname{IgA}$, while $\operatorname{IgG}$ and $\operatorname{IgM}$ are also produced in the intestine but to a lesser extent. Secretory Ig A constitutes the largest humoral immune system of the body and performs antigen exclusion at mucosal surfaces [14].

\section{The mucosal/gut immune system}

The gastrointestinal tract in adults covers an enormous area of approximately $400 \mathrm{~m}^{2}$ which is lined by a single layer of epithelial cells. The large area is achieved by the fingerlike projections called villi and by the microvilli of the enterocytes. The primary function of the intestine is to allow nutrient uptake, but also to protect the body against harmful agents and unwanted immune responses towards food antigens and the normal microbiota. The gut epithelium is the first line of defence in the intestine [15], encountering more antigens, both beneficial and harmful, than any other part of the body. The gastrointestinal tract also hosts the normal microbiota, comprised of commensal bacteria, with a total weight of about $1.5 \mathrm{~kg}$ in humans. The normal microbiota is essential for the well-being of the individual but it has lately also been showed to profoundly influence the development and function of our immune system [16].

The mucosal immune system in the gastrointestinal tract, called the gut associated lymphoid tissue (GALT), is the largest and most complex immune compartment in the human body [15, 17]. The GALT consists of the Peyer's patches (PP), mesenteric lymph nodes (MLNs), isolated lymph follicles, and large numbers of T and B lymphocytes, macrophages, dendritic cells, mast cells and neutrophils scattered in the LP and the epithelium. The PP are lymphoid aggregates found in the submucosa of the small intestine [15] [18] (Figure 4) and consists of $\mathrm{B}$ cell follicles and $\mathrm{T}$ cell areas, which are separated from the intestinal lumen by a single layer of epithelial cells containing specialized enterocytes called microfold (M) cells. The M cells transport luminal antigens to professional APCs, e.g. the DCs, which can move to the T and B cell areas of the PPs and interact with naïve lymphocytes. After activation the lymphocytes migrate to the MLNs, a cross road between the peripheral and mucosal immune system, where they differentiate and mature before they migrate into the systemic blood stream via the thoracic duct. Antigen presentation may also occur if an antigen enters through the intestinal epithelium and is picked up by APCs in the LP and then migrate to the MLNs. Alternatively, the antigen might pass through the intestinal epithelium, disseminating into the blood stream from the gut and then interacting with $\mathrm{T}$ cells in peripheral lymph nodes. 
Additionally, macrophage-like DCs sample the gut lumen by projecting antigen-sampling dendrites across the IEC layer [19, 20]. After capturing the antigen the macrophage-like DCs transfer the antigen to migratory DCs which move to the interfollicular areas of the PPs and MLNs to interact with the T cells. Different adhesion molecules and chemokine receptors, e.g. $\alpha 4 \beta 7$ and chemokine receptor (CCR)9, help the lymphocytes to home back to the mucosa, where they accumulate and redistribute into distinct compartments. After maturation, both the $\mathrm{B}$ and CD4+ cells reside in the LP, whereas the majority of the CD8+ cells migrate into the epithelium. After activation T cells homing to the mucosa might act as effector cells, memory effector cells or regulatory cells however. When the effector cells home back to the intestinal mucosa they re-encounter their specific antigen presented on a diverse population of APCs [21]. This interaction may in invasive infections result in increased production of IFN- $\gamma$, IL17, TNF- $\alpha$, lymphotoxin- $\alpha$ and IL-2, which leads to enhanced function of Th and B cells, but also to increased activation of APCs, macrophages and endothelial cells. The uncontrolled production of Th1/Th17 and macrophage derived inflammatory mediators result in recruitment and activation of additional leukocytes in the gut tissue leading to intestinal inflammation. Under homeostatic/non-infectious conditions, it is believed the activated $\mathrm{T}$ cells differentiate into one of the three effector phenotypes: Th1, Th17 or Treg.

After antigen processing and presentation the B cells proliferate and migrate via the blood stream to mucosal tissues where they differentiate into IgA producing plasma cells [18]. IgA is transported across the epithelial cells via transcytosis. The local availability of the vitamin A metabolite retinoic acid is probably important for the IgA-inducing capacity but also for Treg cells. Retinoic acid skews intestinal B-cell responses toward IgA production, by inducing tolerogenic Foxp3+ Treg cells to produce the IgA inducing factor TGF- $\beta 1$ [19]. 


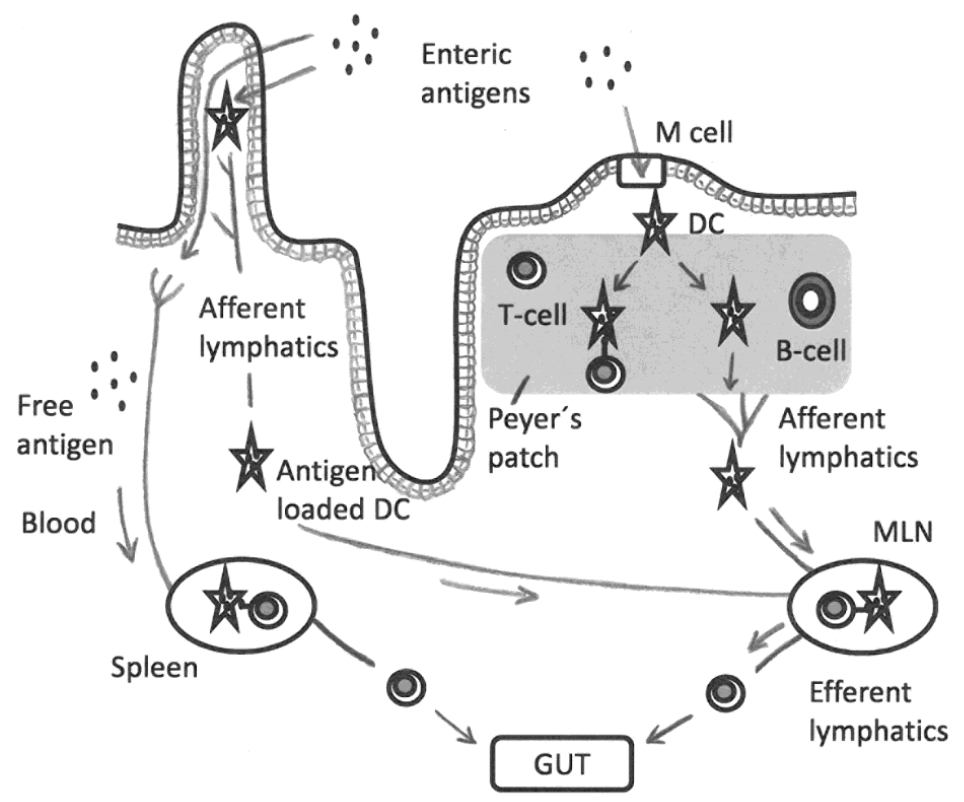

Figure 4. The intestinal mucosal immune response to enteric antigens. Different routes of activation of $\mathrm{T}$ cells by enteric antigens. The figure is modified from [21].

\section{Oral tolerance}

The role of GALT is to maintain gut homeostasis; thus to keep a balance between tolerance and inflammation in the intestine. The usual response to harmless gut antigens is induction of systemic immunological tolerance, known as oral tolerance [15, 22]. This was first described 100 years ago, but the mechanism of oral tolerance is still poorly understood (reviewed in [23]). The immunological consequence of an orally administered antigen depends on where and how the antigen is taken up and presented to the immune cells [24]. Particulate and replicating antigens often induce active immunity instead of tolerance, which might be due to the polysaccharide components. Normally, tolerance is induced to all thymus dependent soluble antigens. Disruption of the oral tolerance might lead to pathological conditions.

Several mechanisms have been implicated in oral tolerance including active regulation by Tregs, clonal deletion and clonal anergy of T cells [22]. A number of different Tregs have 
been implicated in oral tolerance, including Th3 cells, Tr1 cells, nTregs iTregs and also CD8+ Tregs $[18,22]$. Activation of the T cells (Th1, Th2, Th3, Tr1, Treg) and the fate of the immune response depend on how the intestinal DCs are activated [18]. Furthermore, the composition of the gut microbiota has also been suggested to affect oral tolerance [22]. The homeostatic/tolerogenic responses within the GALT induced production of secretory $\operatorname{IgA}$ (SIgA) by B cells (reviewed in [25]). In addition to its neutralizing effects, SIgA preserved the intestinal homeostasis and regulated the mucosal integrity.

\section{Probiotics}

Probiotics, often referred to as "live microorganisms which when administered in adequate amounts confer a health benefit on the host", have been suggested to enhance the intestinal barrier function and to affect the immune system by influencing the composition of the intestinal microbiota [26]. Lactobacilli and bifidobacteria are gram-positive lactic acid bacteria (LAB), which are normal inhabitants of the intestinal microflora. They are also the most commonly used probiotic species, which are considered to be safe for administration to humans. The probiotic preparations are composed of single or mixed cultures of live microorganisms. However, little is known about the exact mechanisms of how lactobacilli may exert their beneficial effects. One possible mechanism is through activation of the innate immune system [27]. Probiotic bacteria may exert their effects on a wide array of immune and mucosal cells including T-cells, B-cells, natural killer (NK) cells, DCs, monocytes/macrophages and epithelial cells. Dependent on cell type and strain of probiotic bacteria used, these immunomodulatory effects can manifest themselves as immune activatory, deviatory or regulatory/suppressive [26]. Probiotics are able to polarize the immune responses by inducing a release of cytokines from activated DCs [28]. This cytokine release induces a $\mathrm{T}$ cell polarization of the naïve $\mathrm{T}$ cells. Probiotic lactic acid bacteria have e.g. been shown to stimulate both pro-inflammatory (Th1) and anti-inflammatory responses (Treg) both in the gut and in PBMC cultures [27] [29, 30](reviewed in [23]). It has also been shown that probiotic lactic acid bacteria up-regulate the surface markers CD40, CD83, CD86 and HLA-DR [31]. Probiotics may also have indirect effects on the on the immune responses mediated by its effects on gut permeability and morphology (reviewed in [23]). 


\section{Infant immunity}

Newborn infants have an immune system with impaired function, which confers increased susceptibility for infections. The infants are mainly dependent on the innate immunity for protection against infections, since the priming of the adaptive immune system is limited in utero (rewieved in [32]). The innate immune system is somewhat immature in newborns, e.g. the numbers of DCs are low and the cells express lower levels of the co-stimulatory molecules CD80/86 [33]. Thus, the DCs are not fully capable of activating both innate and adaptive immune responses. The expression of TLR and its downstream signaling molecules seems however to be stable in young children, and to be similarly expressed as in adults [34].

The adaptive immune system of the newborn is immature. Infants have low numbers of effector memory T cells and effector B cells. Furthermore are the infants CD4+ T cells skewed towards Th2 cytokine production. Normally, a down-regulation of the Th2 deviation is seen with age, in parallel with an up-regulation of the Th1 responses. The antibody production is limited in infants [35], especially during the first year of life. However, maternal $\operatorname{IgG}$ and $\operatorname{IgA}$ antibodies, transferred to the fetus during pregnancy and breast-feeding respectively, confer immune protection of the infant during the first months of life.

The developing immune system depends on environmental exposures in order to mature normally (reviewed in [25]). The intestinal microbiota and its diversity are important for the development of the immune system and immunological tolerance. Colonization with certain bacteria might enhance the maturation of the mucosal SIgA system and might also influence systemic immune responses [36]. An appropriate microbial stimulation is suggested to be of importance for an optimal $\mathrm{T}$ cell development and prevention of disease development (reviewed in [25]).

Colonization of the infant was previously suggested to start immediately after birth [37]. Recent studies have however indicated that the colonization starts already during pregnancy (reviewed in [25]). The way of delivery has been shown to influence the microbiota of the newborn. Infants delivered vagnially are exposed to and colonized by a different microbiota than infants delivered with caesarean section [38]. The diversity of the microbiota has been reported to be increased by breast-feeding [37]. A diverse microbiota early in life might prevent disease development of e.g. allergies [39]. 


\section{Celiac disease (CD)}

\section{History}

Celiac disease (CD), also known as gluten sensitive enteropathy and coeliac sprue, was first described around the first century A.D. as an intestinal disorder associated with malabsorption and diarrhea (Rewieved in: [40]). The first modern description of the disease was made in 1888 by Samuel Gee who described the condition in adults and children (Reviewed in [41]). During World War II it was discovered that the frequency of CD decreased when there was shortage of wheat flour and after the war when wheat flour re-occurred in the diet the CD patients relapsed. Thus, it was discovered that $\mathrm{CD}$ was caused by the consumption of cereal gluten proteins from wheat, barley and rye and it was proposed to treat patients with a lifelong gluten-free diet (GFD) [42](Rewieved in [40, 43]. In the 1950's it was found that the fingerlike projections of the small bowel mucosa, the intestinal villi, were absent in patients with CD who consume gluten (Rewieved in $[40,44]$ ). Later on, it was documented that the intestinal mucosa recovered after GFD treatment [45].

\section{Genetic factors}

Genetic factors play a key role in the predisposition of CD. The disease is considered to be a polygenetic disorder, where MHC/HLA is the most important genetic factor, which accounts for $40-50 \%$ of the genetic variance. The MHC class I and II molecules act as recognition molecules and present antigens to effector cells in the immune system. The primary association in CD is with the MHC/HLA class II present on chromosome 6. The majority of the patients (90\%) carry HLA-DQ2 (DQA1 *05:01, DQB1 *02:01, also called HLA-DQ2.5), whereas it is only carried by a third of the general population [46-48]. The other CD patients are carrying HLADQ8 (DQA1*03, DQB1*03:02) (5\%) or another variant of HLA-DQ2 (DQA1 *02:01, DQB1 *02:02, also called HLA-DQ2.2) (5\%) [49, 50](reviewed in [51]). HLA-DQ2 homozygouts have a five-fold higher risk of developing CD compared to HLADQ2 heterozygouts [52]. APCs homozygous for HLA-DQ2 have stronger gluten-specific Tcell responses than APCs heterozygous for HLA-DQ2, probably since they have a higher number of HLA-DQ2 molecules capable of presenting gluten peptides [53]. The HLA-alleles 
are suggested to be responsible for the aberrant presentation of the transglutaminase modified gliadin peptide and the induction of intestinal inflammation.

The DQ2 and DQ8 haplotypes are necessary but not sufficient for disease development, since they are accounting for $40-50 \%$ of the genetic variance [54]. Thus, approximately $50 \%$ of the genetic variability remains to be explained. So far at least 39 other loci harboring 64 genes (together accounting for 5-14\% of the genetic variance) have been described, most of which are involved in inflammatory and immune responses [55-57](reviewed in [51]). Polymorphisms in the CTLA-4 and protein tyrosine phosphatase, non-receptor type 22 (PTPN22) genes have been suggested to modulate the risk of CD [58-63]. The non-HLA genes together seem to contribute more to the genetic susceptibility than the HLA-genes, but the contribution from each gene appears to be modest [64](reviewed in [51]).

\section{Environmental factors}

Environmental factors are also involved in the predisposition of CD. The major environmental trigger is ingestion of gluten, the protein fraction of wheat, barley and rye. Studies have shown that environmental factors such as breast-feeding as well as gluten introduction during weaning at the age of 4-6 months have a protective effect on early disease development [6568], whereas infections, such as rotavirus infections, have been suggested to increase the risk for CD [69-73] and type 1 diabetes (T1D)[74]. Furthermore, differences in the composition of the microbiota have been reported in patients with active CD and patients on a GFD compared with healthy controls, and may be involved in CD pathogenesis [75-78]. Presence of bacteria in the small intestinal mucosa of CD patients has been suggested to be an indicator of aberrant innate immunity.

\section{Symptoms}

$\mathrm{CD}$ may be difficult to detect since it may present with a wide range of clinical manifestations which vary with age [79-81]. CD was initially considered to be a pediatric disorder, but nowadays $\mathrm{CD}$ is increasingly diagnosed also in adults [82]. The clinical manifestations of CD are quite variable from severe to mild gastrointestinal symptoms, or even absence of symptoms despite presence of a mucosal lesion [73]. Infants and young children generally present with diarrhoea, or constipation, vomiting, abdominal distention, failure to thrive and 
unhappy behaviour [83, 84](reviewed in [44]). The signs of malabsorption often include irondeficiency anaemia, hypoalbuminemia, and vitamin deficiencies. Older children and adolescents often present with vague symptoms such as short statue, neurological symptoms, recurrent abdominal pain, delayed puberty or anemia [44, 80, 83, 84]. Sometimes irondeficiency anaemia or short statue is the only presenting sign of CD in older children and adolescents. Adults often present with diarrhoea, sometimes accompanied by abdominal pain or discomfort [85], anemia, osteoporosis, fatigue, but they may also present with neurological symptoms, e.g. epilepsy, or psychological disturbances such as anxiety and depression [44, 83, 86-89]. Untreated CD is associated with a variety of health problems related to immunological processes and impaired nutrient absorption [90]. The symptoms of a patient with CD seem not to be associated with the degree of the villous atrophy [91, 92]. Instead, the symptoms in CD seem to be related to the length of the affection in the intestine and thus not to the severity of the mucosal lesion. However, symptom resolution, upon GFD treatment, seems to be associated with a normalization of the mucosal lesion [91].

Dermatitis Herpetiformis (DH) is considered a dermatological manifestation of $\mathrm{CD}$, rather than an associated disease. DH is characterized by an itchy blistering skin rash associated with an increased density of IELs in response to gluten challenges [93]. About $75 \%$ of the patients with DH have small-bowel villous atrophy with crypt hyperplasia and the remainder have minor mucosal changes (reviewed in [94]). The symptoms are relieved on a GFD and relapses upon gluten challenge.

The true prevalence of CD is difficult to estimate since the symptoms often are vague and the spectrum of symptoms is wide, leaving a large proportion of cases undiagnosed $[81,83]$. The epidemiology of $\mathrm{CD}$ has been illustrated as an iceberg, where the clinically diagnosed CD cases are the visible part of the iceberg above the waterline, whereas the remaining majority of the CD cases, the subclinical (unrecognized) and potential cases are hidden below the waterline (Figure 5). Meta-analyses have shown that for every patient identified with CD seven to eight remain undiagnosed, thus the majority (of about 90\%) of the celiac subjects remain undiagnosed [95-97]. 


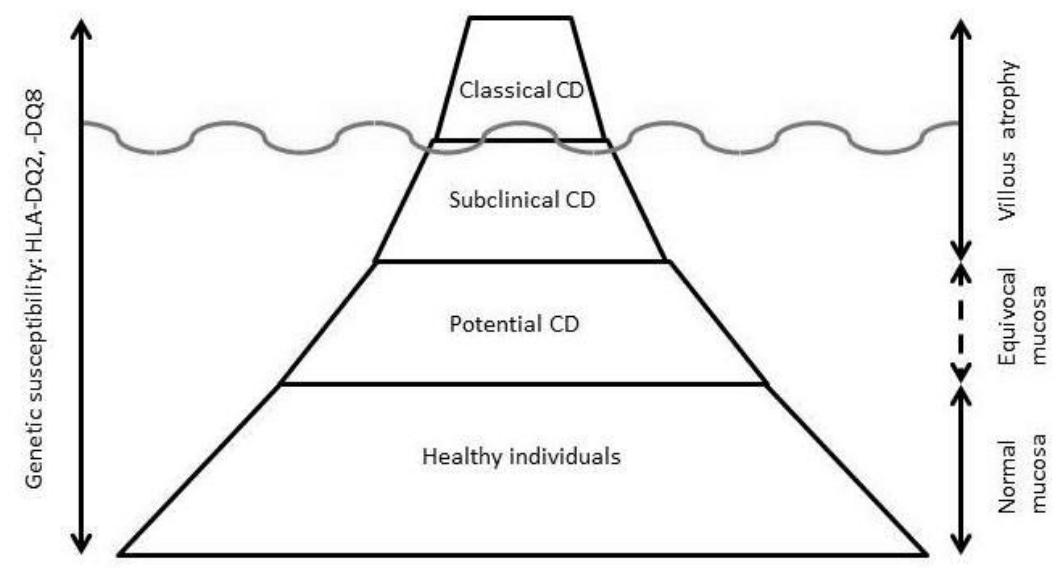

Figure 5. The celiac iceberg, according to the "Oslo definitions". The figure is modified from [98].

Recently new consensus definitions of CD were proposed (the "Oslo definitions"), since there was a lack of consensus regarding the diagnostic criteria of the disease [99]. Classical CD, often presents before the age of two years and is characterized by villous atrophy and clinical signs of malnutrition. Non-classical CD, on the other hand often presents in older children and in adults, in which the features of malnutrition are absent. Symptomatic CD is characterized by clinically evident intestinal symptoms related to the gluten intake. Sub-clinical CD is a more or less symptomless form of $\mathrm{CD}$, which is below the threshold of clinical detection without signs or symptoms sufficient to trigger CD testing. Asymptomatic CD is not accompanied by symptoms even at direct questioning, instead it is often recognized upon screening of patients with autoimmune diseases, genetic disorders or relatives of CD-patients. Potential CD is suggested to be used for those whom the diagnosis latent or low-grade CD should be considered. Potential CD is characterized by a normal intestinal mucosa or a mucosa with minor alterations and inflammatory changes in the epithelium, such as increased density of CD3-positive cells and $\alpha \beta$ - and $\gamma \delta$-TCR-bearing IELs and enhanced HLA-DR and DP expression in epithelial crypts [100-102]. The individual with potential CD may or may not develop the disease later on [103-105]. 


\section{Diagnosis}

The current diagnostic criteria for $\mathrm{CD}$ are proposed by the European society of pediatric gastroenterology, hepatology and nutrition (ESPGHAN). The original ESPGHAN criteria from 1970 included two or more biopsies, the $1^{\text {st }}$ initial biopsy on suspicion of CD during active disease showing abnormal intestinal mucosa, the $2^{\text {nd }}$ biopsy on GDF showing normalization of the gut mucosa and the $3^{\text {rd }}$ biopsy showing deterioration of the gut mucosa during challenge with gluten-containing diet (rewieved in [83]). The ESPGHAN criteria were revised in 1990 when serological markers were added to the diagnostic arsenal. The development of serologic tests has facilitated diagnosing $\mathrm{CD}$, but in some cases it has become more intricate, when the clinical symptoms, serology and histopathological picture are inconsistent.

Normally, diagnosing CD still requires at least one biopsy showing the characteristic findings of the disease, and a positive response to GFD. The $2^{\text {nd }}$ and $3^{\text {rd }}$ biopsies are considered obligatory only when there are doubts about the initial biopsy interpretation and/or the clinical response to a GFD. However, the latest guidelines from the ESPGHAN from 2012 suggest that a biopsy may be omitted in children with typical symptoms, if they have high titers of transglutaminase antibodies (TGA) (with levels 10 times higher than the upper normal limit) together with the predisposing HLA genotypes [106]. The gold standard for diagnosing CD is still a mucosal biopsy taken from the small intestine, preferably from the proximal jejunum. The biopsies are taken by capsule or by endoscopy. In Sweden the biopsies obtained from small children used to be taken by a Watson or a Storz capsule [107], whereas in older children and adults the biopsies were often obtained by endoscopy. Nowadays, endoscopy are often used since multiple samples are recommended because the mucosal lesion may be patchy $[108,109]$.

\section{Histopathology}

Marsh described the CD associated histopathological alterations of the intestine systematically [110]. An inflammatory lesion in the upper small intestinal mucosa characterized by increased frequency of IELs, together with various degrees of small intestinal villous atrophy and crypt hyperplasia is a hallmark of untreated CD $[47,85,111]$. Under normal circumstances the intestinal epithelium is almost impermeable to gliadin, while in $\mathrm{CD}$ the (para-cellular) permeability is enhanced and the tight junction system is comprised. 
In $\mathrm{CD}$ the classical mucosal lesion is characterized by a flat mucosa with absent villi, villous atrophy, and heavily elongated crypts, crypt hyperplasia. The intestinal absorptive area is thereby decreased which leads to malabsorption. A strict GFD generally leads to a normalization of the mucosal lesion. Histological recovery of the mucosa is assumed to occur within 6 to 12 months after introduction of a GFD, simultaneous with clinical remission. However, healing of the mucosa may take from 6 to 24 months after introduction of GFD treatment, and in some cases the recovery may remain incomplete [112]. The healing of the mucosa seems to be faster and more completely in children than in adults. In the youngest patients, a positive response to GFD may be reported by the parents within a week.

In the active celiac lesion, there is also an increased infiltration of T cells in the epithelium and increased activation of T cells in the lamina propria [113]. Both the TCR $\alpha \beta+\mathrm{CD} 8+$ and the TCR $\gamma \delta+$ cells are increased in active CD (reviewed in [111, 114]). The infiltration of T cells in the LP of the active celiac lesion is dominated by CD4+ memory T cells (CD45RO+) bearing the $\alpha / \beta$ TCR [115]. The gluten specific Th1 response is leading to production of proinflammatory cytokines, e.g. IFN- $\gamma$ and TNF- $\alpha$. The increased IEL and LP T-cells are not completely normalized on a GFD [116]. Indeed treatment with a GFD normalizes the TCR $\alpha \beta+\mathrm{CD} 8+$ IELs, whereas the TCR $\gamma \delta+$ IELs remain elevated [117]. The IEL count does not always correlate with the degree of mucosal lesion.

Different classifications have been used for the grading of the histological changes. In Sweden both the Alexander scale, the KVAST grading and the Walker Smith classifications have been used. Nowadays the Marsh-Oberhuber scale is often used for grading of the mucosal lesion where Marsh 0 corresponds to a normal mucosa, Marsh 1 is characterized by a normal mucosa but with increased IEL, Marsh 2 is characterized by a normal mucosa with increased IEL and crypt hyperplasia, Marsh 3 is characterized by villous atrophy, crypt hyperplasia and IEL increase (reviewed in [44])[118, 119]. There are 3 different subtypes of Marsh 3: type a with mild villous flattening, type $b$ with marked villous flattening and type $c$ with a total flattening of the mucosa. Marsh 4 , which is very unusual, is characterized by a flat mucosa but with normal crypt height and number of IELs. 


\section{Serologic markers}

Increased humoral activity with increased density of plasma cells and antibody production is a hallmark of CD. Detection of serological markers is thereby an important tool in the diagnosis of $\mathrm{CD}$. Serological screening of individuals with suspicion of $\mathrm{CD}$ or at risk for CD helps clinicians to decide whom to investigate further. Serological screening is so far generally not a substitute for biopsies. As no single test can definitely diagnose or exclude the disease in every individual, biopsies of the proximal part of the small intestine remain the gold standard test in individuals with positive antibody tests.

Individuals with typical indications for disease undergo serological testing. The available and most sensitive tests include antibody tests of immunoglobulin (Ig)A class to AGA, EMA and TGA, which are used in different combinations at different ages to diagnose CD. Anti reticulin antibodies directed towards connective tissue which were described already in the 1970's (reviewed in [120]) are generally not used any longer due to the low sensitivity (reviewed in [44]). The specificity and sensitivity of the different antibody tests vary considerably. A complicating factor in testing for CD is that IgA deficiency prevalence is high and even increased in the celiac population, and that both the TGA and EMA tests are based on IgA antibodies [121]. In cases of IgA deficiency, tests based on IgG antibodies can be of value [122].

Anti-gliadin antibodies (AGA) were discovered already in 1958 (reviewed in [123]) and thus the AGA test was the first to be used in screening of CD [124]. In screening of normal populations IgA AGA has been shown to have a sensitivity of 82 and a specificity of $90 \%$, which is low. Apart from in CD, AGA may be found in cow's milk intolerance and Crohn's disease. Nowadays IgA AGA is often used in the pediatric population (in children younger than 18 months) due to the higher specificity in children than in adults [95]. Furthermore, AGA is often used in follow-up of CD, as an indicator of dietary compliance [125]. The recent ESPGHAN guidelines suggested that AGA should not be used in CD diagnosing in patients who are negative for other CD-specific antibodies but in whom clinical symptoms raise a strong suspicion of CD [106]. Instead, the new deamidated gliadin peptide (DGP) IgG antibody test, with a sensitivity and specificity of $>90 \%$, was recommended to be used for screening in IgA deficient individuals and young children < 2 years [106](reviewed in [48]). 
EMA which was discovered in the 1980's (reviewed in [123]) has proven to be superior to AGA in screening studies. The EMA test has high sensitivity and specificity for CD (93 and 99\%, respectively) [125-127] (reviewed in [48]), but is generally not used in children younger than two years since they often are false negative [125, 128]. EMA is however not exclusively positive in gluten sensitized individuals, which might be due to the severity of the lesion and the length of the involved intestine [129].

The enzyme tissue-transglutaminase (tTG) was discovered as the autoantigen in CD in 1997 [130]. The TGA test has a high sensitivity and specificity (94 and 97\%, respectively) (Wong 2002) (reviewed in [48]), and is well suited for detection of CD [127, 131-133]. TGA is nowadays suggested to be used in combination with EMA [95], since EMA and TGA has a sensitivity of $>90 \%$ and correlates with the degree of mucosal damage [134-137].

As mentioned before, antibody production is a hallmark of CD and is used for disease prediction. It is however not known if the autoantibodies play a role in the CD pathogenesis or if they are an epiphenomenon. Gluten seems to drive the antibody production since the presence of autoantibodies is strictly dependent on the exposure to gluten.

\section{HLA typing}

HLA typing can also be used for diagnostic purposes. HLA-genotyping is for example useful in subjects with potential $C D$, or uncertain diagnoses. In these cases a negative result, absence of HLA-DQ2, -DQ8 and DQB1*02, is diagnostic since it excludes a CD diagnosis (reviewed in $[137,138]$ )[106]. However, HLA genotyping can also be used to strengthen the diagnosis in individuals with strong clinical suspicion of $\mathrm{CD}$ with high specific $\mathrm{CD}$ antibodies, but where a small intestinal biopsy cannot be performed [106].

\section{Epidemiology}

In the past $\mathrm{CD}$ was considered to be a rare disease mainly affecting individuals of European origin, but it is now considered to be a global problem. Nowadays CD is the most common food-related chronic disease in children, since the prevalence of $\mathrm{CD}$ has increased during the last decades $[85,139,140]$. It has been shown that $\mathrm{CD}$ affects $0.6-1.0 \%$ of the population worldwide with large regional differences in Europe: $0.3 \%$ in Germany and 2.4\% in Finland 
[136, 141-146]. CD is also common in developing countries such as North Africa and the Middle East and has also been described in India and China [55, 147, 148]. The prevalence of $\mathrm{CD}$ is over $5 \%$ in the Saharawi population, living in the western part of Sahara [149].

The concordance of CD in monozygotic twins is 75-80\% [150] in comparison to dizygotic twins where the concordance is about $17 \%$. The risk of developing the disease in first-degree relatives varies between $10 \%$ and $20 \%$ [151]. Children of an affected mother are more likely to develop $\mathrm{CD}$, than children of an affected father. For unknown reasons the disease is more common in girls than in boys, and in children born in the summer [152-154]. This might be explained by the production of sex hormones which influence immune responses [155]. Girls seem generally to be Th1 deviated, in contrast to boys which seem to be more Th2 deviated $[155,156]$. In many affected individuals CD remains undiagnosed, but the rate of diagnosis is increasing due to the frequent screening for the disease [142, 143, 157-163]. Thus, screening studies are an important tool for detection of asymptomatic $\mathrm{CD}$, which confers reduced risks for long term complications.

In Sweden the incidence of CD in children <2 years showed an epidemic pattern during the period 1984-1996 [164]. The incidence increased four-fold in the middle 1980's and remained high until the middle 1990's where there was a rapid decrease. The increase was partly attributed to changes in the infants' dietary advices regarding breastfeeding and gluten introduction with postponement of gluten introduction to 6 months of age [67]. In the 1990`s the national diet recommendations returned to a more favorable gluten introduction, back to introduction at 4 months of age, resulting in a decreased total incidence and a shift toward older age at diagnosis [152]. The birth cohorts during the epidemic were exposed to an infant feeding pattern which seems to affect the risk for CD throughout childhood and possibly also throughout the life span $[152,165]$. A long-term study showed reduced prevalence of CD in 12-year-olds born after compared with during the "celiac epidemic" [166]. Thus, infant feeding affects the risk of developing $\mathrm{CD}$, at least up to the age of 12 years. Further follow-up studies are needed to determine whether the lifetime risk has changed.

\section{Development of $\mathrm{CD} /($ Molecular) Pathogenesis}

$\mathrm{CD}$ is considered to be a systemic autoimmune disorder triggered by the ingestion of gluten (the major protein found in wheat, barley and rye) in genetically predisposed individuals [64, 
167]. Thus, development of the disease is suggested to be determined by an interplay between genetic (HLA-DQ2 or -DQ8) and environmental factors (gliadin, virus infections) (Figure 6).

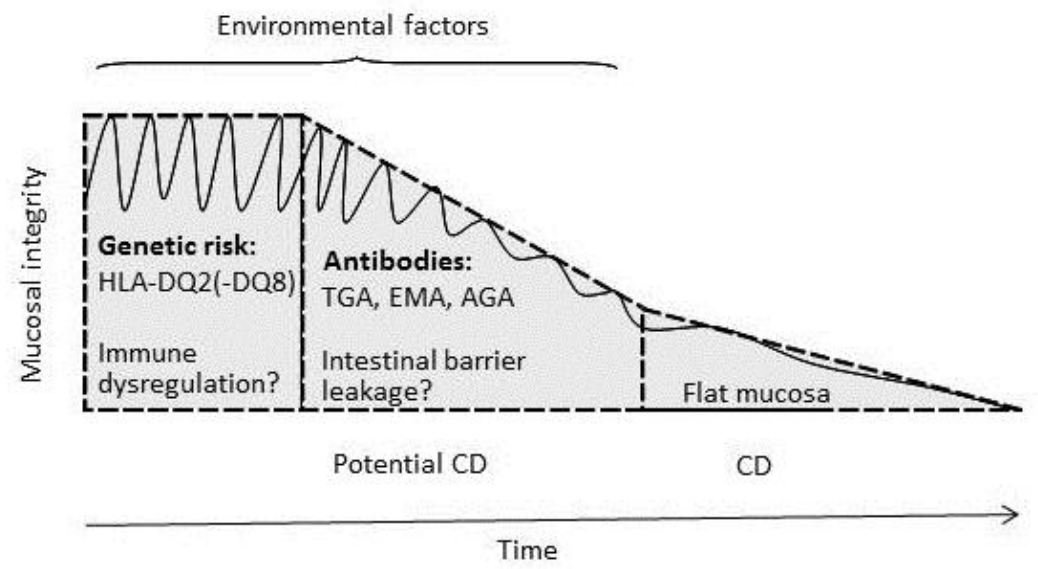

Figure 6. The natural history of CD.

Most of the knowledge of the disease comes from studies of humans. The animal models of CD developed during the last 10 years have provided a new paradigm of CD pathogenesis: consisting of 3 parts: 1) an aberrant innate immune response to gliadin that occurs in 2) the context of HLA-DQ2/DQ8 as well as perturbations to 3) the regulatory arm of the immune system resulting in autoimmunity and CD [168]. Marietta et al suggested that an activation of all three arms would occur simultaneously to induce the gliadin induced villous atrophy in CD. The activation was suggested to be triggered by environmental or behavioural factors. Another study by Catassi et al (2010) showed that loss of gluten tolerance leading to CD occurs at any time of life, due to unknown reasons [169]. The gluten quality and amount, the type and duration of wheat dough fermentation, the spectrum of intestinal microorganisms and their variation, intestinal infections and stressors were suggested to be possible switches of the tolerance-immune responses balance.

Normally the intestine is almost impermeable to gliadin, but in CD the paracellular permeability is enhanced and the integrity of the tight junction system is comprised, for instance due to the up-regulation of zonulin $[170,171]$. Furthermore, inflammatory mediators 
such as IFN- $\gamma$ and TNF- $\alpha$ increase the intestinal permeability and thereby conserve the access of gliadin to the submucosa and the subsequent damage to the mucosa.

The main disease mechanism which subsequently leads to CD is suggested to occur in the LP, where an adaptive immune response to gluten peptides is taking place [170]. HLA-DQ2 and HLA-DQ8 present gluten peptides and induce a CD4+ T-cell response. tTG deamidates the neutral gluten peptides (glutamine) into negatively charged glutamic acid which binds with high affinity to HLA-DQ2 and HLA-DQ8. Activated gluten reactive CD4+ cells produce high levels of pro-inflammatory cytokines, (mainly IFN- $\gamma$ ) which promotes inflammatory effects. This in turn induces secretion of matrix metalloproteinases (MMPs), by fibroblasts or LP mononuclear cells, which are responsible for tissue remodeling. Activated CD4+ cells also drive the activation and clonal expansion of B cells, through production of Th2 cytokines. Subsequently the activated B cells differentiate into plasma cells, which are present in the LP and produce AGA and TGA. TGA deposits might induce epithelial damage by interacting with extra-cellular membrane bound tTG in the basement membrane.

Gliadin, the ingested antigen in $\mathrm{CD}$, is poorly digested in the small intestine, where it generates long peptides and express epitopes for gliadin-specific T-cells. Expression of tTG, the prominent endomysial autoantigen, which is an enzyme important for control of cell and tissue homeostasis, is increased in individuals with $\mathrm{CD}$ both in active disease and in remission (reviewed in $[114,172]$ ). tTG is a cytoplasmic enzyme released extracellularly in response to tissue wounding brought about by stress, inflammation, infection or during apoptosis (reviewed in [44, 173]). In CD tTG has an important role in modifying gluten epitopes prior to their recognition by $\mathrm{T}$-cells, namely to deamidate the glutamine- and proline-rich gluten peptides thereby transforming them into glutamic acid. tTG has also been suggested to crosslink gliadin resulting in gliadin-gliadin complexes and gliadin-tTG complexes which trigger immune responses. tTG also stabilizes the connective tissue by cross-linking of matrix proteins. The modification of the gluten peptides enhances their binding to HLA-DQ2 or DQ8 molecules, which in turn stimulates gluten-specific T-cells leading to production of Th1 proinflammatory cytokines $[174,175]$. The immune system cross-reacts with the mucosa causing an inflammatory reaction, leading to crypt hyperplasia and villous atrophy. T-cells have a central role in the tissue destruction, but the exact mechanism of action of the IELs is unknown. 
One of the hallmarks in $\mathrm{CD}$ is the alteration in the frequency, composition and activation stage of IELs. The precise role of the IELs in CD is however unclear. The most prominent lineage of IELs are the TCR $\alpha \beta+C D 8+C D 4-$ cells, but the TCR $\alpha \beta+C D 8-C D 4+$ cells and the TCR $\gamma \delta+C D 8-C D 4-$ cells also are present (reviewed in [114]). Both $\alpha \beta+C D 8+C D 4-$ and $\gamma \delta+\mathrm{CD} 8-\mathrm{CD} 4-\mathrm{T}$ cells are increased in the small intestine of patients with active CD [101] (reviewed in [114]). The $\alpha \beta$ IEL T-cell number varies with disease activity and returns to normal on GFD [101, 117, 176] (reviewed in [114]). Whether the frequency of $\gamma \delta$ IEL T cells is correlated with disease activity or is constantly elevated even after GFD is still controversial. In active $\mathrm{CD}$, a selective expansion of the otherwise rare natural killer T (NKT) cell-like $\alpha \beta+C D 94+$ IEL subtype is also seen [177]. Furthermore, in the LP of active CD there is an increase in the number of activated CD4+ $\alpha \beta$ T cells [178]. The LP T-cells express CD25, but not the proliferation marker Ki67 [113] (reviewed in [114]). Thus, the cells in the LP are suggested to be non-proliferative and instead produce cytokines which may induce epithelial crypt hyperplasia and local IEL proliferation. This fits well with the increased cytokine production by T-cells in the LP (reviewed in [114]). Imbalance in the cytokine profile, intra-epithelially, is also an important feature of active CD [179].

In active $\mathrm{CD}$ elevated levels of IFN- $\gamma$ are seen [175, 179-187]. Elevated IFN- $\gamma$ levels were also seen in the mucosa of GFD treated patients $[179,180]$. The IFN- $\gamma$ seems to a large extent to be produced by CD $8+\alpha \beta+$ IELs, whereas $\gamma \delta+$ cells and CD $4+\alpha \beta+$ cells also produce IFN $-\gamma$ but at much lower levels [175]. Type 1 cytokines have been implicated in the immunopathogenesis of CD, in particular IFN- $\gamma$ [188] [189], even though only minute levels of the Th1 inducing cytokine IL-12 is produced in the intestine of CD patients [180, 189]. The mechanism by which the IFN- $\gamma$ producing Th1 cells are generated remains unknown. The Th1 cytokines are believed to be involved in the pathogenesis by increasing the intestinal permeability by disruption of tight junctions [190, 191]. IFN- $\gamma$ is also suggested to directly or indirectly damage enterocytes or their maturation alone or together with other mediators, leading to CD-related tissue damage [192].

In addition to the elevated IFN- $\gamma$ levels, active $\mathrm{CD}$ has been reported to be associated with elevated levels of IL-2 [183], IFN- $\alpha$ [193], TNF- $\alpha$ [183, 194], IL-6 [194], IL-4 [183], IL-15 [180, 195], FoxP3 [181, 196, 197], IL-10 [175, 179, 181], IL-17 [184, 186, 198], IL-21 [199], whereas the levels of IL-18 were diminished in active disease [181]. The results from the 
studies of intestinal cytokines are contradictory, since other studies have shown similar levels of several cytokines in CD patients and controls [184, 189, 200, 201] [179, 181, 182, 185, 200]. This divergence may partly be due to methodological differences. Whether, and how these cytokines contribute to the intestinal lesion remains in most cases unclear.

\section{Treatment}

In $\mathrm{CD}$ and $\mathrm{DH}$ there is in most cases a permanent intolerance to gluten. A strict, lifelong GFD is so far the only available medical treatment of the disease. DH is treated with a GFD together with dapsone treatment to relieve the symptoms in the skin. The GFD is effective in most patients and it restores the morphology of the intestinal mucosa, relieves the symptoms [167] and reduces the risk for developing gastrointestinal lymphoma. Furthermore the CD related antibodies decline after introduction of a GFD treatment [202].

$70 \%$ of the CD patients with classical symptoms improve within two weeks after initiation of a strict GFD (reviewed in [123]). The CD related antibodies normalize after three to twelve months, whereas the intestinal inflammation can take somewhat longer to regress.

A strict GFD means that the patient excludes all gluten proteins from the diet. This is not always as easy as it sounds due to gluten contamination in products presumed to be glutenfree. The Codex Alimentarius states that food and ingredients are allowed to be labelled as gluten-free when they are naturally free of gluten, with a gluten level of $\leq 20 \mathrm{mg} / \mathrm{kg}$ (reviewed in [99]). The gluten proteins, so called prolamins, are found in wheat, rye, and barley, but it is the alcohol soluble parts that are toxic to CD patients (reviewed in [44]). The prolamines in wheat are called gliadins and in rye and barley they are called hordeins and secalins, respectively. The disease-inducing properties of rye and barley are suggested to be due to Tcell cross-reactivity against gliadin-, hordein- and secalin-derived peptides [203]. Pure oats, containing avenin, is nowadays considered to be tolerated by most CD patients, and is therefore allowed in the diet in some countries including Sweden [204-210]. However, a subset of celiac patients being on a GFD containing oats did not normalize their intestinal immune responses [211]. This was reported to be an indication of that the intestinal epithelium still was stressed and that oats not was tolerated in these individuals. Neither seemed the gut microflora function to be normalized in patients on an oats-containing GFD 
[212]. Corn, containing zein, as well as rice and millet are generally considered to be nontoxic to CD patients [213] (reviewed in [173]).

\section{Associated diseases}

About $30 \%$ of adults with CD have one or more autoimmune disorders, compared to about $3 \%$ in the general population (reviewed in [140]). Thus, the risk for CD is higher in individuals with other autoimmune diseases, such as type 1 diabetes (T1D) and Sjögren's syndrome, but also in individuals with Down's syndrome and IgA deficiency [214, 215]. CD is relatively frequent among children suffering from T1D, in which the risk seems to be linked to HLA-DQ2 [163, 216]. 5-10\% of patients with T1D develop CD. In many cases CD is discovered after screening initiated after the onset of diabetes, where the individuals often are asymptomatic or have diffuse symptoms [217]. Several studies have revealed an association between CD and Down's syndrome, since there is an increased prevalence of CD among patients with Down's syndrome [218, 219]. Studies have also shown links between CD and Addison's disease and also the autoimmune thyroid disorders; Hashimoto's and Grave's disease, which seem to be associated with HLA-DQ2 and HLA-DQ8. Associations between $\mathrm{CD}$ and the autoimmune disorder; systemic lupus erythematosus (SLE) has also been reported. It seems that by unknown mechanisms, long-term undiagnosed and untreated CD predisposes to autoimmunity [173], which urges early detection and treatment of CD.

\section{Mortality \& malignancy}

The prognosis for young children with CD was poor before the development of a GFD treatment, with mortality rates varying between $10 \%$ and $30 \%$ due to malabsorption and its complications (reviewed in [120]). The mortality and malignancy rates fell markedly after introduction of a GFD treatment [220, 221]. Nowadays people with CD on a GFD have very small increases in overall risks of malignancy and mortality [222-224].

Most CD patients are relieved by a life-long GFD, which interrupts the intestinal gluten response leading to recovery of the villous architecture and alleviated symptoms. However, approximately $5 \%$ of the $\mathrm{CD}$ patients (often older patients with longstanding $\mathrm{CD}$ ) develop a condition called refractory celiac disease (RCD) [47, 225]. Patients with RCD fail to respond to a GFD or they experience a relapse despite such a diet. RCD may be classified as type I or 
type II, both with persistent symptoms, in which the first has a normal IEL population and the second has an aberrant IEL population. RCD type I follows a relatively benign course with a 5-year survival rate of $80-96 \%$, whereas RCD type II is associated with poor prognosis despite conventional therapeutic intervention with a 5-year survival rate of 40-58\% [226]. The poor prognosis of RCD type II patients is mainly explained by the much more frequent progression to enteropathy-associated T-cell lymphoma (EATL). EATL is a gastrointestinal tumor with origins in intraepithelial T cells. In some adult patients, often about the age of 60, EATL occurs in the jejunum. Treatment of EATL is chemotherapy based, but the prognosis is generally poor [112, 227, 228], with a 5-year survival rate of 8-20\% [226].

In conclusion, despite extensive research efforts is the exact mechanism resulting in development of CD still unknown and there is still no cure for the disease. Aberrant intestinal immune responses are known to be associated with disease development. However, little is known about the complex network of intestinal and peripheral immune responses in children with and without $C D$, which urges more studies in this field. Studies of the effect of a GFD on the immune responses are also of importance.

\section{Type 1 diabetes (T1D)}

\section{History}

The first description of diabetes may have been made as early as 1500 B.C. Around the first century A.D. the disease was called diabetes and was described with clinical symptoms. In 1674 Dr Thomas Willis called the disease diabetes mellitus referring to the honey sweet urine associated with the disease. A century later, in 1776, Dr Dobson found sugar in the blood of diabetic patients. Later on, in 1889 Mering and Minkowski discovered that removal of the pancreas from a dog lead to diabetes mellitus and death and that the pancreas secretes a substance called insulin involved in the sugar metabolism. In 1908 pancreatic extracts was used as treatment for diabetes. In 1921 Banting and Best successfully isolated insulin extract from pancreas and gave it to diabetic dogs which lived longer. A year later, in 1922, lack of insulin was discovered to be the cause of the disease when a diabetic 14-year old boy regained health after receiving regular insulin injections. In the 1930's Himsworth discovered that diabetes could also be caused by insensitivity to insulin, not only lack of insulin. Thus, two forms of diabetes, type 1 and type 2, was discovered. Nowadays the term diabetes mellitus 
also refers to gestational diabetes and maturity onset diabetes of the young (MODY) as well as some rare forms of diabetes. T1D accounts for about $5-10 \%$ of those with diabetes in the world, but is proportionally more common (10-15\%) in Sweden and Finland [229] and dominates completely among children and adolescents.

\section{Definition \& Symptoms}

Diabetes mellitus is a collective term describing a group of metabolic disorders characterized by hyperglycemia, due to defects in insulin secretion or insensitivity to its actions, but also disturbances in the fat, carbohydrate and protein metabolism [229]. The clinical symptoms of T1D, also known as juvenile diabetes or insulin dependent diabetes, are characterized by excessive thirst, polyuria, weight loss and sometimes with excessive hunger and blurred vision, which derive from the hyperglycaemia caused by the insufficient insulin secretion. The hyperglycemia is sometimes associated with impairment of growth and increased susceptibility to infections.

\section{Diagnosis}

The criteria for diagnosis of T1D is a fasting plasma glucose of $\geq 7.0 \mathrm{mmol} / \mathrm{L}$ or classic symptoms of hyperglycemia in combination with a plasma glucose of $\geq 11.1 \mathrm{mmol} / \mathrm{L}$ or a 2 hour plasma glucose of $\geq 11.1 \mathrm{mmol} / \mathrm{L}$ during an oral glucose tolerance test (OGTT) performed according to the WHO guidelines. A pre-diabetic state is seen in some individuals with intermediate glucose levels which are higher than normal, although is not meeting the criteria for T1D [229]. These individuals with impaired glucose tolerance and/or impaired fasting glucose have a relatively high risk for developing T1D.

\section{Genetic factors}

Genetic factors play a key role in the predisposition of T1D. T1D is considered to be a polygenetic disorder, where several risk factors both within and outside the MHC/HLA region have been associated with disease. The MHC/HLA locus is the most important genetic factor accounting for about $50 \%$ of the genetic variance. The HLA-DR/DQ alleles can be either predisposing or protective. The majority of the patients carry the DR4-DQ8 or DR3-DQ2. The DQ8 and DQ2 are very common, but not necessary any longer and not sufficient for disease 
development. The heterozygous genotype confers the highest risk for T1D, possibly because the HLA molecule presents islets antigens in a diabetogenic way (reviewed in [230]). The same genetic risk factors play a role in $\mathrm{CD}$ and in $\mathrm{T} 1 \mathrm{D}$, but the highest risk of $\mathrm{CD}$ is associated with HLA-DQ2, whereas in T1D the highest risk is associated with HLA-DQ2DQ8 heterozygocity. During the last decades declining numbers of patients carry the high-risk genotype, instead the moderate risk genotype is becoming more common in T1D patients (reviewed in [230]). The high-risk genotype is still often seen in younger children, an age group where the disease is becoming more common.

Since MHC/HLA only accounts for about $50 \%$ of the genetic variance, approximately $50 \%$ of the genetic variability remains to be explained by other factors. Genetic riskfactors such as the insulin gene (INS), CTLA-4, PTPN22 and the inducible co-stimulator (ICOS) have also been associated with disease susceptibility. Only a relatively small proportion $(<10 \%)$ of genetically susceptible individuals develop T1D, which implies that additional factors are of importance in disease development. Also the rapid increase in the incidence of T1D indicates a significant role for environmental factors in the disease process.

\section{Environmental factors}

Different environmental factors have been associated with T1D development. It has been reported that different forms of stress (during psychological stress and rapid growth) might result in increased $\beta$-cell stress and increased insulin need and thereby might be a risk factor for T1D development [231]. According to the virus hypothesis, enteroviruses such as Coxsackie B4 virus infections, have been related to T1D induction [232]. This is supported by reports of associations between rota- and enterovirus infections and $\beta$-cell autoimmunity in children with risk for T1D [233, 234]. Coxsackie B4 virus infections have been associated with increased autoantibody positivity and T1D onset [235-237].

Some risk factors for T1D are also triggers of gut immune system, and aberrant immune response to them has been suggested to lead to $\beta$-cell autoimmunity. The gut immune system which develops during the first year of life should provide protection towards harmful infections and induce oral tolerance to harmless food and microbes. However, an immature immune system or breaking of oral tolerance may lead to dysfunctional antigen presentation or activation of the immune system and thereby induce aberrant immune responses. It is 
known that environmental factors like infections and dietary factors, which stimulate mucosal immunity, are important for the maturation of the intestinal immune system [238, 239] [37].

Dietary factors such as early exposure to cow's milk formula proteins (bovine insulin, betalactoglobulin, casein and bovine serum albumin) and wheat (gluten) are also suggested to be risk factors for T1D [240-246]. Early or late introduction of gluten was suggested to be a risk factor for induction of T1D autoantibodies [247, 248]. A murine model demonstrated that a gluten free-diet prevented diabetes onset in NOD mice, whereas a gluten containing diet did not (reviewed in [249]). Gluten is suggested to affect diabetes development by inducing changes in immune cell populations or by modifying the cytokine/chemokine pattern towards an inflammatory profile [249]. Infants given cow's milk formula are exposed to insulin from cow's milk protein already during the first months of life, when the immune system still is immature [250]. The exposure to bovine insulin was suggested to trigger immune responses to human insulin, since the amino acid sequence of bovine and human insulin differs with only 3 amino acids. Autoantibodies to insulin are the first signs of the autoimmune process directed towards the insulin producing $\beta$-cells in the pancreas, and are considered to be of importance in T1D development since they preceed the clinical symptoms. Impaired intestinal Tregulatory responses associated with T1D [181], might explain the intestinal immune activation and altered response to dietary antigens seen in T1D patients (reviewed in [251]). Studies have shown that newly diagnosed T1D patients have elevated immunologic responses to cow's milk proteins (insulin, beta-lactoglobulin, casein and bovine serum albumin) and to gluten (gliadin) [240, 241, 252, 253]. The up-regulation of inflammatory markers shown in the intestine of patients with T1D [183, 254] suggests that the development of oral tolerance is dysfunctional and that the gut/intestinal immune system seems to be important in T1D development [255-257].

Breast-feeding has on the other hand been suggested to have a protective effect on T1Ddevelopment, since short duration of breast-feeding was associated with increased risk for T1D autoimmunity and development of T1D [258-260] [247, 261]. Early introduction of cow's milk formula feeding was suggested to be one of the explanations why short duration of breast-feeding increased the risk for T1D [247]. The increased risk for T1D in short termed breast fed infants has also been suggested to be due to an increased weight which is associated with formula feeding [262]. Vitamin D has also been suggested to protect against T1D [263], since it preserves the $\beta$-cells, increases the insulin sensitivity, contributes to the Th2 
deviation, increases Tregs and increases the effect of dendritic cells. Animal studies have shown that the diet either can induce or prevent T1D development [264, 265].

The intestinal permeability has also been suggested to be associated with an increased risk for T1D development. Studies have shown that the gut permeability is increased in T1D patients [266-269] and that it even might precede the clinical onset of T1D [269]. An intestinal leakiness resulting in increased antigenic load might cause activation of T-cells from the intestine and pancreatic lymph nodes [251]. The activated/autoreactive T-cells may circulate between the intestine and Langerhans islets [257, 270] [251] causing inflammation/autoimmune reactions that destroy the insulin producing $\beta$-cells.

The intestinal microbiota has been reported to modify the gut permeability, but also the function of intestinal immune cells and oral tolerance. It has been suggested that T1D is caused by synergistic effects between aberrant intestinal microbiota, dysfunctional intestinal barrier and altered mucosal immunity [251]. Changes in the intestinal microflora due to administration of probiotics, commensal intestinal microbes with beneficial effects on the health and well-being of the host, may modulate the immune system towards a tolerogenic state, which in turn might prevent T1D. Probiotics (e.g. lactobacilli) have been shown to induce gut maturation and induce oral tolerance. The mechanism of how probiotics influences the immune system is not known, but normalization of the intestinal permeability [271], stabilisation of the intestinal microflora [272], enhanced immunological barrier [239, 273], down-regulation of inflammatory responses in the gut [274] and activation of monocytes and DCs $[29,275]$ are suggested to be of importance. Probiotics may modulate the immune system via pattern-recognition receptors, such as TLRs, which are expressed on DCs and regulatory T-cells as well as on epithelial cells. This is supported by animal studies which have shown that commensal microbial signals induce T-regulatory responses and cytokine production by DCs [276].

In the hygiene hypothesis, a decreased microbial load early in life was suggested to induce changes in the gut microbiota, which influences programming of the immune system and thereby also the risk of developing autoimmune reactions [255]. Studies in non-obese diabetic (NOD) mice have shown that the diabetes incidence is high in a low microbial environment and vice versa [277, 278]. 


\section{Serologic markers}

Autoantibodies to insulin (IAA), glutamic acid carboxylase (GADA), tyrosine phosphataselike insulinoma antigen-2 (IA-2A), islet cells (ICA) and the zinc transporter ZnT8 (ZnT8A) alone or in combination are the first markers of the on-going autoimmune process and can be detected years before diagnosis of T1D [279-283]. Positivity for a single autoantibody represents in most cases a harmless non-progressive autoimmunity, whereas presence of 2 or more autoantibodies reflects a progressive process that only rarely reverts. Usually positivity to multiple autoantibodies are present in $85-90 \%$ of individuals at the point when the patient is diagnosed with T1D [229]. However it is not known if the antibodies contribute to the pathogenesis or if they are an epiphenomenon.

IAA are generally the first autoantibodies appearing in young children with $\beta$-cell autoimmunity, but the levels generally decrease with age [284, 285]. IAA which are $\beta$-cell specific autoantibodies found in 40-70\% of newly diagnosed T1D children before any insulin is administered [286-289](reviewed in [290]).

Autoantibodies to GAD65, an intracellular membrane anchored protein expressed at high levels on the pancreatic $\beta$-cells, have also been reported in about $50-80 \%$ of newly diagnosed T1D [282, 286-289] and have been shown to persist many years after development of T1D. Autoantibodies to GAD have also been reported in latent autoimmune diabetes of adults (LADA)-patients [291].

IA-2A, which are associated with rapid disease progression [292-294], are detected in 50-80\% of newly diagnosed T1D patients [282, 286, 288, 289, 295]. IA-2A seem to be a strong predictor of T1D, but have been shown to vary with age and HLA genotype [296].

ICA, which were detected already in the 1970's in newly diagnosed T1D, are reported in 70$80 \%$ of individuals with recently onset T1D [286, 289, 297], but their frequency decreases after diagnosis [288]. ICA are recognising islet cell cytoplasmic antigens on all endocrine cells of the pancreatic islets ( $\alpha, \beta, \delta, \varepsilon$ and PP cells).

The recently discovered antibodies to (the C-terminal part of) ZnT8 have been shown to be strongly associated with T1D [298] and to increase with age. ZnT8A have been reported to be 
present in $60-80 \%$ of newly diagnosed T1D and were therefore suggested to be utilized as an additional disease marker of T1D in older subjects in whom IAA wanes [298].

Positivity for multiple autoantibodies is used as a marker of T1D in prospective studies, since the majority of those individuals will develop the disease [292, 299] [294]. A combined measurement of ZnT8A, GADA, IA-2A, and IAA raised autoimmunity detection rates to $98 \%$ at disease onset [298]. High levels of ICA (above 20 JDRF units) were earlier used as a cutoff for risk of type 1 diabetes in the ENDIT-project, where nicotinamide was tested in a prevention study of T1D. In the general population, autoantibody-positivity is not a certainty for T1D-development. About $1 \%$ of healthy individuals have detectable levels of IAA, GADA or IA-2A.

\section{Epidemiology}

T1D is most common in Caucasians. In Europe, the incidence is highest in northern countries, with the exception for Sardinia where the incidence also is high. Sweden has second to Finland the highest incidence of T1D in the world. The incidence of T1D has increased in Western countries during the last decades and especially so in Finland and Sweden [300]. From 1978 to 1997 the incidence among children and adolescents increased in Sweden, with the largest increase in children younger than 5 years [301]. During the last decade, from 20002007, the increase in incidence seems to have levelled off in the youngest children, with a shift towards older ages at T1D onset [302]. T1D in young adults has been shown to be two to three times more common than previously reported [303].

Seasonal variation in T1D incidence has been noted in all parts of the world, with increased incidence in autumn and winter (reviewed in [290]). Family studies indicate that environmental factors seem to be involved in disease initiation.

The risk for T1D in the general population is about $0.5 \%$, whereas the concordance rate in monozygotic twins is $30-50 \%$ (reviewed in [290] [74]) and in dizygotic twins it is 6\%. Children of an affected father are nearly 3 times more likely to develop T1D, than children of an affected mother (reviewed in $[288,290])$, the reason for this is however unknown. 


\section{Development of T1D/(Molecular) Pathogenesis}

Development of T1D is believed to be associated with a combination of genetic, environmental and immunological factors, since no individual factor has been proven to induce T1D (Figure 7). The prediabetic period may be a few months (in very young children) or several years (in older children and adults) (reviewed in [288]). The earliest sign of $\beta$-cell autoimmunity is the development of autoantibodies. When the $\beta$-cell mass or function has declined to less than $50 \%$ an impaired fasting glucose or glucose tolerance is common. By the time acute symptoms of T1D develop, the $\beta$-cell mass or function is believed to have decreased by $90 \%$.

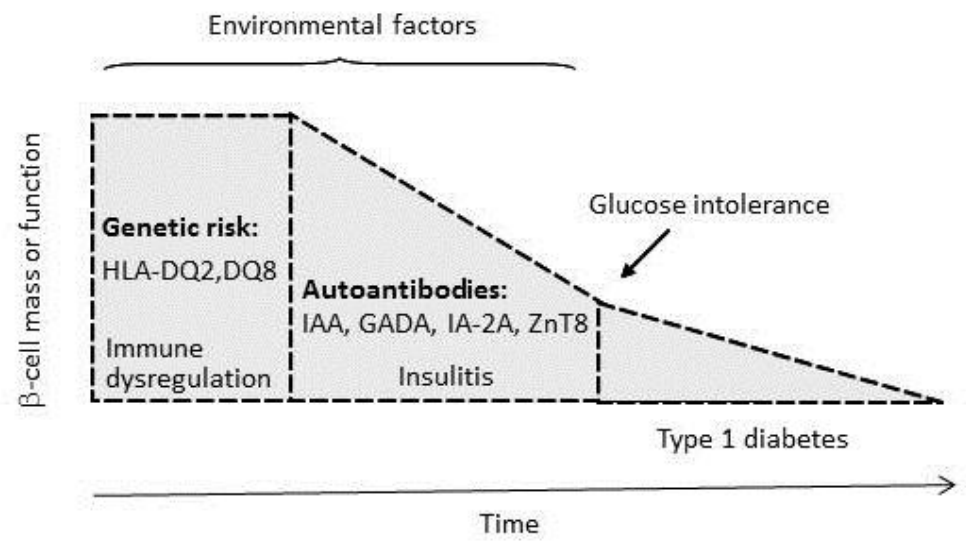

Figure 7. The natural history of T1D. The figure is modified from [304].

In T1D, the common view is that this is an autoimmune disease, autoreactive immune cells infiltrate the pancreatic islets destroying the insulin producing $\beta$-cells, eventually leading to insulin deficiency [305-307]. At diagnosis of T1D most of the $\beta$-cells are destroyed [290]. The inflamed islets of Langerhans consist of an infiltrate of cells dominated by Tc (CD8+) cells, but also by Th (CD4+) cells, B-cells, macrophages and NK-cells (reviewed in [290])[308]. Cytokines produced by Th cells are thought to be involved in the process by recruiting and activating macrophages and Tc cells destroying the $\beta$-cells [309]. The insulitis lesion has been suggested to be $\beta$-cell destructive when Th1 cytokines produced by islet-infiltrating lymphocytes dominate over Th2 cytokines. Elevated Th2 cytokine responses have on the other hand been suggested to down-regulate Th1 cytokine responses and thereby prevent $\beta$-cell destruction [310]. 
Results from studies of cytokines in the peripheral blood from T1D patients are discrepant, however. Some reported high production of Th1 cytokines and low production of Th2 cytokines in T1D [311], confirming results from animal studies [305], while others detected low production of Th1 cytokines in peripheral blood [312]. Furthermore, up-regulation of the Th17 cell associated cytokine IL-17 has been reported in peripheral blood of T1D patients [313-316]. The results from studies of Tregs in T1D are discrepant. Studies have reported increased, decreased or equivalent levels of FoxP3 peripherally in T1D [313-319]. Furthermore, studies of the intestinal immune responses in T1D have displayed elevated levels of IL-1 $\alpha$, IL-18, IL-4, intercellular adhesion molecule (ICAM)-1 and the HLA antigens HLA-DP and HLA-DR, which indicates an activation of the intestinal immune system in patients with T1D [181, 257]. However, the intestinal levels of IFN- $\gamma$, FoxP3, TNF- $\alpha$, TGF- $\beta$, IL-4, IL-6, IL-8 and IL-15 were similar in T1D and in controls.

\section{Treatment}

The only available treatment of T1D consists of a lifelong and regular administration of exogenous insulin by injections or by pumps along with measurements of blood glucose levels to prevent acute and late complications. The insulin dose is adjusted in relation to the measured blood glucose levels. An optimal glycemic control is a cornerstone of diabetes care [320]. A long-acting basal insulin is generally given once or twice a day and covers $40-60 \%$ of the insulin demand/day. Regular insulin or rapid-acting insulin analogs is generally given as a bolus insulin at multiple times a day to coincide with meals and snacks. Physical activity, which is a part of the treatment, influences the insulin sensitivity and blood sugar levels. The treatment; the food restrictions, the regular insulin injections and blood sugar measurements comprise a heavy burdon on the families. Diabetic children have lower health-related quality of life compared to non-diabetic children [321], furthermore has it been reported that diabetic girls have lower quality of life than diabetic boys [322]. Psychosocial mechanisms and support from diabetes teams are of importance for a successful treatment.

\section{Associated diseases}

T1D is associated with other autoimmune disorders such as: Grave's disease, Hashimoto's thyroiditis, Addison's disease, $\mathrm{CD}$ and autoimmune hepatitis but also with other genetic syndromes such as Down's syndrome and Turner's syndrome, [229]. About 4-9 \% of patients with T1D develop CD [323, 324]. Children with T1D undergo screening for CD since less than 
$10 \%$ of patients with T1D who develop CD show gastrointestinal symptoms, thus most of the children are either asymptomatic or only mildly symptomatic [325].

\section{Mortality \& Complications}

Patients with T1D have increased mortality rates compared to the general population [326329]. This depends on both acute complications such as hypoglycemia and keto-acidosis, but patients have also increased risk of death caused by traffic accidents and suicide [330]. The chronic hyperglycemia of patients with T1D cause dysfunction and failure of various organs, especially the eyes, kidneys, nerves, heart and blood vessels [229]. The retinopathy is leading to potential loss of vision, the nephropathy to renal failure and the neuropathy to risk for foot amputations, gastrointestinal and cardiovascular symptoms. Good metabolic control can decrease the incidence [331-333], but it is very difficult to completely avoid late complications.

\section{Intervention \& prevention studies in T1D}

Multiple intervention and prevention trials have been carried out in individuals with elevated risk for T1D and in T1D-patients, respectively. Plasmapheresis which was used on newly diagnosed T1D patients already in the 80's seemed to preserve the beta cell function somewhat [334]. Another agent, Cyclosporine A, was also tried in T1D patients with moderate results [335]. Anti-CD3 treatment of T1D patients resulted in preserved C-peptide levels and lowered insulin doses [336, 337]. Other monoclonal antibody-based agents, e.g. anti-CD20 and anti-CD25, have also been used in T1D intervention trials. Autoantigen based therapies, using GAD and insulin, have also been performed. Treatment of T1D patients with GAD was initially shown to preserve the fasting C-peptide levels, but later on it was shown that the treatment not had any clinical benefit [338, 339]. Administration of subcutaneous, nasal and oral insulin have also been tested in individuals with risk for T1D, but without clinical success [340-342]. Another prevention trial performed in high-risk individuals failed to show that hydrolyzed infant formula compared to conventional cow's milk based formula decreased the risk of developing T1D [343]. The European Nicotinamide Diabetes Intervention Trial (ENDIT), which was performed on high-risk individuals, positive for diabetes associated autoantibodies, did not prevent or delay T1D development and was therefore discontinued [344]. Furthermore in 2003-2005 the PRODIA pilot study, an immune 
prevention study of T1D by oral supplementation of probiotic bacteria, was conducted in Linköping. Infants with genetic risk for T1D were given probiotics during their first 6 months of life in order to investigate whether the probiotic supplementation could decrease $\beta$-cell autoimmunity in the children [345]. Experimental studies in nonobese diabetic (NOD) mice had previously shown that probiotics might prevent autoimmune diabetes [346, 347]. None of the intervention or prevention therapies have so far been used in common clinical practice, due to the fact that the agents had transient effects or were associated with unaccepted adverse effects.

In conclusion, despite extensive research efforts is the triggering factors resulting in T1D development still unknown, and there is still no cure for the disease. It is however known that the gut immune system seems altered in T1D patients and that treatment with probiotics influences the immune system. Studies of the intestinal immune responses in T1D are of importance in order to elucidate the role of the gut immune system in T1D. Little is known about how supplementation of probiotics influences the innate immune responses in infants at risk for T1D, and if probiotics modulates the risk of development of autoimmunity and T1D. 


\section{AIMS OF THE THESIS}

The general aim of this thesis was to explore intestinal and peripheral immune responses in children at different stages of celiac disease (CD) and in children with type 1 diabetes (T1D). Additionally, we aimed to investigate the effects of probiotic treatment during the first 6 months of life on the peripheral immune responses in children at risk for T1D (PRODIA study).

The specific aims of each individual paper were:

Paper I.

To explore the activation of a broad range of genes associated with the Th1-Th2-Th3 signalling pathway in the small intestine and peripheral blood of children with $\mathrm{CD}$, before and after 1 year of gluten-free diet (GFD) treatment.

\section{Paper II.}

To explore the intestinal activation of IL-17 pathway together with the regulatory T-cell marker FOXP3 in different stages of CD including children with potential CD i.e. transglutaminase antibody (TGA) positive, children with untreated CD, CD children treated with GFD and children with T1D.

\section{Paper III.}

To explore the mucosal activation of genes associated with the Th17 signalling pathway in children at different stages of $\mathrm{CD}$; including children with increased risk for $\mathrm{CD}$ (potential CD), children with untreated CD and CD children treated with GFD.

\section{Paper IV.}

To explore the effects of probiotic supplementation on the innate immune system in the children at genetic risk for T1D. 


\section{MATERIAL \& METHODS}

\section{Study subjects}

The study populations included in paper I-III are presented in Figure 8.

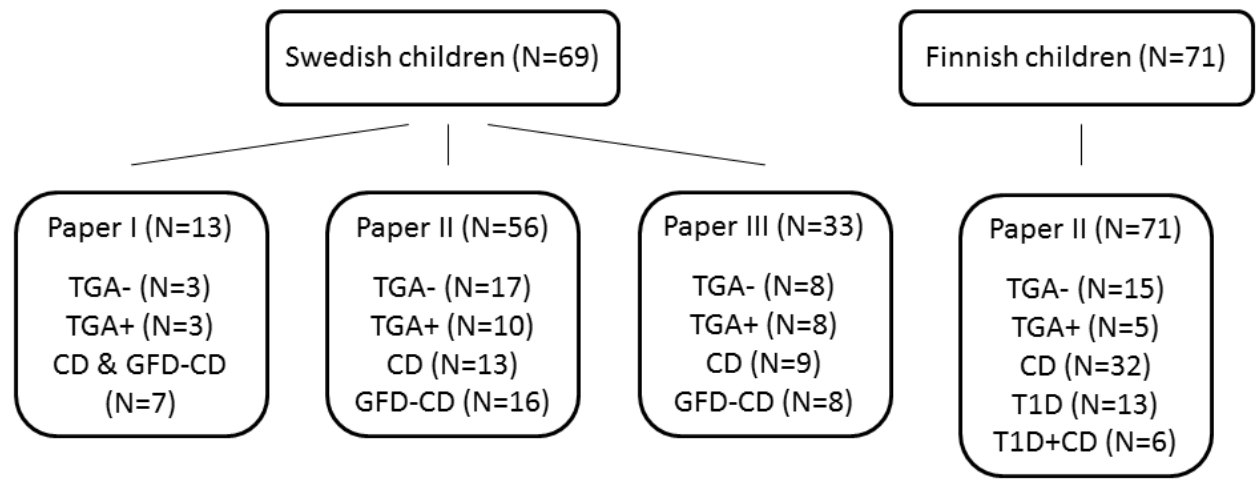

Figure 8 . The study populations in paper I-III. TGA- = transglutaminase negative reference children, $\mathrm{TGA}+=$ transglutaminase positive children with potential celiac disease $(\mathrm{CD}), \mathrm{CD}=$ children with untreated celiac disease, GFD-CD = children with gluten free-diet treated celiac disease, $\mathrm{T} 1 \mathrm{D}=$ children with type 1 diabetes, $\mathrm{T} 1 \mathrm{D}+\mathrm{CD}=$ children with both T1D and $\mathrm{CD}$.

\section{Paper I}

The study cohort comprised small intestinal biopsies and peripheral blood samples from 7 children with untreated celiac disease (CD), with follow-up samples after one year of treatment with a strict gluten free-diet (GFD), and 6 reference children (Figure 8).

\section{Paper II}

The study comprised two study cohorts, one from Sweden and one from Finland (Figure 8, Table 1). The Swedish study cohort used for qPCR analyses consists of small intestinal biopsies from children with untreated $\mathrm{CD}$, children with $\mathrm{CD}$ after one year of GFD-treatment, TGA-positive children with potential-CD and TGA-negative reference children. The Finnish study cohort used for immunohistochemistry and qPCR analyses consists of small intestinal 
biopsies from children with untreated CD (all with obvious structural changes in the intestine), TGA-negative reference children undergoing endoscopy for different clinical reasons such as stomach ache (all with a healthy mucosa) and children with previously established type 1 diabetes (T1D) who were screened for CD. None of the T1D children had $\mathrm{CD}$ according to the European Society of Pediatric Gastroenterology, Hepatology and Nutrition criteria [348]. The Finnish study cohort used for cytokine assessment in in vitro cultures consists of small intestinal biopsies from children with untreated CD, TGA-positive children with potential CD, TGA-negative reference children and children with concomitant CD and T1D.

Table 1. Description of the study population.

\begin{tabular}{lcccccc}
\hline & Ref & Pot-CD & CD & GFD-CD & T1D & T1D+CD \\
\hline $\begin{array}{l}\text { IHC and } \\
\text { qPCR/Fin }\end{array}$ & 10 & - & 15 & - & 13 & - \\
qPCR/Swe & 17 & 10 & 13 & 16 & - & - \\
In vitro biopsy & 5 & 5 & 17 & - & - & 6 \\
culture/Fin & & & & & & \\
\hline
\end{tabular}

IHC: immunohistochemistry, qPCR = quantitative real-time polymerase chain reaction, $\operatorname{Ref}=$ reference children, pot $\mathrm{CD}=$ potential $\mathrm{CD}, \mathrm{CD}$ : children with untreated $\mathrm{CD}, \mathrm{GFD}-\mathrm{CD}=$ children with $\mathrm{CD}$ after 1 year of gluten free-diet treatment, $\mathrm{T} 1 \mathrm{D}=$ children with type 1 diabetes, $\mathrm{T} 1 \mathrm{D}+\mathrm{CD}=$ children with T1D and untreated CD.

\section{Paper III}

The study cohort comprised small intestinal biopsy samples from 8 children with TGA elevation (potential CD), 9 children with untreated $\mathrm{CD}, 8 \mathrm{CD}$ children on a strict gluten free diet (GFD) for a year and 8 reference children (TGA negative) (Figure 8). A subgroup of 8 children with T1D was initially included in the study. This group was however excluded from the paper, since it was a small and heterogenous group including four children with untreated CD, two with GFD-treated CD, one with potential CD (TGA-positive) and one TGA-negative reference. The four children with T1D and untreated CD are included in the results and discussion part of this thesis. 


\section{Paper IV}

The PRODIA study was a double blind randomized placebo controlled pilot study of infants with genetic risk for T1D in which supplementation with probiotics during the first 6 months of life was used for prevention of T1D. All parents to new-born infants between February 2003 and June 2005 at Linköping University Hospital were informed about the PRODIA study. After informed consent by the parents, 1057 infants were screened for HLA genotypes associated with risk for T1D. Twohundredsixtyfour (264) infants with risk genotype were randomized to receive either probiotics or placebo during the first 6 months of life. The probiotic preparation, given as powder from capsules once a day by parents at home, consisted of a mixture of freeze dried Lactobacillus rhamnosus GG $\left(5 \times 10^{9} \mathrm{cfu}\right)$, Lactobacillus rhamnosus LC705 (5 x $\left.10^{9} \mathrm{cfu}\right)$, Bifidobacterium breve Bbi99 (2 x $\left.10^{8} \mathrm{cfu}\right)$ and Propionibacterium freudenreichii ssp. Shermani JS ( $\left.2 \times 10^{9} \mathrm{cfu}\right)$ together with microcrystalline cellulose. The placebo capsules contained only microcrystalline cellulose. Apart from this supplement, the diet of the infants was not manipulated.

Venous blood samples were collected at 6,12 and 24 months of age for assessment of T1D related autoantibodies, from the infants participating in the PRODIA-study. The study cohort in which T1D related autoantibodies were assessed comprises serum samples from 202 infants. CRP was analysed in the 6 months plasma sample from 142 infants.

Based on availability, blood samples from the infants were used for flow cytometric analyses of ex vivo innate immune responses and also for analyses of innate immune responses in in vitro stimulated cultures (Table 2). Furthermore, blood samples were used for PCR array analyses of genes associated with the TLR signalling pathway. 
Table 2. Samples included in the flow cytometric and PCR array analyses.

\begin{tabular}{lcc}
\hline & Probiotics (N) & Placebo (N) \\
\hline F.C., ex vivo, 6m & 28 & 19 \\
F.C., ex vivo, 12m & 27 & 18 \\
F.C., stimulated, 6m & 18 & 12 \\
F.C., stimulated, 12m & 19 & 14 \\
PCR arrays, 6m & 10 & 10 \\
PCR arrays, 12m & 10 & 10 \\
\hline
\end{tabular}

F.C. $=$ flow cytometry

\section{Laboratory methods}

\section{Sample collection (paper I-IV)}

The venous blood and biopsy samples from the Swedish children included in this thesis were collected between the years 2003 and 2009 and the biopsy samples from the Finnish children were collected between the years 2003 and 2005. Venous blood samples, from children with or without $\mathrm{CD}$ or children included in the PRODIA study, were drawn into heparin treated tubes (Vacuette, Greiner Labortechnik, Kremsmünster, Austria). Peripheral blood mononuclear cells (PBMC) were separated on Ficoll Paque Density gradient (Amersham, Pharmacia, Biotech, Uppsala, Sweden), from fresh blood samples, according to standardised methodology and cryopreserved in freezing medium (50\% fetal calf serum, 40\% RPMI 1640 and $10 \%$ DMSO) (Sigma-Aldrich, Stockholm, Sweden) and kept in liquid $\mathrm{N}_{2}$ until RNA isolation.

Assessment of the CD-related antibodies: TGA, EMA, AGA and IgA in sera were routinely performed at the laboratory for Clinical Chemistry, Linköping, Sweden. TGA and AGA were analysed by ELISA and EMA was analysed by indirect immune fluorescence. CD-related antibodies in the Finnish samples were analysed using ELISA.

Small intestinal biopsies taken with the capsule method from the distal part of the duodenum were used in the studies. The biopsy specimens, from children at different stages of CD, were 
divided for routine histology and the surplus was used for PCR studies. For the Swedish samples the routine histology was performed at the laboratory for Clinical Pathology, Linköping, Sweden. The surplus part was placed in RPMI medium, transported to the laboratory where the medium was aspirated off and the biopsies were snapfrozen and cryopreserved in liquid $\mathrm{N}_{2}$ until RNA isolation.

\section{RNA isolation (Paper I-IV)}

PBMC from Swedish infants (in Paper I and II), after being thawed and washed in PBS, were subsequently lysed and homogenized using RLT buffer (Qiagen, Hilden Germany) with $\beta$-ME (Sigma, Stockholm, Sweden) and QIA shredders (Qiagen). The Swedish biopsies (in paper IIII) were on the other hand lysed and homogenized using RLT buffer (Qiagen), Stainless Steel Beads (Qiagen) and Tissue Lyser II (Qiagen). Total RNA was subsequently isolated from the lysates using RNeasy® Mini Kit (Qiagen) with on-column DNase treatment using RNase free DNase Set (Qiagen), according to the manufacturer's guidelines. The isolated total RNA (paper I and III) was concentrated by precipitation with ethanol, ammonium acetate and glycogen. The quantity of the RNA was assessed with NanoDrop® ND 1000 spectrophotometer (NanoDrop Technologies Inc, Wilmington, DE, USA) while the quality of the RNA was examined with RNA 6000 Nano LabChip® Kit (Agilent Technologies, Palo Alto, CA, USA) and an Agilent 2100 Bioanalyser (Agilent Technologies) according to the manufacturer's guidelines.

The remaining biopsies from Finnish children (in Paper II) were dissected from matrix of optimal cutting temperature (OCT) compound (Miles Laboratories, Elkhart, IN, USA), lysed and homogenized using lysis buffer (Sigma, St Louis, MO, USA) and a pestle (Starlab, Ahrensburg, Germany). Total RNA was subsequently isolated using GenElute mammalian total RNA miniprep kit (Sigma), according to the manufacturer's guidelines. The quality and quantity of the RNA was assessed with NanoDrop® ND 1000 spectrophotometer (NanoDrop Technologies).

In paper II, total RNA from Caco-2 cell cultures (see below) was isolated using GenElute mammalian total RNA miniprep kit (Sigma), according to the manufacturer's guidelines. The quality and quantity of the RNA was assessed, as described earlier. 


\section{Real-time polymerase chain reaction (PCR)-array analyses (Paper I, III and IV)}

In Paper I, total RNA from intestinal biopsies and from PBMCs from children with CD, GFDtreated $\mathrm{CD}$ and references was used in the studies. The expression of immune markers associated with the Th1-Th2-Th3 cytokine signalling network was analysed with real-time PCR arrays (Human Th1-Th2-Th3 PCR Array: PAHS-034, SA Biosciences, USA) (Table 3).

In Paper III, total RNA isolated from intestinal biopsies from children at different stages of CD was used in the studies. The expression of immune markers associated with the Th17 cytokine signalling network was analysed with real-time PCR arrays (Human Th17 for Autoimmunity \& Inflammation PCR Array: PAHS-073, SA Biosciences, USA) (Table 4).

In Paper IV, total RNA isolated from the 6 and 12 months PBMC-samples from the PRODIAchildren supplemented with probiotics or placebo was used in the studies. The gene expression of immune markers related to TLR-mediated signal transduction (innate immunity) was analysed with real-time PCR arrays (Human Toll-Like Receptor Signaling Pathway PCR Array: PAHS-018, SA Biosciences, USA) (Table 5). 


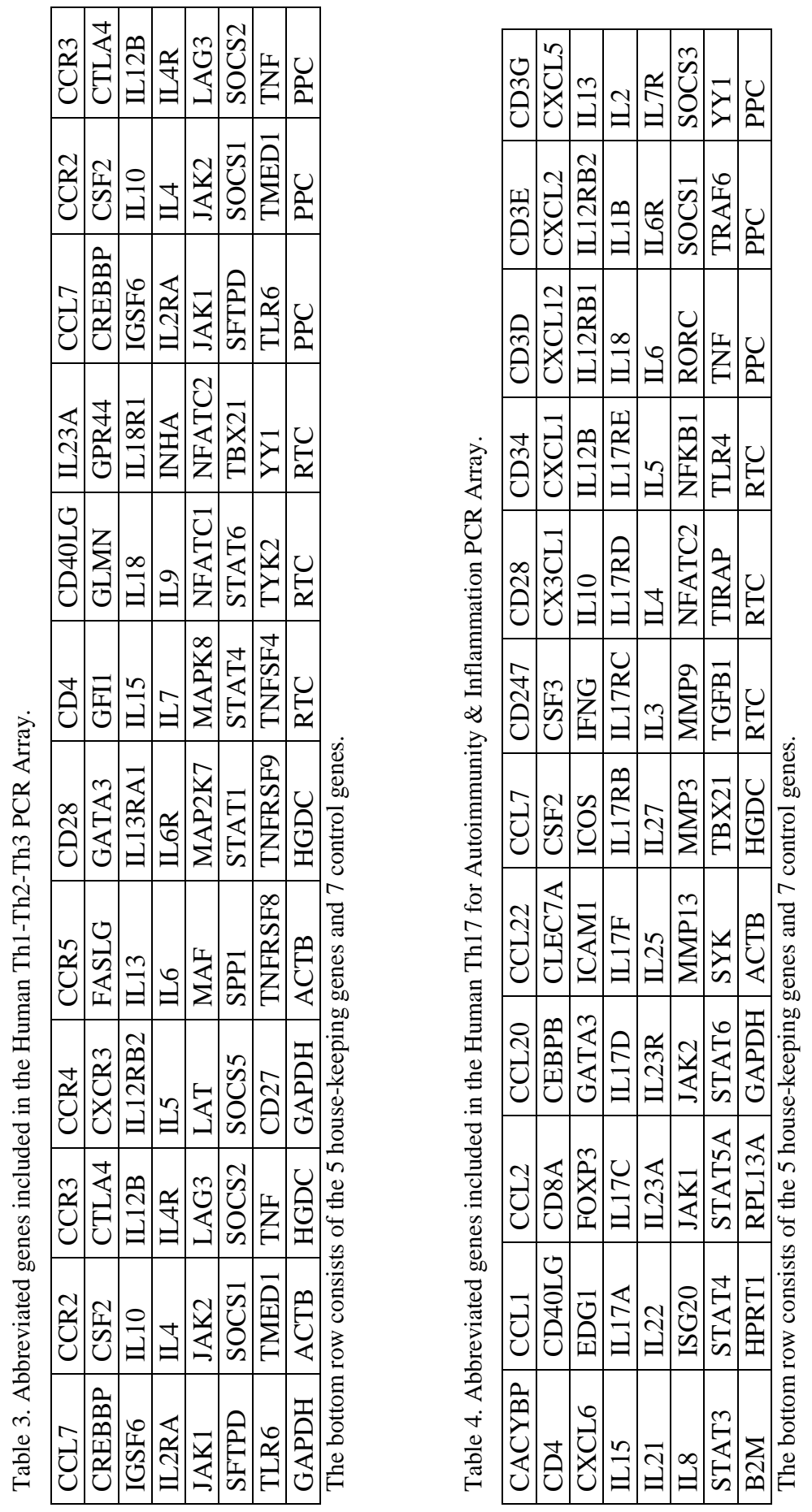




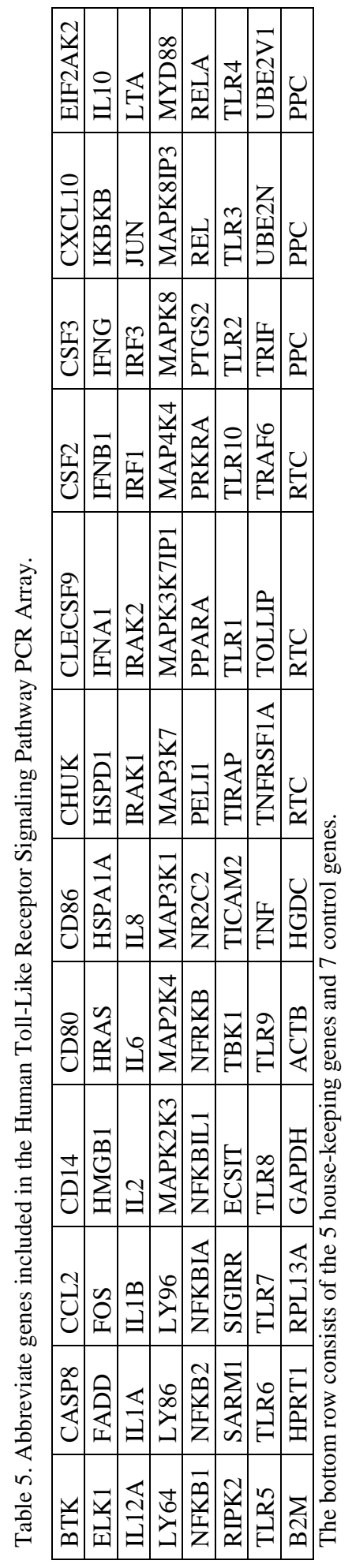


In Paper I, III and IV, genes with threshold cycle $(\mathrm{Ct})$-values $<35$ were considered to be detectable, according to the manufacturer's guidelines. Normfinder (MultiD Analyses/TATAA Biocenter, Gothenburg, Sweden) were used to determine which gene(s) that was optimal for normalization of the genes of interest.

In Paper I, III and IV, the five housekeeping genes (HKG) included on the array were used for normalization of the 84 genes of interest on each array. The Ct-values of the genes of interest were normalized with the average Ct-value of all five housekeeping genes (HKG) on the array: Beta-2-microglobulin (B2M), Hypoxanthine phosphoribosyltransferase 1 (HPRT1), Ribosomal protein L13a (RPL13A), Glyceraldehyde-3-phosphate dehydrogenase (GAPDH) and $\beta$-actin (ACTB). The $\Delta \mathrm{Ct}$ and the median fold change $\left(2^{-\mathrm{MEDIAN} \Delta \Delta \mathrm{Ct}}\right)$ were calculated for the genes on the array.

\section{Quantitative real time reverse transcription (RT)-PCR analyses (Paper II and III)}

Quantitative PCR analyses on the available small intestinal biopsy samples from the Swedish and Finnish populations were performed at National Institute for Health and Welfare in Helsinki. Reverse transcription of the total RNA, from the Finnish and Swedish biopsy samples, was performed with TaqMan reverse transcription reagents (Applied Biosystems, Foster City, CA, USA), according to the manufacturer's guidelines. In the Finnish samples with an additional DNase treatment with DNase I (Roche Diagnostics, Mannheim, Germany). Quantitative real time PCR was performed using StepOnePlus instrumentation (Applied Biosystems) with TaqMan Fast Universal PCR Master Mix and predesigned FAM-labelled gene expression assay reagents (Applied Biosystems). The selected cytokines and transcription factors were IL-17A, FOXP3, RORc, IFN- $\gamma$. Ribosomal 18s RNA served as the endogenous control.

The quantities of target gene expression were analysed by a comparative threshold cycle $(\mathrm{Ct})$ method (as recommended by Applied Biosystems). An exogenous cDNA pool calibrator was collected from PHA-stimulated PBMC and considered as an inter-assay standard, to which normalized samples were compared. Calculation of $2^{-\Delta \Delta \mathrm{Ct}}$ represents the relative amount of target gene in the sample compared with the calibrator, both normalized to an endogenous 
control (18S). For presentations, the relative amounts $\left(2^{-\Delta \Delta C t}\right)$ of the target genes (IL-17A, FOXP3, RORc and IFN- $\gamma$ ) were multiplied by a factor of 1000 and expressed as relative units. If the samples $\mathrm{Ct}$ value for target gene did not reach quantitative level, then an artificial value that was half of the lowest quantitative value in relative units was given to the sample.

Quantitative real time RT-PCR was also used for the analyses of target gene expression in in vitro stimulated Caco- 2 cells (see below). The qPCR analyses were performed as described above for the biopsy samples. Markers of apoptosis were bcl-2 and BAX. The expression of the target genes were normalized using the endogenous ribosomal 18s RNA and the exogenous cDNA pool calibrator. The relative expression $\left(2^{-\Delta \Delta C t}\right)$ was calculated for the target genes, which was related to the expression levels of the unstimulated controls.

\section{Immunohistochemical analyses (Paper II)}

Small intestinal biopsy samples from the Finnish children were used for the immunohistochemistry studies which were performed at National Institute for Health and Welfare in Helsinki. The LP lymphocytes on frozen sections were stained with the avidinbiotin immunoperoxidase system according to Vectastain ABC Elite kit instructions (Vector Laboratories, Burlingame, CA, USA). The slides were incubated with the following primary antibodies: mouse monoclonal antibodies for FOXP3 (clone 236 A/E7; Abcam, Cambridge, UK), CD4 (clone RPA-T4, BD Pharmingen, CA, USA) or rabbit polyclonal antibody for IL17 (Santa Cruz Biotechnology, CA, USA). Methanol-hydrogenperoxidase was used to quench endogenous peroxidase activity. The slides were incubated with a biotinylated antibody and thereafter in ABC reagent. 9-amino-ethyl-cardatzole was used as a chromogen. Harris haematoxylin was used to counterstain the slides. Negative controls were performed by omission of the primary antibodies.

The slides were microscopically evaluated blinded to the clinical data. The number of positively stained cells in the LP was counted systematically under a Leica DM4000B light microscope through a calibrated eyepiece graticule: positive cells in approximately 30 fields were counted using an objective of 100x and an eyepiece at 10x. The cell densities were expressed as the mean number of positive cells per square millimetre (cells $/ \mathrm{mm}^{2}$ ) which were used in the statistical analysis. 


\section{Cytokine assessment in in vitro cultured biopsies (Paper II)}

Small intestinal biopsy samples from Finnish children: 17 with untreated CD, five with potential $\mathrm{CD}$, six with both $\mathrm{CD}$ and T1D, and five TGA-negative references were in vitro cultured for 72 hours in RPMI with 5\% human AB serum. Flow-cytometric bead array (Bender Medsystems) was used to assess the spontaneous secretion of IL-17, IL-1 $\beta$ and IL-6 in the culture supernatants. The cut-off-values of IL-17, IL-1 $\beta$ and IL-6 were 70,30 and $9 \mathrm{pg} / \mathrm{mL}$, respectively. Samples below the detection limit (or the cut-off level) of the method were considered undetectable, but were given half of the cut-off value to enable statistical analyses.

\section{Analyses of apoptotic markers in IL-17 treated Caco-2 cells (Paper II)}

The human colon adenocarcinoma cell line (Caco-2) was obtained from ATCC (Teddington, UK) and were grown in Eagles's minimal essential medium (Sigma, St. Louis, MO, USA) containing $10 \%$ heat activated fetal bovine serum (FBS) supplemented with penicillin and streptomycin. Caco-2 cells were grown in a $75 \mathrm{~cm}^{2}$ flask for six days and were thereafter plated into 48 well plates (Greiner Bio-One GmbH, Frickenhausen, Germany) and grown for another 4 days at a density of $1.5 \times 10^{5}$ cells per well. Then the cells were incubated with rhIL-17), without rhIL-17 (unstimulated control) or with rhIL-17 in combination with TNF- $\alpha$. Then the cells were collected for RNA isolation followed by subsequent quantitative real-time RT-PCR analysis of the apoptotic markers BAX and bcl-2 (as described above).

\section{Analyses of T1D related autoantibodies (Paper IV)}

In the PRODIA study the autoantibody levels of the T1D related autoantibodies; glutamic acid decarboxylase (GADA), tyrosine phosphatase like insulinoma antigen 2 (IA-2A) and insulin (IAA) were analysed in serum with radiobinding assay as described previously [287]. For GADA and IAA the 98th percentile corresponding to 95 and $4.1 \mathrm{WHO}$ units respectively was used as cut-off for positivity, whereas for IA-2A the 99th percentile corresponding to 5.8 WHO units was used as the cut-off limit. The cut-off limits originated from a cohort of healthy 5-6 year old children [287]. 


\section{Whole blood cultures in vitro stimulated with LPS or LTA (Paper IV)}

In the PRODIA study, whole-blood was incubated with or without lipopolysacharide (LPS) (Escherichia coli 026:B6 SigmaAldrich) or lipoteichoic acid (LTA) (Staphylococcus Aureus, SigmaAldrich) in 96 well plates (3799 Costar® Corning Incorporated, Corning, NY, USA).

\section{Flow cytometric analyses (Paper IV)}

In the PRODIA study, the expression of monocyte activation markers was analysed in fresh whole-blood (ex vivo) and in in vitro whole-blood cultures stimulated with LPS or LTA. The monoclonal flourochrome conjugated antibodies used were: Flourescein isothiocyanate (FITC)- conjugated mouse anti-human monoclonal antibodies, anti-CCR5 (BD Pharmingen), Phycoerythrin (PE)- conjugated mouse anti-human monoclonal antibodies, anti-CD80 (Becton Dickinson (BD) Biosciences, San José, CA, USA), anti-CD58 (BD Biosciences); Peridin chlorophyll protein (PerCP)- conjugated mouse anti-human monoclonal antibodies anti-CD14 (BD Biosciences). The isotype control antibodies used were FITC and PE conjugated $\gamma 1$ and $\gamma 2 \mathrm{a}$ (BD Biosciences), PerCP conjugated $\gamma 1$ (BD Biosciences) and APC conjugated $\gamma 1$ (BD Biosciences). The samples were stained according to manufacturer's instructions. Fresh unstimulated or stimulated whole-blood samples were incubated with the respectively antibodies at room temperature and the cells were thereafter lysed with optilyse B (Beckman Coulter, Bromma, Sweden). Finally, the samples were analysed with a fourcoloured FACS Calibur (Becton-Dickinson, San José, CA, USA). The monocytes were gated according to FSC and SSC combined with CD14 staining. The acquired data was analysed with CellQuest software (Becton-Dickinson, San José, CA, USA). The limit for positivity was set with isotype controls.

\section{Analyses of C-reactive protein (CRP) (Paper IV)}

The CRP concentrations in the 6 months plasma samples were analysed using an ELISA method (BenderMedSystems human CRP, Vienna, Austria), with a sensitivity of $3.0^{*} 10^{-6}$ $\mathrm{mg} / \mathrm{L}$.

\section{Statistical methods}

The data analysis was performed with SPAW Statistics for Windows (SPSS Inc., Chigaco, IL, USA). The expression of the immunological markers were not normally distributed, therefore non-parametric Kruskal-Wallis test, Mann-Whitney U test and Wilcoxon test were used for 
comparisons between the study groups. Spearman's rank correlation test was applied to analyse correlations between different parameters. P-values $<0.05$ were considered significant.

\section{PCA}

Unsupervised Principal Component Analysis (PCA) of the normalized real-time PCR array data was performed with GeneEx (MultiD Analyses/TATAA Biocenter, Gothenburg, Sweden). The expression data was pre-processed for PCA by calculating the relative expression of the genes in the samples (Relative quantity: maximum), log2-transformation and mean-centering (mean: 0).

\section{Clustering}

The gene expression profiles of the HKG-normalized genes were visualized with Self Organizing Map (SOM)-clusters formed by GeneCluster 2.0 (Whitehead Institute, Center for Genome Research, Massachusetts Institute of Technology, Cambridge, MA), using Tamayo's algorithm [349]. The expression data was pre-processed by normalization (mean: 0, variance: 1) before it was clustered according to Tamayo et al [349].

\section{Ethical considerations}

The studies were approved by the Regional Ethics Committee for Human Research, at the Faculty of Health Sciences, Linköping University and the ethics committee of the Hospital for Children and Adolescents, Helsinki University Central Hospital, Finland. Informed consent was obtained from the parents of the participating children and when possible also from the participant children in the studies. 


\section{RESULTS \& DISCUSSION}

\section{Methodological aspects}

To study genes involved in the immunological network, real-time PCR arrays were used in paper I, III and IV, whereas real-time PCR and immunohistochemistry were used in paper II. The PCR array system is an ideal tool for focused gene expression studies, since it combines real-time PCR and microarray technology, and thus represents a sensitive method to study many genes simultaneously providing a broad picture of the immune responses. One advantage of the PCR array system is that it yields high positive call rates and has a high reproducibility [350], which was confirmed in our studies where most of the analyzed genes were detectable in the majority of the samples.

Since the studies were exploratory, the achieved p-values from the univariate analysis of PCR array results were not Bonferroni corrected. Hence, data of exploratory studies has been suggested to be analysed without multiplicity adjustment [351]. Furthermore, the expression of many of the genes can be considered as dependent on each other and the Bonferroni procedure has been reported to ignore dependencies among the data and was therefore considered to be much too conservative if the number of tests was large [352] as in array studies.

In Paper I and III unsupervised multivariate exploratory analysis techniques e.g. Principal Component Analysis (PCA) and cluster analysis were used in addition to the univariate statistics. PCA and cluster analysis are geared towards the discovery of patterns in the data and are commonly employed for analysis and visualization of complex data sets such as expression array data [353-355], even though their statistical emphasis does not use statistical cut-off values.

PCA can be used to visualize differences between complex data sets (rewieved in [356]). The goal of PCA is to reduce the high dimensionality of the datasets by identifying the genes/samples that contribute most to the variation and plotting them in a multidimensional format (rewieved in [354]). The new variables (axes) called principal components (PCs) are utilized to visualize the data as a cloud of points, where each point represents a sample/gene 
in a multidimensional space (reviewed in [357]). PCA reduces the large number of dimensions of a dataset into a smaller number of dimensions in such a way that most of the variance of the dataset is described by the first principal components (PC). PCA was used in Paper I and III, to display the expression pattern of the differently expressed genes. Not all of the studied genes were included in the PCA due to the "noise" in the data.

Clustering seeks to organize information about various variables so that groups of similarly expressed genes/samples can be formed (rewieved in [354]), which may indicate associations between genes/samples. Self organized maps (SOMs) organize the clusters into a map where similar clusters are close to each other [358]. The SOM-clusters may consist of genes for which the gene expression profile/pattern is not statistically significant. SOM-clustering was used in Paper III, to display the expression pattern of the differently expressed genes.

\section{Mucosal immune responses in $C D$}

\section{Type 1 responses in CD}

One of the hallmarks of active CD is the elevated IFN- $\gamma$ responses seen in the intestinal mucosa [181-187]. In three different study cohorts we found elevated Type 1 (Th1 and Tc1) immune responses intestinally in untreated $\mathrm{CD}$, which is in agreement with previous studies $[175,179,188,189,359]$. Here, the Th1 and Tc1 responses were characterized by elevated expression of IFN- $\gamma$, STAT1, IRF1 and CD8A (Figure 9). Treatment with a GFD for a year did not normalize the Th1 and Tc1 response to similar levels as in the reference group. The levels of the Th1 markers was somewhat reduced after GFD, but they remained higher than the levels in the reference group. This finding indicates that $\mathrm{CD}$ is associated with a continuous activation of the immune cells. It is not known if the elevated Type 1 response is a predisposing factor for $\mathrm{CD}$, a consequence of previous episodes of active $\mathrm{CD}$ or due to a failure to totally eliminate gluten from the diet. However, it seems not to be entirely dependent on the gluten exposure, but rather a feature of $\mathrm{CD}$, since they remain elevated after GFD. Another possible explanation might be that the imbalanced immune responses required a longer duration than 1 year to completely normalize, as indicated by the gut microflora activity in GFD-treated CD patients [360]. STAT1 and IRF1 have as far as we know not been studied in GFD-treated children previously. Our results support the observation by Forsberg et al. indicating that IELs in treated symptom-free CD patients display increased IFN- $\gamma$ levels compared with controls [179]. Wapenaar et al also showed elevated IFN- $\gamma$ responses in 
biopsies from GFD-treated patients in complete remission [361]. Our results extend these findings, including also the IFN- $\gamma$ downstream signaling related marker STAT1.

In individuals with active CD the number of CD8+ TCR $\alpha \beta+$ and $\gamma \delta+$ IELs has been shown to be increased. It is however not known if this is due to changes in the epithelium or a consequence of the pro-inflammatory milieu created by the CD4+ T-cell response in the LP. Forsberg et al reported that $\mathrm{CD} 8+\alpha \beta+\mathrm{T}$ cells within the epithelium producing IFN- $\gamma$ were believed to drive the formation of intestinal lesions in active CD [175]. This is consistent with our findings of elevated CD8A and IFN- $\gamma$ in the untreated CD patients. However, the CD8A and IFN- $\gamma$ remained elevated even though the intestinal lesion had healed suggesting that the IELs are continuously activated and that CD8+ cells seem to contribute the most to the IFN- $\gamma$ production, which is in concordance with a previous study [175]. That study also showed that CD4+ IELs, the $\gamma \delta+$ IELs and the NKT (CD94+CD8+) IELs also contributed to the IFN- $\gamma$ production but in a minor degree. Increased IFN- $\gamma$ levels might indicate an altered barrier function in the CD patients, as suggested by Forsberg et al [179]. IFN- $\gamma$ has been shown to disrupt epithelial barrier function by decreasing the levels of the tight junction protein TJP1, also known as zonula occludence protein ZO-1 (reviewed in [362]) [363]. This is supported by studies showing low expression of ZO-1 in untreated CD patients $[359,364,365]$ and particularly in those with concomitant CD and T1D [364]. It have been reported that treatment with a GFD improved and in some cases normalized the TJP1 (ZO-1) levels [365, 366]. Thus, CD patients with active disease may suffer from considerable loss of epithelial tight junctions leading to increased intestinal permeability. Markers of an altered intestinal barrier has however not been studied here. 

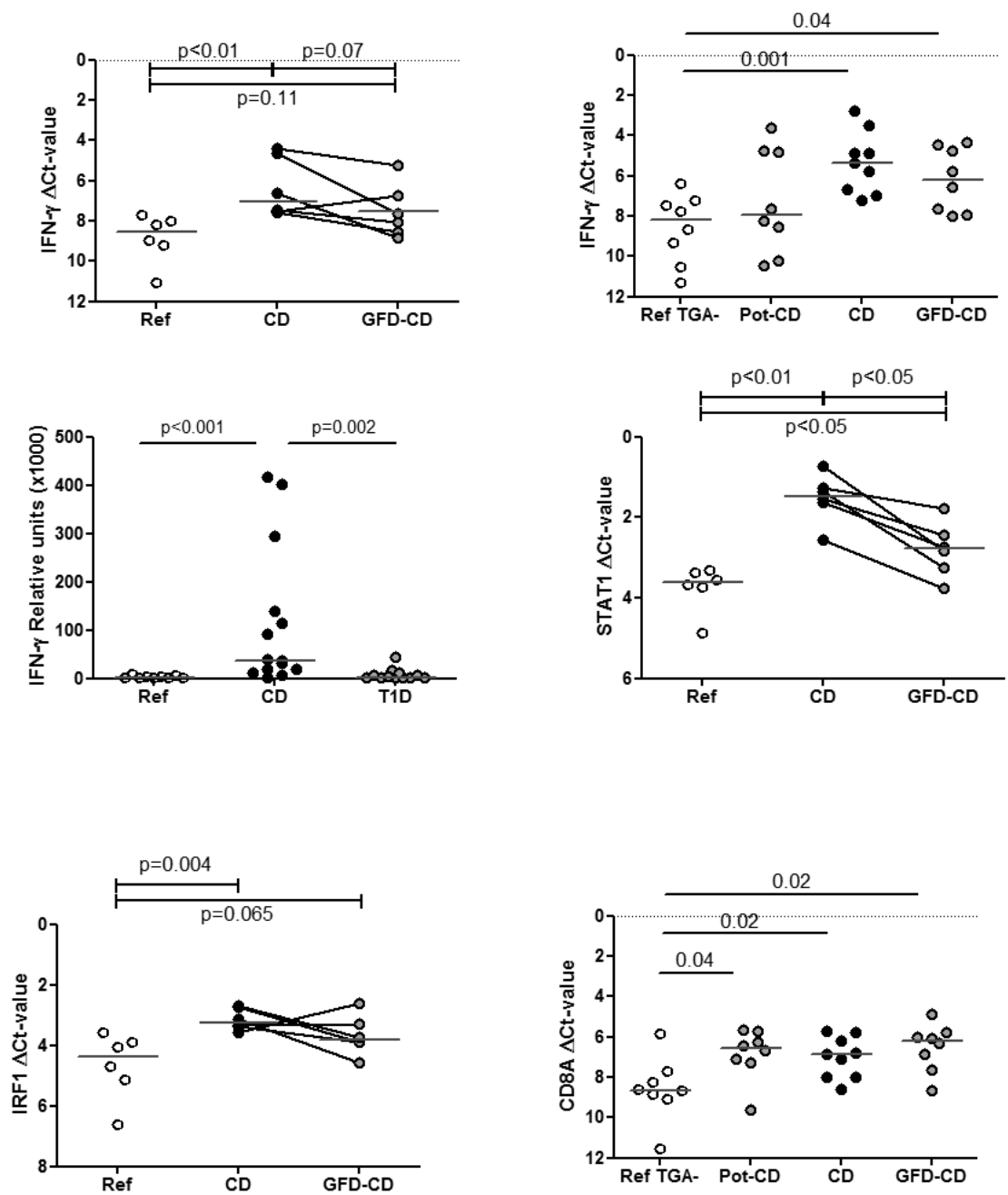

Figure 9. Gene expression profiles of Th1 associated markers in biopsies from children with and without $\mathrm{CD}$. Ref $=$ reference children, Ref TGA- $=$ TGA negative reference children, pot $\mathrm{CD}=$ children with potential $\mathrm{CD}, \mathrm{CD}=$ children with untreated $\mathrm{CD}, \mathrm{GFD}-\mathrm{CD}=$ children with $\mathrm{CD}$ after 1 year of gluten free-diet treatment. T1D = children with type 1 diabetes.

\section{Th2 and Th3 responses in CD}

Activated CD4+ T cells are believed to drive the differentiation of B-cells to plasma cells and secretion on AGA and TGA, by production of Th2 cytokines. Elevated Th2 cytokine responses were however not detected in our studies. Instead, in two different study cohorts, 
we found diminished intestinal Th2 responses in active CD, characterized by IL-4R, CCL22, STAT6, IL-13RA1 (Figure 10). In contrast to our studies where the IL-4 responses generally were undetectable, previous studies have reported similar or elevated Th2 responses (IL-4) in CD [181, 183, 201]. The discrepant results might be due to usage of different immunological methods (immunohistochemistry and in situ hybridization vs Real-time PCR arrays). In two studies, we showed down-regulated IL-18 responses in children with untreated CD (Figure 11). Previous studies have in agreement with our results reported diminished levels of IL-18 in CD [181, 359], whereas others have reported elevated or similar IL-18 responses in CD patients and controls $[182,200]$. The contradictory results may be due to usage of different immunological methods (Western Blot and Real-time PCR vs Real-time PCR arrays). In one study we also showed that the expression of the Th3 related marker TGF- $\beta$ was downregulated in untreated CD (Figure 11), which is in contrast to another study showing similar levels of TGF- $\beta$ in CD compared to controls and individuals with potential CD (but also patients with T1D and concomitant CD and T1D) [181]. Since both the Th2 and Th3 responses were normalized by the GFD to levels similar as in the reference group, they are probably a reflection of the elevated Th1 response. 

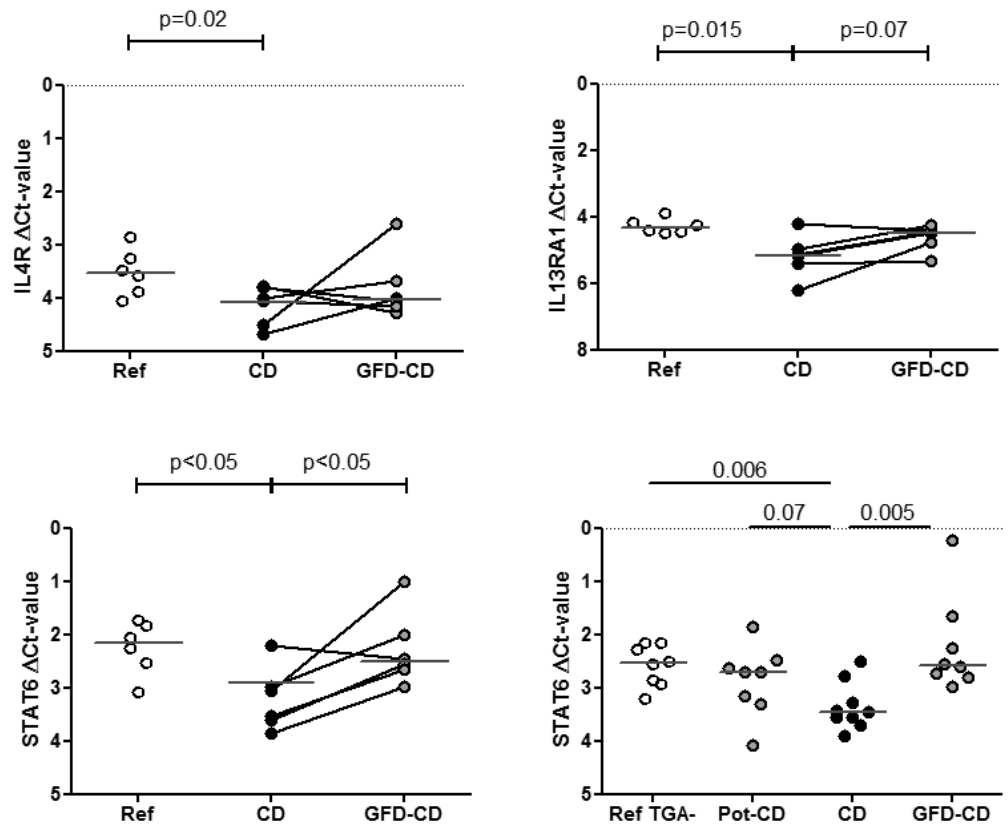

Figure 10. Gene expression profiles of Th2 associated markers in biopsies from children with and without $\mathrm{CD}$. Ref $=$ reference children, Ref TGA $-=$ TGA negative reference children, pot $\mathrm{CD}=$ children with potential $\mathrm{CD}, \mathrm{CD}=$ children with untreated $\mathrm{CD}$, GFD-CD = children with $\mathrm{CD}$ after 1 year of gluten free-diet treatment. 

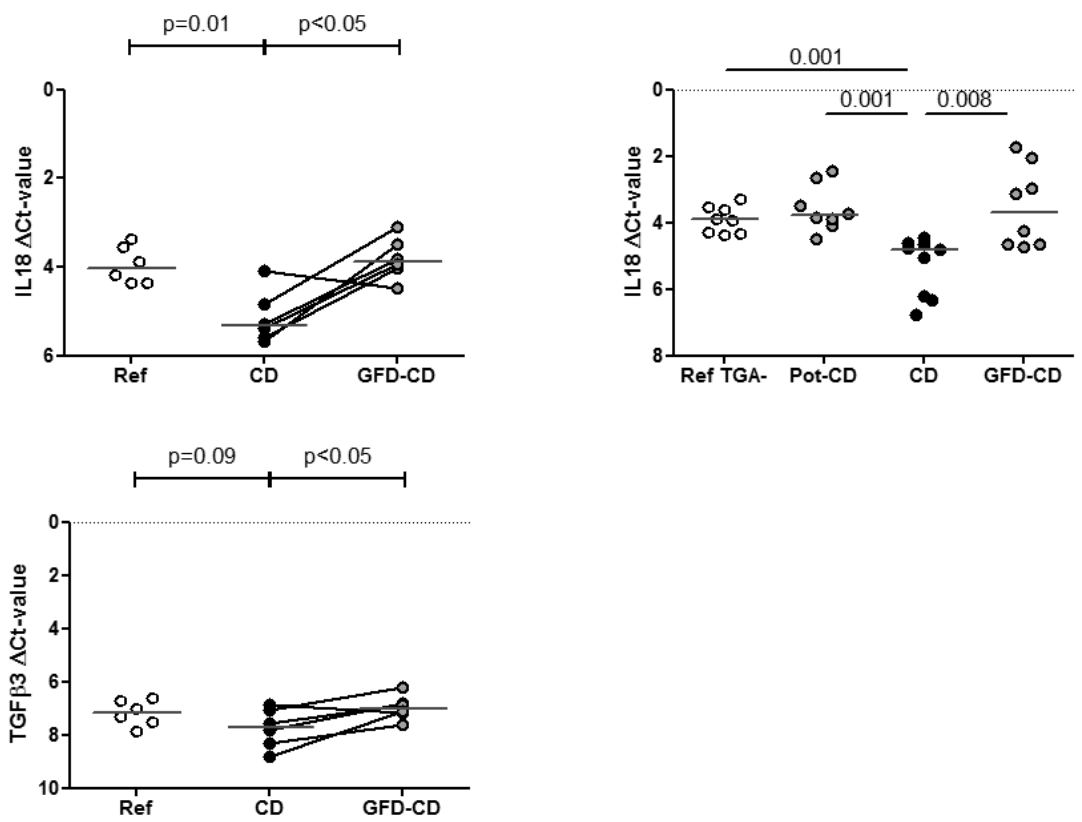

Figure 11. Gene expression profiles of Th2 and Th3 associated markers in biopsies from children with and without $\mathrm{CD}$. Ref $=$ reference children, Ref TGA- $=$ TGA negative reference children, pot $\mathrm{CD}=$ children with potential $\mathrm{CD}, \mathrm{CD}=$ children with untreated $\mathrm{CD}, \mathrm{GFD}-\mathrm{CD}=$ children with $\mathrm{CD}$ after 1 year of gluten free-diet treatment.

\section{Th17 and Treg responses in CD}

In two different studies we saw that active $\mathrm{CD}$ was characterized by enhanced intestinal IL-17 levels (Figure 12), which is in concordance with other studies [184, 186, 198, 211, 359, 367]. The up-regulation of IL-17 was seen both at the mRNA and protein level, and in both the Finnish and Swedish study populations. However, the numbers of IL-17 positive cells were not significantly increased in the Finnish children with untreated CD compared to the reference children. This might indicate an up-regulation of the IL-17 production without an expansion of the Th17 cells. However, the number of IL-17 positive cells tended to correlate with the mRNA levels of IL-17 in children with untreated CD $(R=0.444 ; p=0.111)$, whereas no correlation was found in the T1D group $(\mathrm{R}=-0.104 ; \mathrm{p}=0.775)$ or in the references $(\mathrm{R}=-$ 0247; $\mathrm{p}=0.555$ ). Furthermore, biopsies from children with untreated $\mathrm{CD}$ (with or without T1D) spontaneously secreted more IL-17 than the references. 

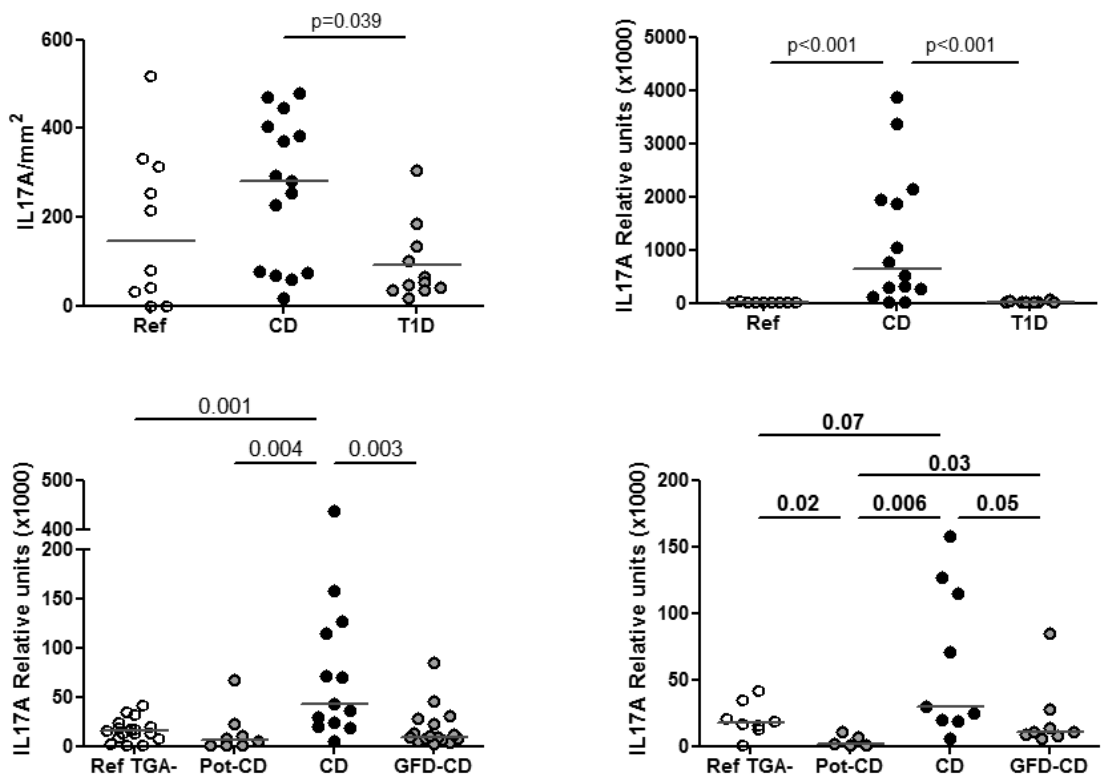

Figure 12. The protein and mRNA expression of the Th17 associated marker IL-17A in biopsies from children with and without $\mathrm{CD}$ and T1D. Ref $=$ reference children, Ref TGA- $=$ TGA negative reference children, pot $\mathrm{CD}=$ children with potential $\mathrm{CD}, \mathrm{CD}=$ children with untreated $\mathrm{CD}$, GFD-CD $=$ children with $\mathrm{CD}$ after 1 year of gluten free-diet treatment, T1D = children with type 1 diabetes .

In contrast to IL-17, we showed that the expression of the IL-17 related markers: RORc, IL17RE, IL-23R was diminished in active CD (Figure 13). We also reported that the T-reg marker FOXP3 was elevated in untreated CD (Figure 14), which is in concordance with other reports $[181,196,197]$. The up-regulated FOXP3 levels were seen both at the mRNA and protein level in the Finnish study population, but also in the Swedish study population. However, RORc did not correlate with IL-17, which instead correlated with FOXP3. This indicates that the T cells that express IL-17 might be plastic, instead of being classical Th17 cells [368-370]. Alternatively this might indicate a simultaneous attempt to regulate the elevated IL-17 expression. A GFD-treatment normalized the levels of the aforementioned Th17 and Treg related markers (IL-17, RORc, IL-17RE, IL-23R, FOXP3) to levels similar as in the reference group, thus their expression seemed to be related to the gluten exposure. 

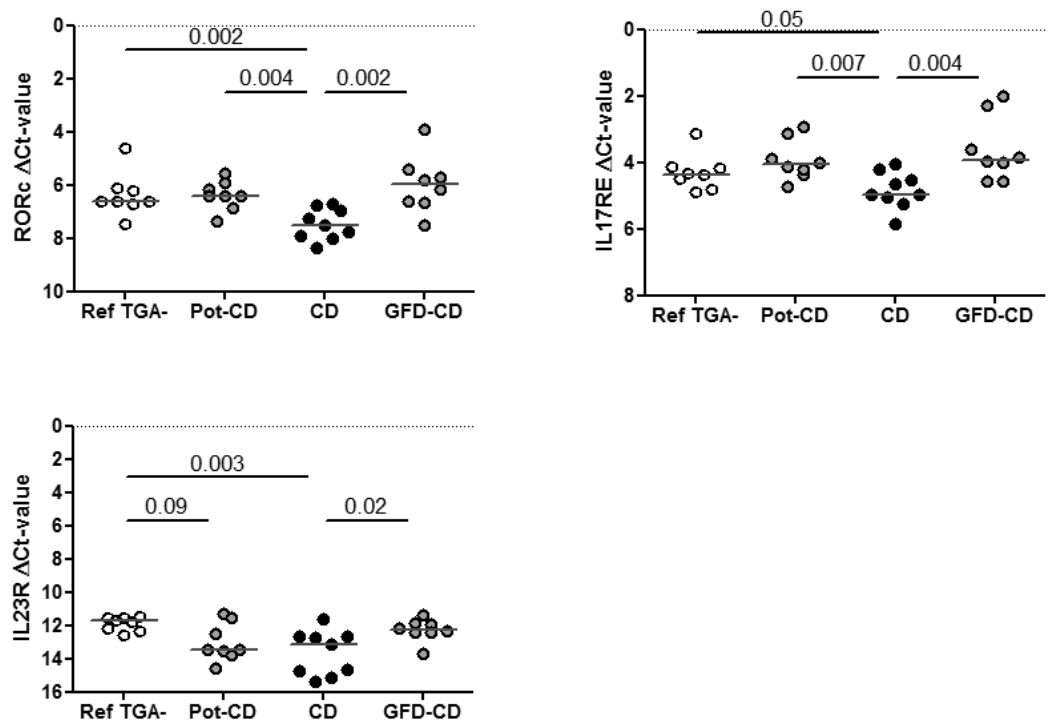

Figure 13. The expression profile of Th17 associated markers in biopsies from children with and without $\mathrm{CD}$. Ref $=$ reference children, Ref TGA $-=$ TGA negative reference children, pot $\mathrm{CD}=$ children with potential $\mathrm{CD}, \mathrm{CD}=$ children with untreated $\mathrm{CD}$, GFD-CD = children with $\mathrm{CD}$ after 1 year of gluten free-diet treatment. 

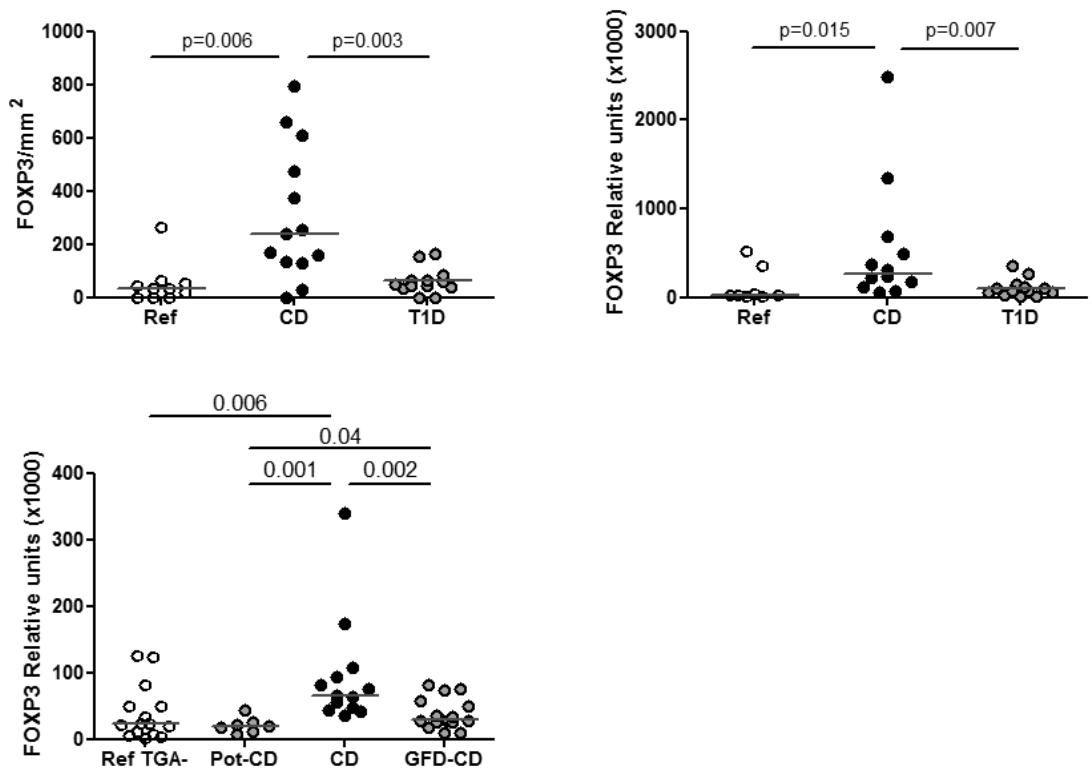

Figure 14. The protein expression of the Treg associated marker FOXP3 in biopsies from children with and without CD and T1D. Ref = reference children, Ref TGA- = TGA negative reference children, pot $\mathrm{CD}=$ children with potential $\mathrm{CD}, \mathrm{CD}=$ children with untreated $\mathrm{CD}, \mathrm{GFD}-\mathrm{CD}=$ children with $\mathrm{CD}$ after 1 year of gluten free-diet treatment, T1D = children with type 1 diabetes.

In one of our studies biopsies from Finnish children with active $\mathrm{CD}$, spontaneously secreted more IL-6 and IL-1 $\beta$ than samples from reference children (Figure 15). It has been shown that an inflammatory cytokine environment (with IL-6 and IL-1 $\beta$ ) supports the conversion from FOXP3 expressing Tregs towards IL-17 secreting cells [371]. It has also been shown that Th17 cell clones might change phenotype, into IFN- $\gamma$-producing FOXP3+ cells, when RORc is down-regulated and FOXP3 up-regulated upon repeated TCR engagement [372]. This plasticity might explain the low RORc expression in association with the elevated IL-17, FOXP3 and IFN- $\gamma$ in our samples from children with untreated CD.

The expression of all the aforementioned Th17 and Treg associated genes were normalized upon GFD treatment, which indicated that the genes were dependent on the gluten exposure, since they normalized concurrently with the healing of the mucosa. 

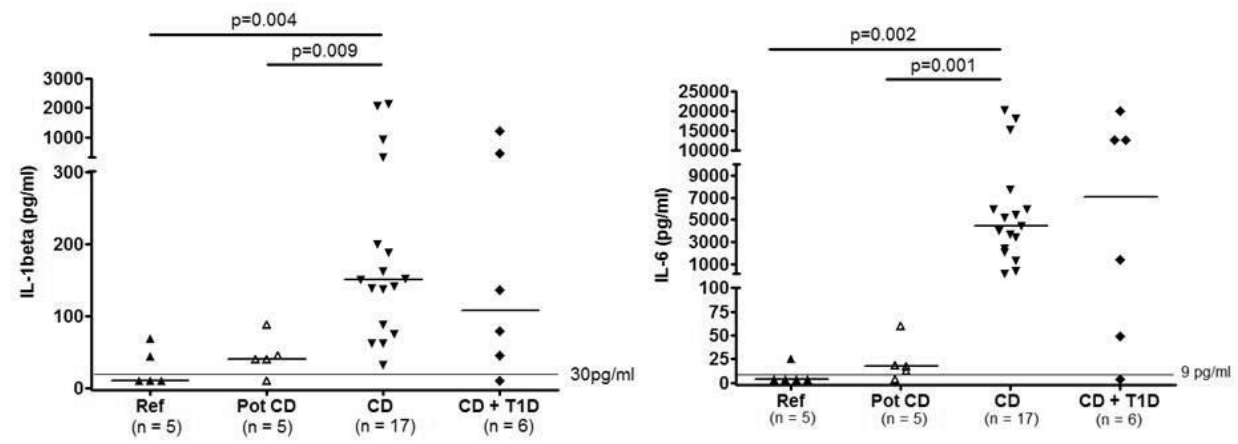

Figure 15. The protein expression of IL-1 $\beta$ and IL-6 in in vitro cultured whole biopsies. $\operatorname{Ref}=$ reference children, pot $\mathrm{CD}=$ children with potential $\mathrm{CD}, \mathrm{CD}=$ children with untreated $\mathrm{CD}, \mathrm{CD}+\mathrm{T} 1 \mathrm{D}$ $=$ children with $\mathrm{CD}$ and type 1 diabetes.

\section{Th17 and Treg expression in potential CD}

Interestingly, in another study we found diminished levels of IL-21, FOXP3 and IL-17A in children with potential CD (Figure 12 and Figure 16). Down-regulated IL-21 and FOXP3 responses in potential CD have previously been reported by Sperandeo et al and Tiittanen et al respectively [181, 373]. The diminished IL-17 expression in the TGA-positive children, with potential CD, indicates that up-regulation of IL-17 immunity does not occur in children with increased risk for $\mathrm{CD}$, but instead in the late phase of $\mathrm{CD}$ when a villous atrophy has developed.
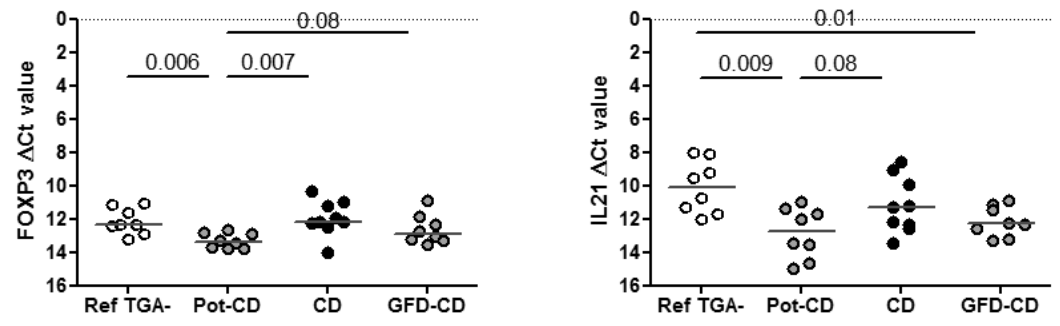

Figure 16. The gene expression profile of Treg and Th17 associated markers in biopsies from children with and without CD. Ref TGA- = TGA negative reference children, pot CD = children with potential $\mathrm{CD}, \mathrm{CD}=$ children with untreated $\mathrm{CD}, \mathrm{GFD}-\mathrm{CD}=$ children with $\mathrm{CD}$ after 1 year of gluten free-diet treatment. 


\section{Expression of apoptosis markers in Caco-2 cells}

In active $\mathrm{CD}$ the mucosa is characterized by damage of the epithelial layer, in which apoptosis is one of the mechanisms behind the gluten-triggered villous atrophy. IL-17 has been suggested to play a role in apoptosis, and was therefore used in an in vitro experiment with the epithelial cell line $\mathrm{CaCo}-2$. In our experiments however incubation of $\mathrm{CaCo}-2$ cells with IL-17 resulted in up-regulated expression of the anti-apoptotic marker bcl-2 (Figure X). On the other hand, in vitro stimulation with IL-17 and the apoptosis trigger TNF- $\alpha$ resulted in diminished bcl-2 expression (Figure 17). Interestingly, the observed effect, of IL-17 with or without TNF- $\alpha$, on the BAX expression was weak. These findings suggest that IL-17 was not contributing to apoptosis of epithelial cells, but instead might induce protective anti-apoptotic mechanisms. Thus, our results supports that up-regulation of IL-17 in the intestine might be linked to the mechanism of protection from tissue damage in the inflamed mucosa, as also suggested by others [374]. IL-17 immunity may play a dual role; apoptotic or anti-apoptotic, dependent on the cytokine milieu and the target tissue.
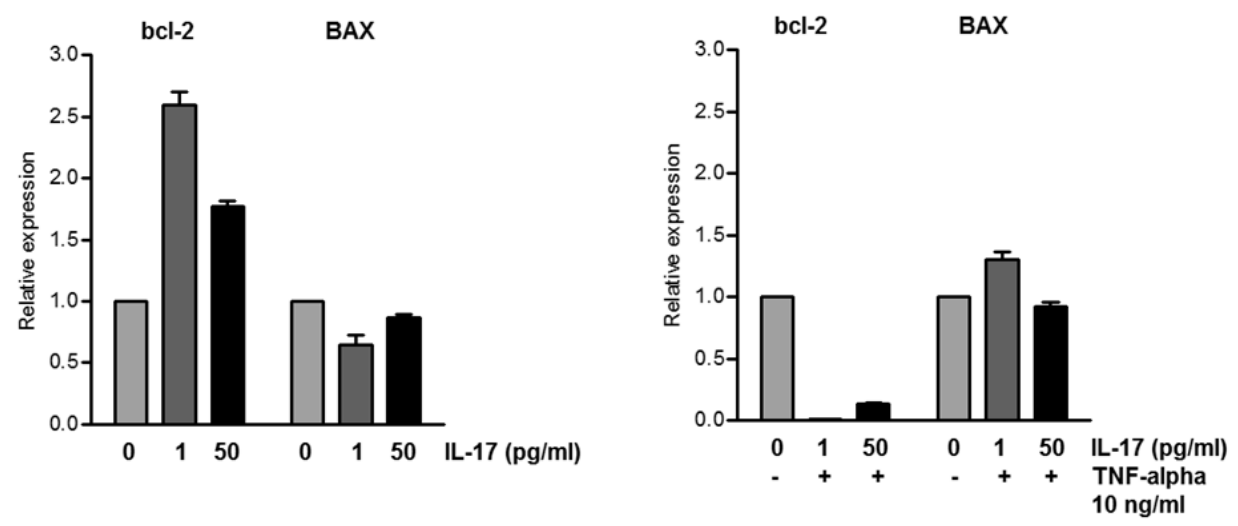

Figure 17. The expression of the apoptotic and anti-apoptotic markers BAX and bcl-2 respectively in CaCo- 2 cells incubated with IL-17 alone or in combination with TNF- $\alpha$.

\section{MMPs in CD}

The mechanism by which cytokines cause mucosal alterations remains unclear. Recent studies suggest that they induce degradation of extracellular matrix (ECM) in mucosal sites. The villus atrophy observed in patients with CD strongly suggests a loss of ECM. The epithelial 
cell shedding in CD might be the result from ECM degradation by MMPs. MMPs has been shown to be elevated in active CD [187, 375] and in DH [376]. MMPs are a family of endopeptidases, e.g. expressed by activated subepithelial fibroblasts, myofibroblasts, macrophages and lymphocytes, playing a key role in ECM turnover, but they do also function in intestinal mucosal defence. We observed that the expression of MMP3 was elevated in untreated CD (Figure 18), which is in agreement with previous studies [375, 377], but differed from another study showing similar levels of MMP3 in CD patients and controls [187]. The discrepant findings might be due to methodological differences; Real-time PCR vs Real-time PCR arrays or the fact that the subjects were adults in comparison to our studies which are performed on children. We found in contrast that the expression level of MMP9 was reduced in CD (Figure 18), which is not in accordance with other studies [187, 376, 377]. The different results might be due to usage of different methods (Real-time PCR and immunohistochemistry vs Real-time PCR arrays) and usage of samples from adults instead of from children. The down-regulated MMP9 responses might be a reflection of the increased intestinal permeability, since low levels of gelatinases (e.g. MMP9) facilitate T cell migration through connective tissues [378]. We observed that MMP3 and MMP9 both normalized upon GFD treatment to levels resembling those in the references, which is in agreement with the report by Daum and colleagues [375]. Thus, it seemed that the MMPs normalized concurrently with the intestinal mucosa. The simultaneous up-regulation of IL-17 and MMP3 is of interest, since a previous study showed that IL-17 induces secretion of MMP3 in vitro [379]. Interesting, e.g. IFN- $\gamma$ has been shown to up-regulate and correlate with the expression of some MMPs [187] but down-regulated MMP9 (reviewed in [378]). Thus the reduced MMP9 expression seen here might be a reflection of the elevated IFN- $\gamma$ response. MMPs are thought to be involved in the pathophysiology of CD [380], but whether they have a causative role in the development of the villous atrophy or are a consequence of the disease process is unknown. The results from this study suggestes that MMP3, but probably not MMP9, might be associated with the epithelial destruction at the time of villous atrophy. The activity of the MMPs is regulated by tissue inhibitors of metalloproteinases (TIMPs), thus the degradation of matrix might be due to an imbalance in the MMP and TIMP concentrations in the LP environment [381]. TIMP is however not analysed here. Here, it is however unknown if the MMPs are in their active form or if they are inactivated by TIMPs. 

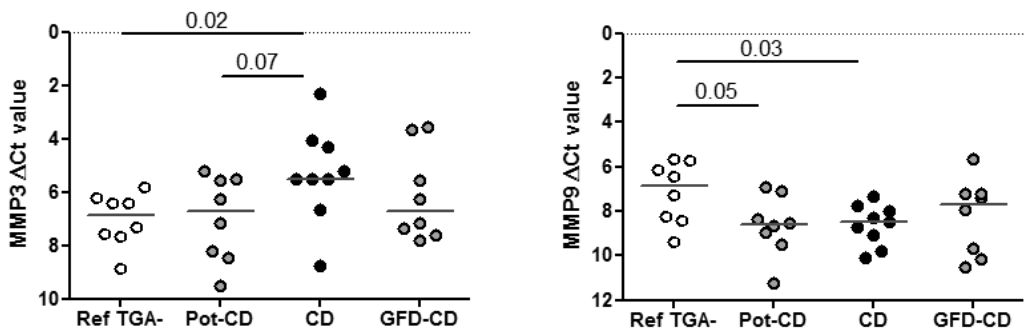

Figure 18. The expression of metalloproteinases in biopsies from children with and without CD. Ref TGA- = TGA negative reference children, pot $\mathrm{CD}=$ children with potential $\mathrm{CD}, \mathrm{CD}=$ children with untreated $\mathrm{CD}$, GFD-CD = children with $\mathrm{CD}$ after 1 year of gluten free-diet treatment.

\section{Activation markers in CD}

One of our studies showed diminished expression of IL-2 in untreated and GFD-treated CD (Figure 19). Thus, the down-regulated IL-2 response was not affected by the GFD treatment. Previous studies have also reported diminished IL-2 responses in active CD [179, 359]. The low IL-2 response may be a sign of long standing immune activation. The phenomenon might be associated with the disease itself, rather than the gluten exposure, since the levels remains dysregulated after GFD-treatment. In another study, the IL-2 levels were low in untreated CD but not significantly lower than in controls.

The function of Tregs, which express high levels of IL-2R, is dependent on IL-2 and TGF- $\beta$. Accordingly, low expression of IL-2 in the CD mucosa could indicate conditions where the function of Tregs is impaired. The function of ICOS is also dependent on IL-2 [382]. It has been shown that ICOS supports differentiation of Tregs when co-stimulatory signals are suboptimal. Interestingly, in parallel with the reduction of IL-2, we also found reduced expression of ICOS (significant only for GFD treated CD) (Figure 19). Furthermore, the expression of CD80 was decreased both in untreated and GFD-treated CD (Figure 19). Since these factors were not corrected by GFD, they may represent so-called intrinsic factors related to the development of CD. The dysfunction of ICOS in CD is supported by the finding of ICOS gene polymorphism in association with CD susceptibility [383]. 

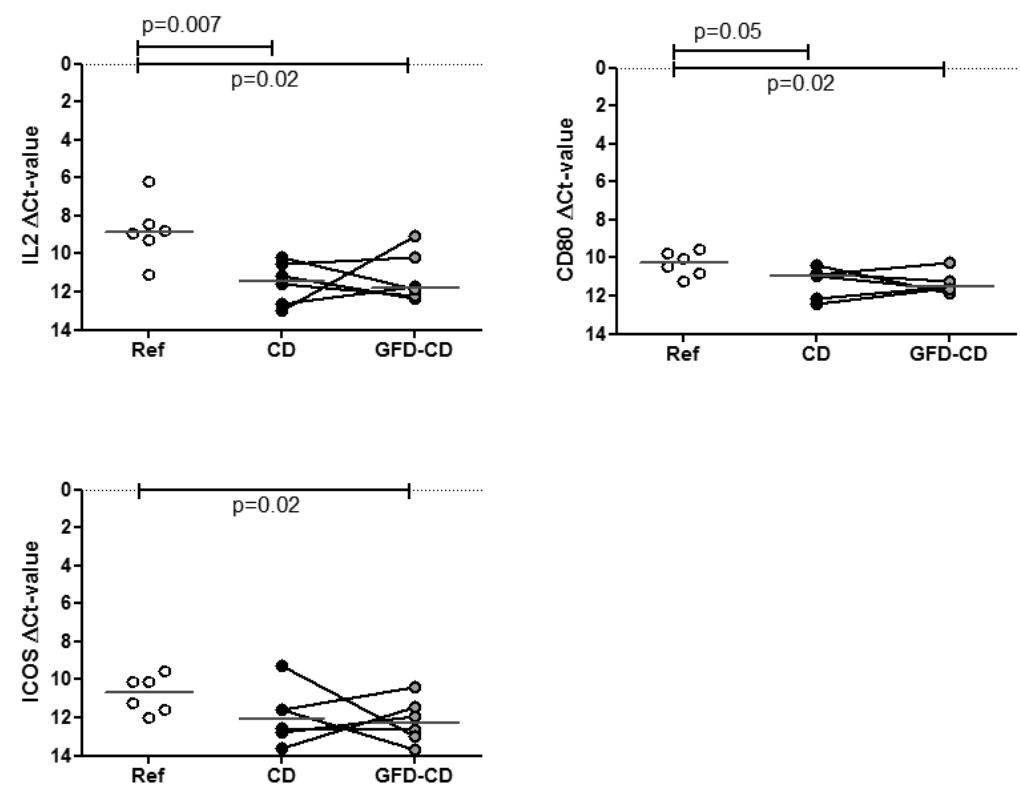

Figure 19. The expression of T-cell associated markers in biopsies from children with and without CD. Ref $=$ reference children, $C D=$ children with untreated $C D, G F D-C D=$ children with $C D$ after 1 year of gluten free-diet treatment.

In one of our studies we saw diminished expression of the CD247, CD4 and NFATC2 in untreated CD compared to the references and GFD treated patients (Figure 20), indicating that the T-cell activation and signaling is dysfunctional in active CD. CD247 is an amplification molecule in the TCR/CD3 signaling cascade and a master regulator and sensor of innate and adaptive immune responses. Aberrant CD247 responses have been reported to be associated with pro-inflammatory conditions, autoimmune diseases and refractory CD [384-387]. Cells expressing low levels of CD247 have been shown to produce IFN- $\gamma$, but also to possess enhanced migratory capacity and to enrich in inflamed tissues. However, it is unclear whether the down-regulation of CD247, which often occurs concurrently with a Th1 response, is a cause or a consequence of chronic inflammatory responses. NFATC2 is a multifaceted activation marker, important for cytokine production by peripheral $\mathrm{T}$ cells, which also has been suggested to regulate mucosal T-cell activity and to be important in innate and mucosal immune responses [388]. Treatment with GFD seem to normalize the defective T cell 
activation and signaling to levels similar as in the references, indicating that the mechanism might be a normal phenomenon to regain intestinal homeostasis.

In one of our studies we observed elevated CTLA-4 responses in untreated CD, especially compared to GFD-treated CD (Figure 20). CTLA-4, which is expressed by Treg cells and activated T-cells, contributes to down-regulation of T cell activation via CD80/CD86 and is essential for maintenance of immune homeostasis [389]. The elevated CTLA-4 responses in active CD might indicate a prolonged activation of T-cells or elevated levels of Treg cells. In another study we saw elevated FOXP3 responses in untreated CD compared to GFD-treated children and references, which indicates that the elevated CTLA-4 response might be a reflection of the elevated Treg response. The down-regulated IL-2, ICOS, CD80, CD247 and NFATC2 expression in active CD might be a consequence of the elevated CTLA-4 response, thus a normal mechanism to regain intestinal homeostasis. However, a GFD did not normalize all of the markers which indicates that additional factors are of importance or that one year of GFD not is enough to normalize the dysregulated mucosal immune responses. 

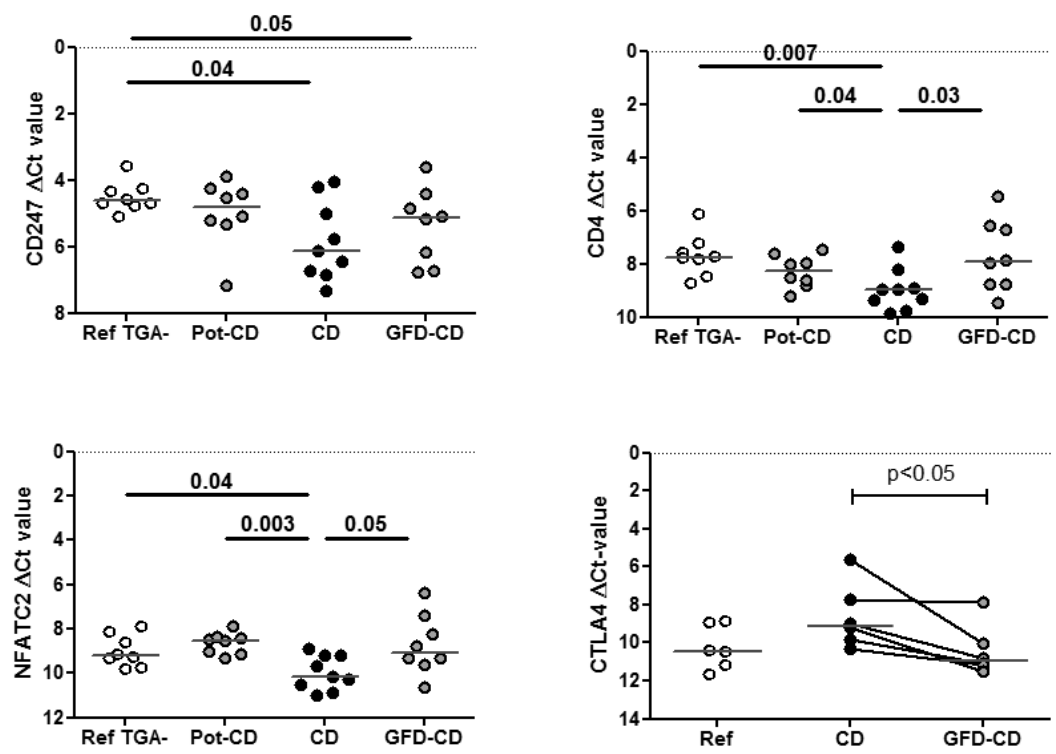

Figure 20. The expression of T-cell associated markers in biopsies from children with and without CD. Ref $=$ reference children, Ref TGA $-=$ TGA negative reference children, pot $\mathrm{CD}=$ children with potential $\mathrm{CD}, \mathrm{CD}=$ children with untreated $\mathrm{CD}, \mathrm{GFD}-\mathrm{CD}=$ children with $\mathrm{CD}$ after 1 year of gluten free-diet treatment.

\section{Mucosal immune responses in T1D}

In one of the studies we included patients with T1D and patients with concomitant T1D and $\mathrm{CD}$, in addition to the $\mathrm{CD}$ patients. Previous studies have reported elevated IL-4, IL-1 $\alpha$, HLA class II antigens and ICAM-1 in patients with T1D, indicating an enhanced immune activation in the intestine of T1D patients [257]. We studied the expression of Th1, Th17 and Treg markers IFN- $\gamma$, IL-17A and FOXP3 respectively, in children with T1D (without CD) (Figure 9, Figure 12 and Figure 14, respectively). The study showed similar levels of the aforementioned genes in T1D patients and reference children, which is in agreement with previous studies $[181,257]$. Patients with T1D have on the other hand been reported to display elevated IL-17 responses in peripheral blood [313]. The T1D-duration might have 
influenced the results, thus newly diagnosed T1D patients might display a different intestinal cytokine expression compared to patients with a longer T1D duration.

Children with concomitant T1D and CD have previously been reported to express high levels of IL-1 $\alpha$, IL-2, IL-4, IFN- $\gamma$, TNF- $\alpha$, FOXP3 [181, 197, 257, 364, 390]. This is in contrast to our findings, where Swedish children with both T1D and CD seemed to express similar levels of IL-2, FOXP3 and IL-21 as reference children (unpublished results, data not shown).

Children with CD and T1D seemed to express higher levels of IFN- $\gamma$ and MMP3 than reference children, thus at levels similar to children with untreated CD (Figure 21). On the other hand, children with T1D and CD seemed to express low levels of IL-17RE, RORc, IL-18, STAT6 and NFATC2 compared to the references, thus similarly as children with untreated CD (unpublished results) (Figure 21-22). The STAT6 expression tended to be diminished in children with concomitant T1D and CD compared to children with untreated CD (Figure 22). 

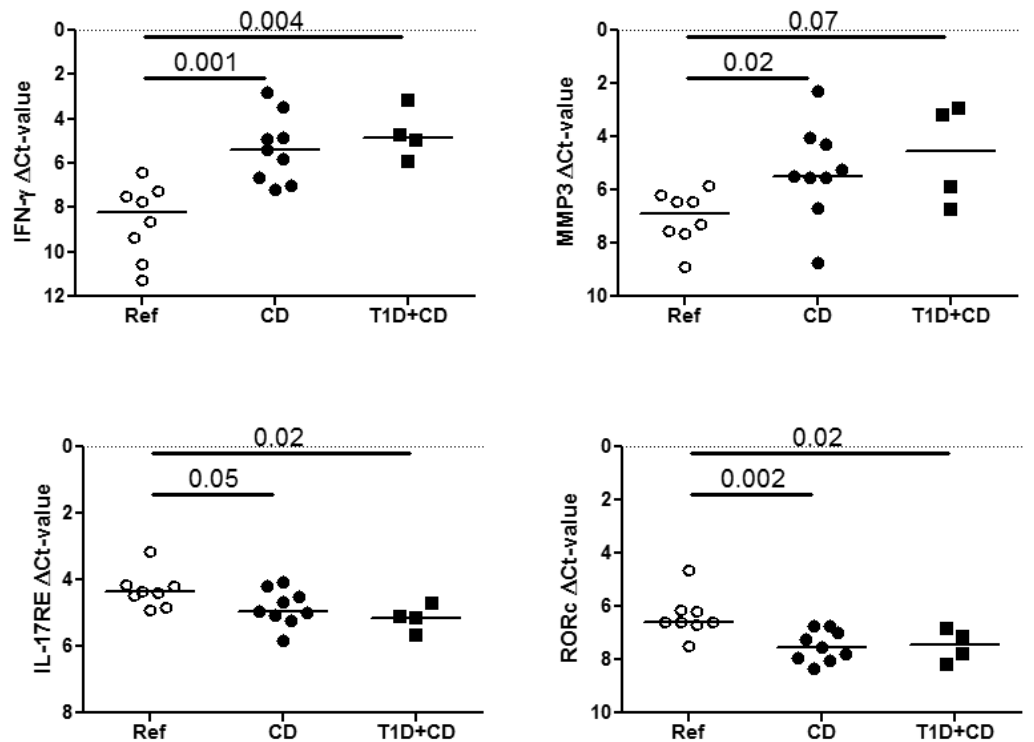

Figure 21. The expression of Th1 and Th17 associated markers in biopsies from children with and without $\mathrm{CD}$ and T1D. Ref $=$ reference children, $\mathrm{CD}=$ children with untreated $\mathrm{CD}, \mathrm{T} 1 \mathrm{D}+\mathrm{CD}=$ children with $\mathrm{CD}$ and type 1 diabetes. 

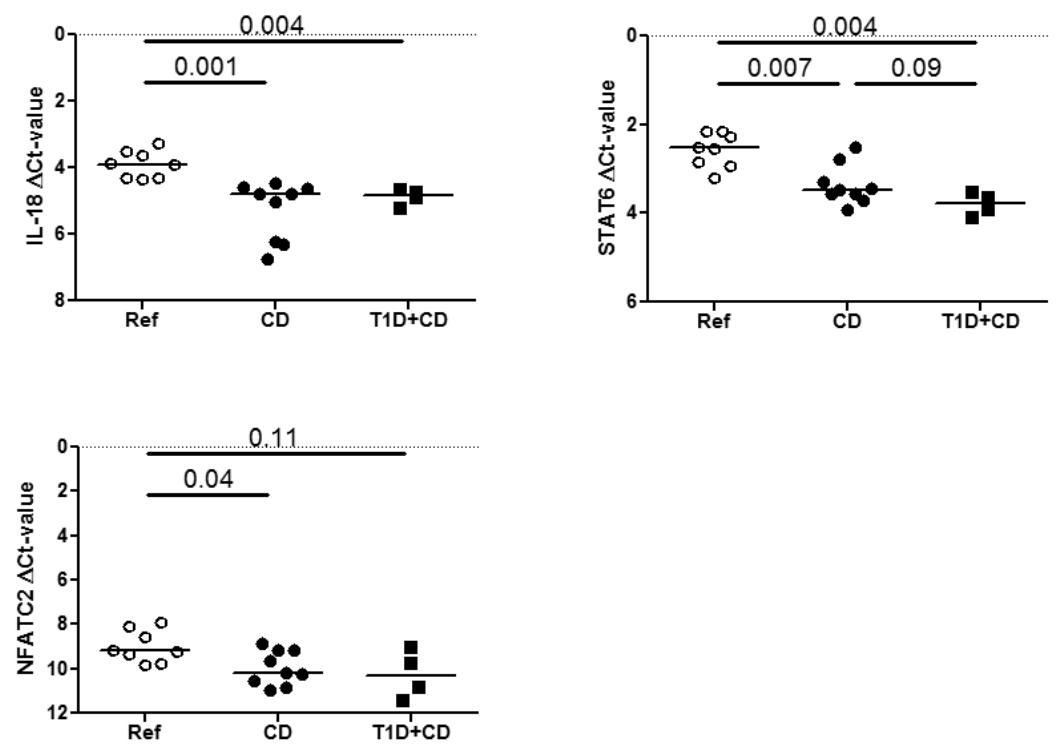

Figure 22. The expression of Th2 associated markers in biopsies from children with and without CD and T1D. Ref $=$ reference children, $C D=$ children with untreated $C D, T 1 D+C D=$ children with $C D$ and type 1 diabetes.

Interestingly, children with both CD and T1D displayed a pronounced IL-8 and SOCS3 response compared to references (unpublished results)(Figure 23). This in contrast to another study where no differences in IL-8 expression were found in children with T1D and CD compared with children with untreated CD, T1D and references [181]. However, others have shown that stimulation of an intestinal epithelial cell line with IL-17 and IFN- $\gamma$ induced high levels of IL-8 [391]. This is in line with our results where children with CD and T1D had elevated IFN- $\gamma$ and IL-17 levels. Furthermore, elevated serum levels of IL- 8 have been reported in patients with active CD compared to GFD-treated CD [392]. SOCS3 has previously been reported to be elevated upon in vitro stimulation of pancreatic islets with proinflammatory cytokines ( $\operatorname{such}$ as IFN- $\gamma$, IL-1 $\beta$ and TNF- $\alpha$ ) and also in the inflamed pancreas of T1D patients [393]. Thus, SOCS3 seem to be elevated both in the intestine and pancreas of T1D-patients. Furthermore has SOCS3 deficient mice been shown to be resistant 
to $\beta$-cell destruction and T1D development induced by streptozotocin [394], indicating that SOCS3 may play a role in pancreatic $\beta$-cell autoimmunity.
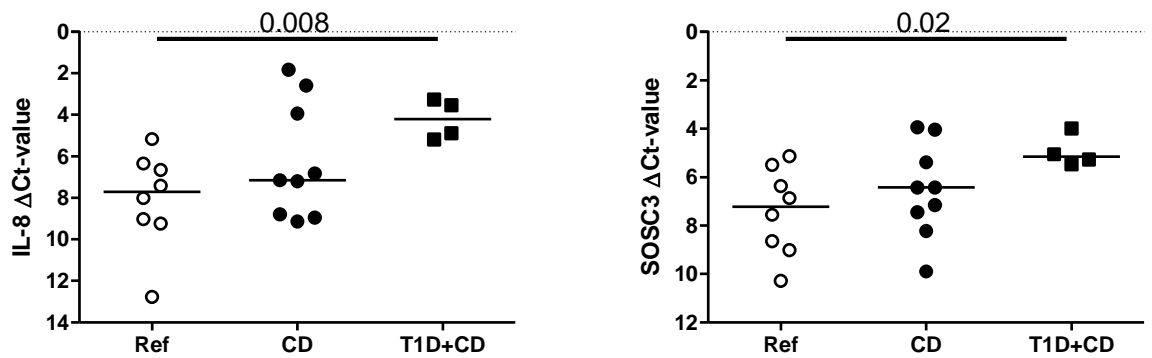

Figure 23. The expression of IL-8 and SOCS3 in biopsies from children with and without CD and T1D. Ref $=$ reference children, $C D=$ children with untreated $C D, T 1 D+C D=$ children with $C D$ and type 1 diabetes.

In Paper II we studied the spontaneous production of IL-1 $\beta$, IL-6 and IL-17A from intestinal biopsies from children with concomitant T1D and CD (Figure 15 and Figure 24). The spontaneous secretion of the aforementioned genes seemed to be elevated in children with T1D and CD compared to reference children. The Swedish children with concomitant T1D and CD seemed to have elevated IL-17A and IL-6 expression as compared to references and for IL-17 also compared to children with untreated CD (unpublished results)(Figure 24). Thus, the cytokine environment supports the IL-17 differentiation in children with both T1D and CD. CD patients with concomitant T1D seemed to spontaneously release more IL-17 than patients with CD alone, whereas patients with T1D alone did not express IL-17. This indicates that T1D might induce IL-17 production under certain conditions, such as at high-grade mucosal inflammation associated with villous atrophy. Interestingly, IL-17 transcripts were elevated in the Langerhans islets from a newly diagnosed patient with T1D when compared to non-diabetic individuals [395]. It is thus possible that IL-17 positive cells infiltrate the Langerhans islets and therefore are absent in the intestine. 

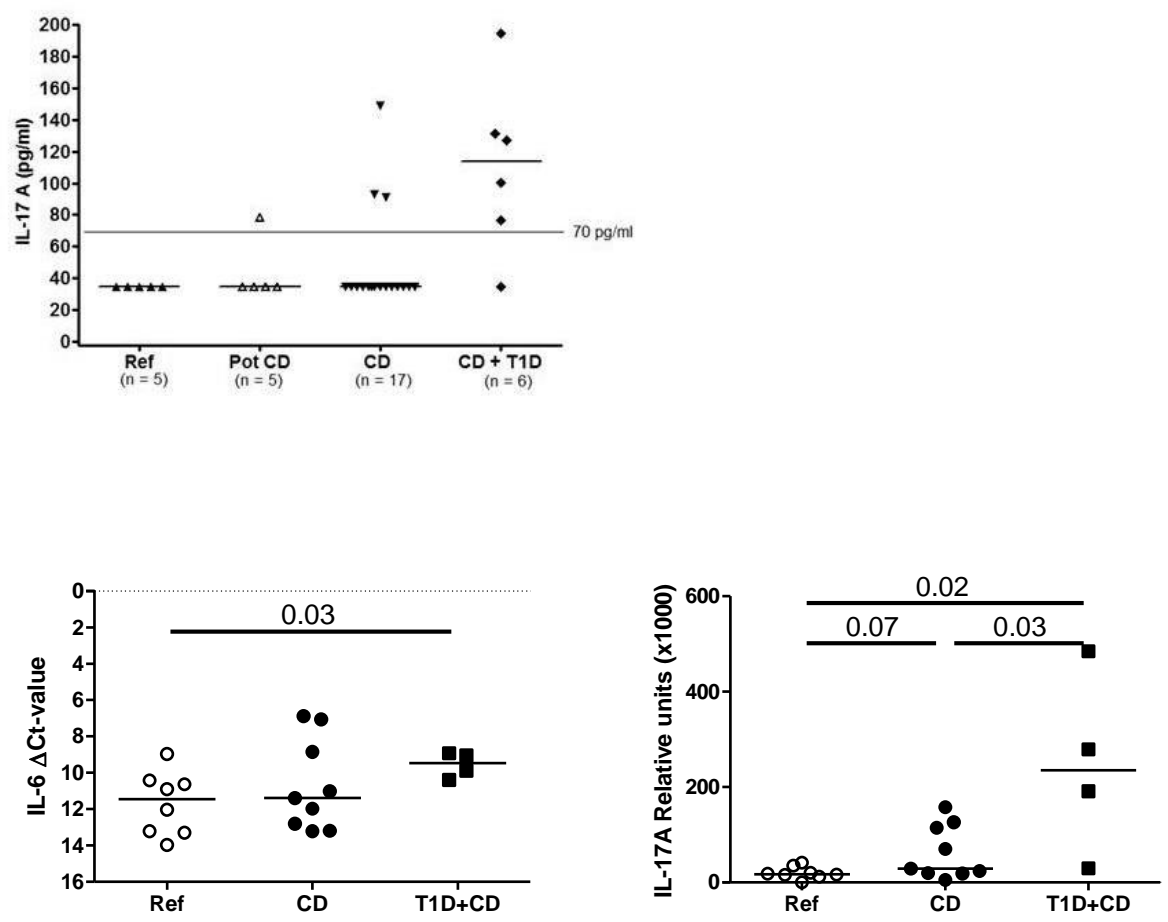

Figure 24. The protein expression of IL-17 in in vitro cultured whole biopsies. The expression of IL-6 and IL-17 in biopsies from children with and without $\mathrm{CD}$ and T1D. Ref $=$ reference children, pot $\mathrm{CD}=$ children with potential $\mathrm{CD}, \mathrm{CD}=$ children with untreated $\mathrm{CD}, \mathrm{T} 1 \mathrm{D}+\mathrm{CD}=$ children with $\mathrm{CD}$ and type 1 diabetes.

\section{Peripheral immune responses in $C D$}

We have studied both intestinal and peripheral immune responses, to investigate if the intestinal responses were reflected in peripheral blood. Our results showed that in CD the peripheral immune responses generally differed from the intestinal immune responses. In contrast to the Th1, Th2 and Th3 genes being dysregulated in the intestine of CD-patients, other genes were differentially expressed in the peripheral blood of children with CD. Children with CD expressed elevated levels of the Th1 associated markers: TBX21 (also known as T-bet) (Figure 25) and STAT4 peripherally. This is in agreement with a previous study reporting elevated T-bet levels in patients with active CD [396]. Here, the peripherally elevated T-bet expression was not concomitant with elevated IFN- $\gamma$ levels in the blood. Thus, the peripheral Th1 response was different from the intestinal Th1 response. 
Furthermore, children with untreated and GFD-treated CD expressed elevated levels of (the innate immunity related markers) IL-15, IL-18 and IL-18R1 peripherally compared to reference children (Figure 25). The elevated IL-18 response seen in this study is in agreement with a previous study reporting elevated serum levels of IL-18 in children with active CD, which in contrast to this study normalized after GFD [397]. Here the peripheral and intestinal IL-18 responses were inversed, since the intestinal IL-18 expression was diminished in untreated CD. It has been suggested that IL-15 contributes to the inflammatory response in CD by inhibition of TGF- $\beta$ signaling in mucosal T-cells [398]. Thus, it is not excluded that the mucosal inflammation is potentiated by systemic factors.
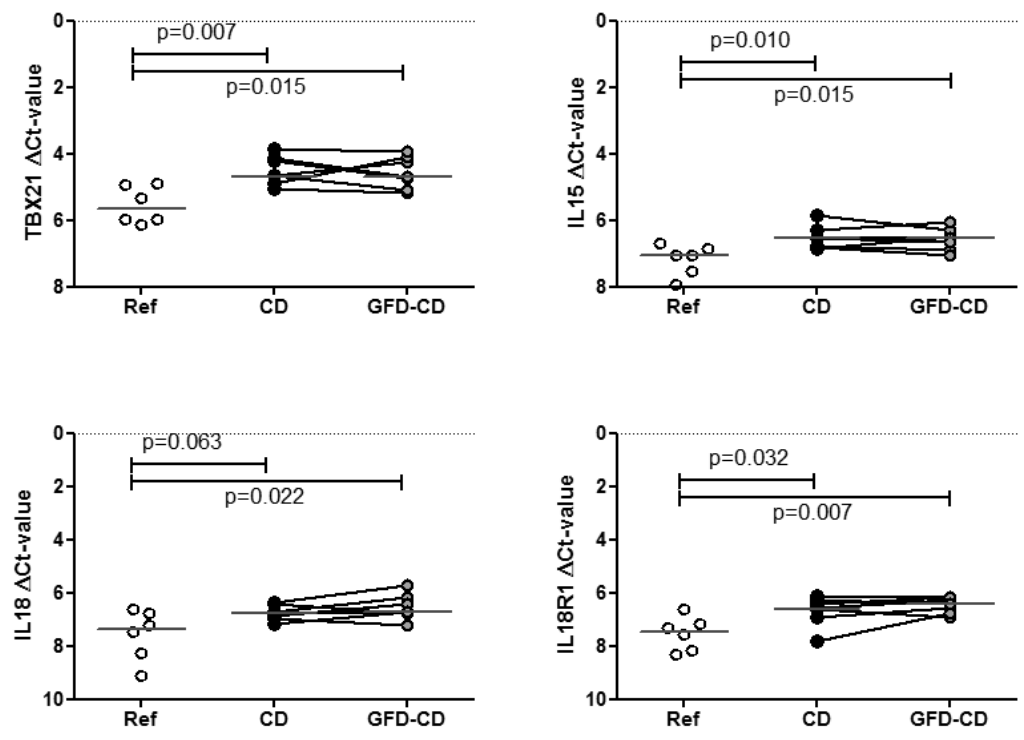

Figure 25. The expression profile of the T-cell associated markers in PBMCs from children with and without $\mathrm{CD}$. Ref $=$ reference children, $\mathrm{CD}=$ children with untreated $\mathrm{CD}, \mathrm{GFD}-\mathrm{CD}=$ children with $\mathrm{CD}$ after 1 year of gluten free-diet treatment. 
Children with untreated and GFD-treated CD expressed diminished peripheral levels of ICOS compared to the reference children (Figure 26). The intestinal ICOS response also seemed down-regulated in CD, significantly so between GFD-treated CD and references (data not shown). The dysregulated expression of the aforementioned genes in this study was not normalized by GFD-treatment, indicating that they might be disease related rather than related to the gliadin exposure.

Children with untreated CD expressed elevated levels of FASLG peripherally compared to GFD-treated children and references (Figure 26). This is in agreement with a previous study showing elevated FAS-FASLG expression in untreated CD [399]. Here, the FASLG levels in GFD-treated children resembled those in the reference group, thus the FASLG expression was normalized after GFD-treatment. The increased FASLG expression in active CD might indicate an increased susceptibility of PBMCs to undergo Fas-mediated apoptosis.
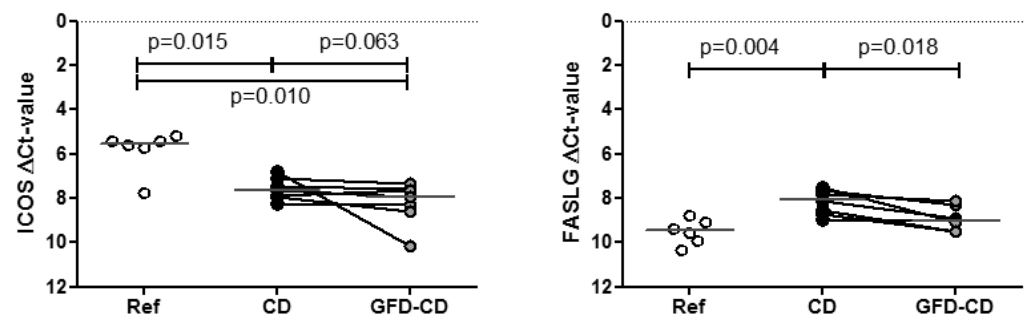

Figure 26. The expression of T-cell associated markers in PBMCs from children with and without CD. Ref $=$ reference children, $C D=$ children with untreated $C D, G F D-C D=$ children with $C D$ after 1 year of gluten free-diet treatment.

An interesting finding was the up-regulated expression of GLMN seen both in the intestine and in the peripheral blood samples of children with untreated and GFD-treated CD (Figure 27). The simultaneous up-regulation of GLMN suggests that GLMN is related to the disease itself and not only triggered by dietary gliadin. Little is known about the role of GLMN in humans. The GLMN expression was studied with conventional Real-time PCR in a larger study cohort, in order to repeat and confirm the results from Paper I. The results from the confirmatory study did however not display a significantly elevated GLMN expression in the 
intestine or in the blood of children with untreated or GFD-treated CD (unpublished results)(Figure 27).

Biopsies

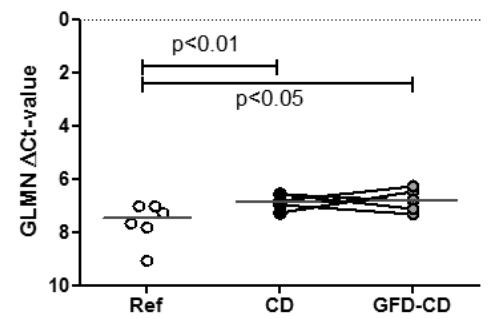

Biopsies

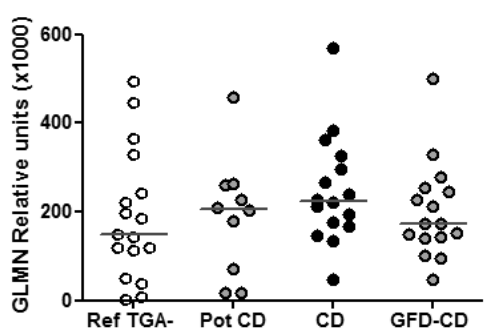

PBMC

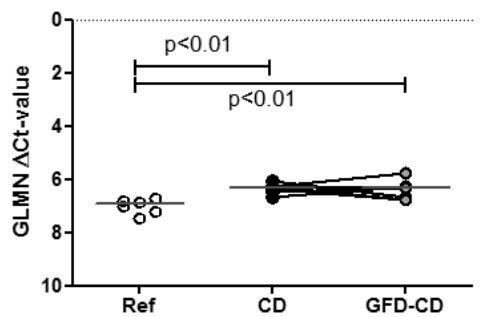

PBMC

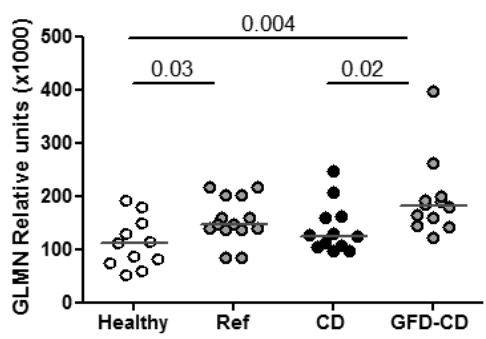

Figure 27. The expression of GLMN in biopsies and PBMCs from children with and without CD. Ref $=$ reference children, Ref TGA- $=$ TGA negative reference children, pot $\mathrm{CD}=$ children with potential $\mathrm{CD}, \mathrm{CD}=$ children with untreated $\mathrm{CD}, \mathrm{GFD}-\mathrm{CD}=$ children with $\mathrm{CD}$ after 1 year of gluten free-diet treatment.

\section{Multivariate data analysis of the gene expression}

PCA was used to visualize the differently expressed genes (Paper I) in intestinal samples from children with untreated CD (black squares), GFD-treated CD (red circles) and references (green squares) (Figure 28, left). The 20 genes being significant with univariate statistics separated the 3 study groups in the PCA. The genes included in the "peripheral" PCA plot, were not the same as in the "intestinal" PCA plot. PCA was used to visualize the differently expressed genes in peripheral blood from children with untreated CD (blue squares), GFDtreated CD (purple circles) and references (yellow squares) (Figure 28, right). The 17 genes 
being significant with univariate statistics separated the 3 study groups in the PCA, but in a different way than in the "intestinal" PCA.
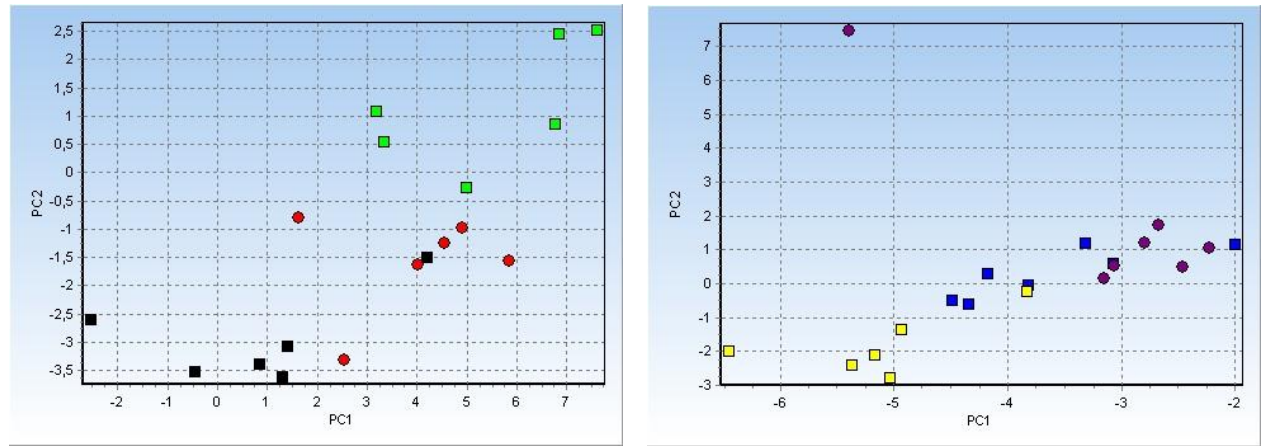

Figure 28. PCA visualization of the differentially expressed genes in biopsies (left) and PBMC (right) from children with and without $\mathrm{CD}$. Black squares: biopsies from untreated $\mathrm{CD}$, red circles: biopsies from GFD-treated CD, green squares: biopsies from references, blue squares: PBMCs from untreated $\mathrm{CD}$, purple circles: PBMCs from GFD-treated CD and yellow squares: PBMCs from references.

In Paper III PCA was used to visualize differently expressed genes in intestinal samples from children with potential CD (red circles), untreated CD (black squares), GFD-treated CD (light blue circles) and references (green squares) (Figure 29, left). The 23 genes being differently expressed with univariate statistics partially separated the 4 study groups in the PCA. The children with untreated $C D$ were separated from the references, whereas the children with potential CD and GFD-treated CD were found in between the untreated CD and references. When the samples from children with potential CD and GFD-treated CD were excluded from the PCA plot of the 23 differently expressed genes, the group of children with untreated CD was clearly separated from the references (Figure 29, right). 

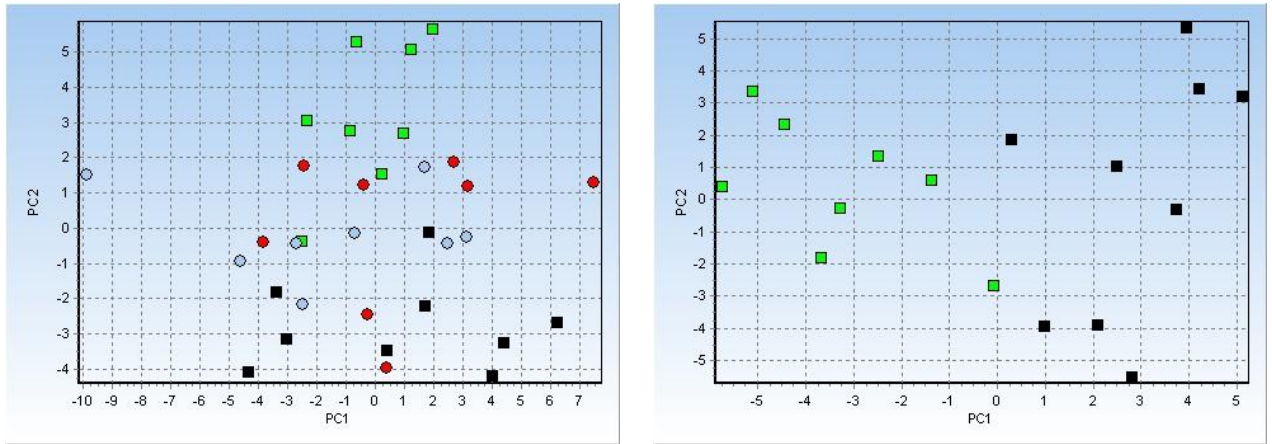

Figure 29. PCA visualization of the differentially expressed genes in biopsies from children with or without $\mathrm{CD}$. Red circles: potential CD, black squares: untreated CD, light blue circles: GFD-treated $\mathrm{CD}$, green squares: references.

In Paper III SOM-clustering formed four distinct clusters with differentially expressed genes in children at different stages of CD (Figure 30). The $1^{\text {st }}$ cluster contained genes being upregulated in untreated and GFD-treated $\mathrm{CD}$, the $2^{\text {nd }}$ cluster contained genes being downregulated in potential $\mathrm{CD}$, the $3^{\text {rd }}$ cluster contained genes being down-regulated in potential $\mathrm{CD}$ and untreated $\mathrm{CD}$ and the $4^{\text {th }}$ cluster contained genes being down-regulated in untreated CD. 


\begin{tabular}{|l|l|l|l|l|l|l|l|l|l|l|l|l|l|l|}
\hline $\begin{array}{l}\text { TGA- } \\
\text { neg } \\
\text { Ref }\end{array}$ & $\begin{array}{l}\text { Pot } \\
\text { CD }\end{array}$ & CD & $\begin{array}{l}\text { GFD- } \\
\text { CD }\end{array}$ & $\begin{array}{l}\text { TGA- } \\
\text { neg } \\
\text { Ref }\end{array}$ & $\begin{array}{l}\text { Pot } \\
\text { CD }\end{array}$ & CD & $\begin{array}{l}\text { GFD- } \\
\text { CD }\end{array}$ & $\begin{array}{l}\text { TGA- } \\
\text { neg } \\
\text { Ref }\end{array}$ & $\begin{array}{l}\text { Pot } \\
\text { CD }\end{array}$ & $\begin{array}{l}\text { CD } \\
\text { C0: }\end{array}$ \\
\hline
\end{tabular}

Figure 30. SOM-clustering of the differentially expressed genes in biopsies from children with and without CD. TGA-neg Ref = TGA negative reference children, pot $\mathrm{CD}=$ children with potential $\mathrm{CD}$, $\mathrm{CD}=$ children with untreated $\mathrm{CD}, \mathrm{GFD}-\mathrm{CD}=$ children with $\mathrm{CD}$ after 1 year of gluten free-diet treatment.

\section{Immune responses in the PRODIA children}

The clinical outcome of the PRODIA study was development of $\beta$-cell autoantibodies or development of T1D during the follow-up in the probiotic and placebo group. Most of the children were as expected, autoantibody negative during their first 2 years of life, whereas a few children displayed transient autoantibody positivity (Table 6). No differences in the emergence of $\beta$-cell autoantibodies were seen between the treatment groups. However, one child in the placebo group and one child in probiotic group displayed multiple autoantibody positivity. These children have been followed yearly after the intervention study, since positivity for multiple autoantibodies at the age of 2 years together with HLA related genetic risk of T1D is considered as a significant risk of T1D [285, 400]. The boy who received placebo during the intervention was positive for GADA and IAA at 24 months of age and has been continuously seropositive for both autoantibodies, but he has so far not developed T1D. Another boy who received probiotics was positive for IAA already at 6 months and also at 12 months, and multiple positive for IAA, GAD and IA-2A at 24 months of age and was 
continuously seropositive for all three autoantibodies at the yearly follow-up until he was diagnosed with T1D at the age of 6.5.

Table 6. Autoantibody positivity in plasma samples from 6,12 and 24 months old children who received probiotics (Pro) or placebo (C) during the first six months of life.

\begin{tabular}{|c|c|c|c|c|c|c|c|c|c|c|}
\hline & \multicolumn{2}{|c|}{ GADA } & \multicolumn{2}{|c|}{ IA-2A } & \multicolumn{2}{|l|}{ IAA } & \multicolumn{2}{|c|}{$\begin{array}{l}\text { Positive for at } \\
\text { least one } \\
\text { A.a.b. }\end{array}$} & \multicolumn{2}{|c|}{$\begin{array}{l}\text { Pos for at least } \\
\text { two A.a.b. }\end{array}$} \\
\hline Age & pos/tot & & pos/to & & pos/to & & pos/tot & & pos/to & \\
\hline & Pro & $\mathrm{C}$ & Pro & $\mathrm{C}$ & Pro & $\mathrm{C}$ & Pro & $\mathrm{C}$ & Pro & $\mathrm{C}$ \\
\hline $\begin{array}{l}6 \\
\text { months }\end{array}$ & $0 / 101$ & $1 / 92$ & $0 / 101$ & $0 / 92$ & $1 / 101$ & $1 / 92$ & $1 / 101$ & $2 / 92$ & $0 / 101$ & $0 / 92$ \\
\hline $\begin{array}{l}12 \\
\text { months }\end{array}$ & $0 / 101$ & $0 / 96$ & $1 / 101$ & $0 / 96$ & $2 / 101$ & $0 / 96$ & $3 / 101$ & $0 / 96$ & $0 / 101$ & $0 / 96$ \\
\hline $\begin{array}{l}24 \\
\text { months }\end{array}$ & $2 / 91$ & $1 / 86$ & $2 / 91$ & $0 / 86$ & $1 / 91$ & $1 / 86$ & $2 / 91$ & $2 / 86$ & $1 / 91$ & $1 / 86$ \\
\hline
\end{tabular}

pos=positive samples, above the cut-off limit, tot=total number of samples, A.a.b.=autoantibody

Flow cytometric analyses showed that the percentage of CD58+ CD14 cells in the peripheral circulation were lower in the probiotic group compared to the placebo group at 6 months of age (Figure 31). Thus, continuous TLR stimulation by probiotics seems to induce endotoxin tolerance and down-regulation of the monocyte activation marker CD58, as reported by others [401]. At 12 months of age, 6 months after the probiotic treatment had ended, the CD58 levels had increased in the probiotic group to levels similar to the placebo group. The monocyte activation stage was not limited to the intervention period, the first 6 months of life. Hence, 6 months after the intervention had ended, at 12 months of age, the percentage of CCR5+ CD14 cells was lower in the probiotic group compared to the placebo group (Figure 31). In the probiotic group, TLR stimulation tended to induce lower percentage of CCR5, CD80 and CD58+ monocytes at 6 months compared to at 12 months of age. This indicates that the probiotic treatment during infancy might induce hyporesponsive/deactivated monocytes. 

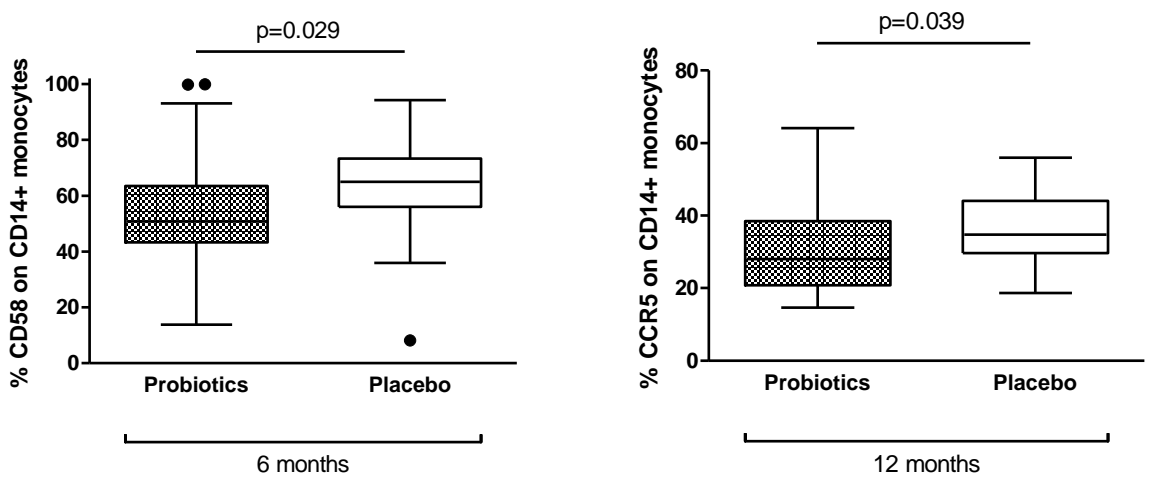

Figure 31. The expression of CD58 at 6 months and CCR5 at 12 months on circulating monocytes in infants given probiotics or placebo during their first 6 months of life.

The PCR-array analyses displayed that there were small differences in gene expression levels between the study groups at 6 and 12 months of age. There were no differences in the expression levels of TLRs signalling related genes in the PBMC population between the probiotic and placebo group at 6 months of age. At 12 months of age the expression of TLR9 was elevated in the probiotic children compared to in the placebo group (Figure 32). Thus, early exposure to probiotics might induce prolonged effects on TLR signalling. Probiotic bacteria may use other signalling pathways than LTA-TLR2 to induce its immunomodulatory effects [402]. TLR9 is known to be involved in recognition of bacterial DNA. Recently it was shown that the probiotic strains Bifodobacterium breve and Lactobacillus rhamnosus and L.casei seem to induce different cytokine responses (in in vitro stimulated PBMCs), which seem to be dependent on TLR9 [30]. 


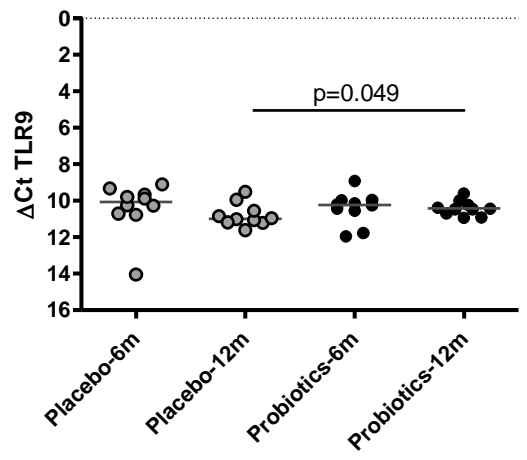

Figure 32. Gene expression of TLR9 in probiotic and placebo treated infants at 6 and 12 months of age.

When the samples from infants who received probiotics and placebo were grouped together, we found increased number of CD80+ monocytes from 6 to 12 months of age in nonstimulated samples, and also significant increase in the number of CCR5, CD80 and CD58 expressing monocytes in response to stimulation (Figure 33). These age related changes indicate maturation of circulating monocytes and their stimulation response. The enhanced expression of the activation marker/co-stimulatory molecule CD86 detected by PCR arrays in PBMC samples from 6 to 12 months of age also supports the idea of maturation of the infants' innate immune system during the first year of life. 

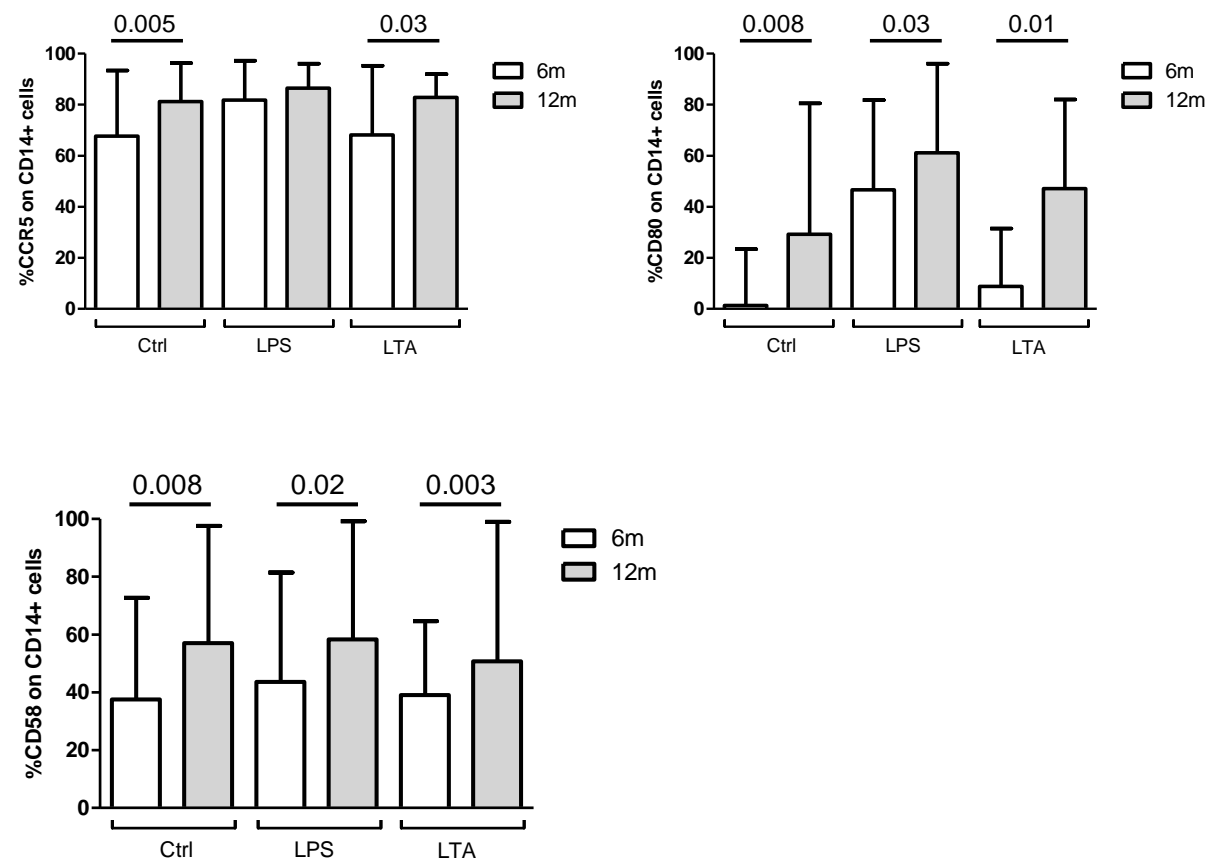

Figure 33. Expression of CCR5, CD80 and CD58 on monocytes from LPS and LTA stimulated whole blood at 6 to 12 months of age in the whole study group.

In the PRODIA study CRP was included as a marker of an ongoing inflammation. There was no difference in CRP levels between the probiotic and the placebo groups at 6 months of age (data not shown). The same mixture of probiotic bacteria given to infants with an allergic predisposition have previously been reported to induce elevated plasma levels of CRP at 6 months of age [403], suggesting the induction of a low-grade inflammation in infants with an allergic predisposition. This effect was not seen in this study of infants with a genetic predisposition for T1D. The low grade inflammation was speculated to be the link between probiotics and prevention of allergy, which has been related with the impaired function of the innate immunity [403]. It is possible that children with a different genetic background, with risk for T1D instead of allergy, might not have an aberrant innate immunity and may therefore not display differences in the CRP response.

Collectively, probiotic supplementation for the first 6 months of life in children with genetic risk for T1D did not seem to affect the risk for T1D autoimmunity. Instead, stimulation of the 
gut immune system by probiotics induced moderate changes in the children's innate immune responses studied peripherally. Due to ethical reasons it is not possible to study the intestinal responses of the probiotic supplementation. 


\section{SUMMARY \& CONCLUDING REMARKS}

Extensive research has been performed in order to elucidate the triggering factors resulting in development of CD and T1D. So far the exact disease mechanisms are unknown and there is still no cure for the diseases. However, both CD and T1D are known to be associated with aberrant intestinal immune responses.

Previous studies have generally been analyzing few markers at a time, thus little is known about the complex network of immunological responses taking place in individuals with and without CD and T1D, or at risk for the diseases. In this thesis we analyzed a broad range of immunological markers in peripheral and intestinal samples from children with and without CD and/or T1D.

As seen in previous studies and also in this thesis, the immune alterations in the periphery and in the target tissue do not seem to correlate. This urges sample collection from the target tissue rather than from the peripheral blood. Samples from the target tissue are however more difficult to obtain especially in T1D. In our studies, the peripheral immune responses in CD were generally not reflecting the intestinal immune responses, since different immune markers were elevated in the blood compared to the intestine.

Our results suggest that an aberrant expression of Th1 (Tc1), Th2, Th3, Th17 and Treg associated markers is an important feature of active CD. Our results support the idea that the intestinal Th1 response is a dominant and fundamental feature in CD. This might lead to enhanced epithelial leakiness and permit more gliadin to enter the mucosa, which subsequently leads to further immune activation and tissue damage. The peripheral immune responses were generally not reflecting the intestinal immune responses, although a Th1 deviated immune response was also present in peripheral blood.

Our findings show that GFD treatment for 1 year restored balance/homeostasis to a large extent, and the expression of Th2, Th3, Th17 and Treg associated markers are normalized. Interestingly, the Type 1 response (Th1, Tc1) remained elevated after GFD treatment, suggesting that while the imbalanced Th2, Th3, Th17 and Treg immune responses seemed to be dependent on the gliadin exposure, the Type 1 response seemed to be fundamentally associated with the disease itself. 
Intestinal immune responses in children with concomitant CD and T1D were characterized by increased expression of inflammatory markers and resembled the ones observed in children with untreated CD. Interestingly, children with T1D alone had similar intestinal Th1, Th17 and Treg responses as the reference children, It is worth noticing that most children with concomitant CD and T1D in our study were not newly diagnosed T1D patients, and it can not be excluded that newly diagnosed T1D might display a different expression pattern of the Tcell associated markers.

Since IL-17 was reported in inflammatory conditions, we focused our studies on IL-17 and Th17 associated markers in individuals with and without CD and/or T1D. We studied the expression of IL-17 associated markers in biopsies, but also the production of IL-17 from in vitro biopsy cultures. Both the expression and spontaneous release of IL-17 was higher in the children with concomitant CD and T1D than in the patients with CD alone, whereas patients with T1D alone did not show enhanced IL-17 activation. Interestingly, children with potential CD had diminished levels of IL-17, whereas children with untreated CD had elevated levels of IL-17, indicating that the IL-17 immunity developed in the late phase of CD when villous atrophy had developed.

We also proceeded to perform functional experiments to clarify the role of IL-17 in apoptosis, as it has been suggested that this cytokine might be involved in intestinal apoptosis. In active $\mathrm{CD}$ damage of the intestinal epithelial layer is characteristic for the disease and apoptosis is one of the mechanisms behind the gluten triggered villous atrophy. Although it has been suggested that IL-17 might be involved in intestinal apoptosis, our results suggests that IL-17 did not contribute to apoptosis of epithelial cells, but instead it seemed to induce antiapoptotic mechanisms in our experiments with an epithelial cell line. Thus, activation of IL17 immunity at the late stage of CD may be a protective response to tissue damage.

MMPs play a key role in ECM turnover and are also believed to be involved in the pathophysiology of $\mathrm{CD}$. Whether they have a causative role in the development of the villous atrophy or are a consequence of the disease process is unknown. Our study showed that active CD was associated with elevated MMP3 levels, which normalized after GFD treatment, thus concurrently with the intestinal mucosa. This indicates that the MMP elevation is related to the gliadin induced tissue damage. 
In the PRODIA study, the number of children with genetic risk for T1D developing T1D related autoantibodies during their first 2 years of life was low as expected and no difference in the autoantibody emergence was seen between infants supplemented with probiotics compared to placebo. Immunological studies support the notion that probiotic supplementation modulated the activation stage and stimulation response of monocytes. 


\section{ACKNOWLEDGEMENTS}

I would like to express my sincere gratitude to all of you who in one way or another has contributed to or supported me during the work with this thesis.

First of all I would like to thank all participants in the studies. This thesis would not have been possible without you.

My former main supervisor Outi Vaarala, thank you for believing in me and giving me the opportunity to do a $\mathrm{PhD}$. Thanks for your encouragement and support during these years and for sharing your great knowledge and enthusiasm for research.

My present main supervisor Johnny Ludvigsson and co-supervisor Rosaura Casas, thank you for your support and sharing of your great knowledge and enthusiasm for research especially during the last years.

My co-author Karin Fälth-Magnusson, thank you for your encouragement and support during these years and for sharing your great knowledge and enthusiasm for research. Thanks for the clinical support and for always being there for me.

Peter Bang is acknowledged as the representative of the Division of Paediatrics.

Maria Jenmalm, Lennart Nilsson and Malin Fagerås-Böttcher, thank you for introducing me into the research world and for sharing your great knowledge and enthusiasm for research. Karin Regnström, Eva Ragnarsson and Lucia Lazorova, thank you for sharing your expertise and teaching me the microarray technology. Maria Faresjö, thanks for our collaboration in the ENDIT-project and for sharing your knowledge and your enthusiasm for research.

All co-authors in the different projects are acknowledged for sharing their expertise with me: Lotta Högberg, Veera Hölttä, Terhi Ruohtula, Harri Salo, Laura Orivuori, Mia WesterholmOrmio, Erkki Savilahti, Martin Ljungberg, Anna Lundberg and Riitta Korpela. 
My collaborators in the projects: Lars Stenhammar, Louise Forslund, Pia Laurin, Maria Nordwall and the research nurses at the Division of Paediatrics in Linköping, Motala and Norrköping are gratefully acknowledged for the clinical support and help with the sample collection. Elisabeth Hollen is also thanked for providing me with some clinical data.

The laboratory technicians Malgorzata Smolinska Konefal and Ingela Johansson are thanked for their help with the sample collection during my parental leaves and for help with the autoantibody analyses. Åsa Shippert and Annette Molbaeck are thanked for being helpful during my PCR array experiments.

Anneli Jonsson is acknowledged as the study coordinator of PRODIA and for providing me with clinical data. Thomas Abrahamsson is acknowledged for providing me with the "PRODIA-code".

Ann-Christine Gilmore Ellis, Madeleine Örlin and Humlan Svensson are thanked for always being helpful and supportive with administrative issues.

Thanks to all present and former colleagues at the Division of Paediatrics and KEF, especially Anna L, Martina, Anna R, Kristina W, Ammi, Anna K, Malgorzata, Ingela, Maria H, Camilla S, Camilla J, Jenny, Hanna, Sara, Thomas, Felix, Carl-Oscar, Martin, Susanne, Linda, Stina, Mikael C and Mikael P. Thanks also to my present room-mates Karolina B and Naomi.

Mina vänner Anna L, Mikael, Petra, Daniel, Karin T, Roger, Karolina, Jonas, Anneli och Rikard tack för alla roliga stunder tillsammans med era familjer som har fått mig att tänka på annat än forskning.

Anita, Jouko och Arja tack för allt stöd och uppmuntran genom åren. Stefan och Tina med familj, tack för allt stöd, för alla roliga stunder tillsammans och för alla samtal om hur livet $\mathrm{i}$ forskarvärlden kan se ut. Sofia och Tobias med familj, tack för alla trevliga stunder tillsammans.

Familjen Petersson, Ax, Johansson, Berg och Mörtzell, tack för att jag alltid känner mig välkommen hos er. Tack för alla trevliga stunder tillsammans i Uvanäs. 
Henrik, tack för allt stöd och all uppmuntran under de här åren!

Erik och Emmi, tack för att ni får mig att tänka på annat än jobbet på fritiden.

The Biomedical Research School and the multidisciplinary graduate school Forum Scientium at Linköpings Universitet are acknowledged for providing a rewarding research environment.

This work was generously supported by the Swedish Research Council, the Sigrid Juselius Foundation, the Academy of Finland, the Diabetes Research foundation, Valio Ldt, the Foundation for Strategic Research, the Swedish Child Diabetes Foundation (Barndiabetesfonden), the Medical Research Found of the County of Östergötland, Anna Cederbergs Foundation, Lions Foundation. 


\section{REFERENCES}

1. Murphy K. Janeway's Immunobiology. 8th Edn. New York: Garland Science, Taylor \& Francis Group, 2012.

2. Medzhitov R, Janeway C, Jr. Innate immunity. N Engl J Med 2000; 343:338-44.

3. Kamdar K, Nguyen V, DePaolo RW. Toll-like receptor signaling and regulation of intestinal immunity. Virulence 2013; 4:207-12.

4. Takeishi Y, Kubota I. Role of Toll-like receptor mediated signaling pathway in ischemic heart. Front Biosci (Landmark Ed) 2009; 14:2553-8.

5. Hogquist KA, Baldwin TA, Jameson SC. Central tolerance: learning self-control in the thymus. Nature reviews Immunology 2005; 5:772-82.

6. Mosmann TR, Kobie JJ, Lee FE, Quataert SA. T helper cytokine patterns: defined subsets, random expression, and external modulation. Immunol Res 2009; 45:173-84.

7. Mosmann TR, Sad S. The expanding universe of T-cell subsets: Th1, Th2 and more. Immunol Today 1996; 17:138-46.

8. O'Shea JJ, Paul WE. Mechanisms underlying lineage commitment and plasticity of helper CD4+ T cells. Science 2010; 327:1098-102.

9. Peterson RA. Regulatory T-cells: diverse phenotypes integral to immune homeostasis and suppression. Toxicol Pathol 2012; 40:186-204.

10. Cosmi L, Maggi L, Santarlasci V, Liotta F, Annunziato F. T helper cells plasticity in inflammation. Cytometry A 2014; 85:36-42.

11. Tuomela S, Lahesmaa R. Early T helper cell programming of gene expression in human. Seminars in immunology 2013; 25:282-90.

12. Spencer J, Isaacson PG, Diss TC, MacDonald TT. Expression of disulfide-linked and non-disulfide-linked forms of the T cell receptor gamma/delta heterodimer in human intestinal intraepithelial lymphocytes. Eur J Immunol 1989; 19:1335-8.

13. Abbas AK, Lichtman AH, S. P. Cellular and molecular immunology. Philadelphia: Elsevier Saunders, 2012.

14. Brandtzaeg P. Secretory IgA: Designed for Anti-Microbial Defense. Frontiers in immunology 2013; 4:222.

15. Mowat AM. Anatomical basis of tolerance and immunity to intestinal antigens. Nat Rev Immunol 2003; 3:331-41.

16. Belkaid Y, Hand TW. Role of the microbiota in immunity and inflammation. Cell 2014; 157:121-41.

17. Mesin L, Sollid LM, Di Niro R. The intestinal B-cell response in celiac disease. Front Immunol 2012; 3:313.

18. Castro-Sanchez P, Martin-Villa JM. Gut immune system and oral tolerance. Br J Nutr 2013; 109 Suppl 2:S3-11.

19. Gutzeit C, Magri G, Cerutti A. Intestinal IgA production and its role in host-microbe interaction. Immunological reviews 2014; 260:76-85.

20. Rescigno M. Dendritic cell-epithelial cell crosstalk in the gut. Immunological reviews 2014; 260:118-28.

21. Koboziev I, Karlsson F, Grisham MB. Gut-associated lymphoid tissue, T cell trafficking, and chronic intestinal inflammation. Ann N Y Acad Sci 2010; 1207 Suppl 1:E86-93.

22. Pabst O, Mowat AM. Oral tolerance to food protein. Mucosal Immunol 2012; 5:232-9.

23. Vaarala O. Immunological effects of probiotics with special reference to lactobacilli. Clin Exp Allergy 2003; 33:1634-40. 
24. Strobel S. Oral tolerance, systemic immunoregulation, and autoimmunity. Ann N Y Acad Sci 2002; 958:47-58.

25. West CE, Jenmalm MC, Prescott SL. The gut microbiota and its role in the development of allergic disease: a wider perspective. Clinical and experimental allergy : journal of the British Society for Allergy and Clinical Immunology 2014.

26. van Baarlen P, Wells JM, Kleerebezem M. Regulation of intestinal homeostasis and immunity with probiotic lactobacilli. Trends in immunology 2013; 34:208-15.

27. Galdeano CM, de Moreno de LeBlanc A, Vinderola G, Bonet ME, Perdigon G. Proposed model: mechanisms of immunomodulation induced by probiotic bacteria. Clin Vaccine Immunol 2007; 14:485-92.

28. Dongarra ML, Rizzello V, Muccio L, Fries W, Cascio A, Bonaccorsi I, et al. Mucosal immunology and probiotics. Curr Allergy Asthma Rep 2013; 13:19-26.

29. Miettinen M, Matikainen S, Vuopio-Varkila J, Pirhonen J, Varkila K, Kurimoto M, et al. Lactobacilli and streptococci induce interleukin-12 (IL-12), IL-18, and gamma interferon production in human peripheral blood mononuclear cells. Infect Immun 1998; 66:6058-62.

30. Plantinga TS, van Maren WW, van Bergenhenegouwen J, Hameetman M, Nierkens S, Jacobs C, et al. Differential Toll-like receptor recognition and induction of cytokine profile by Bifidobacterium breve and Lactobacillus strains of probiotics. Clin Vaccine Immunol 2011; 18:621-8.

31. Zeuthen LH, Christensen HR, Frokiaer H. Lactic acid bacteria inducing a weak interleukin-12 and tumor necrosis factor alpha response in human dendritic cells inhibit strongly stimulating lactic acid bacteria but act synergistically with gramnegative bacteria. Clinical and vaccine immunology : CVI 2006; 13:365-75.

32. Dowling DJ, Levy O. Ontogeny of early life immunity. Trends in immunology 2014.

33. Willems F, Vollstedt S, Suter M. Phenotype and function of neonatal DC. European journal of immunology 2009; 39:26-35.

34. Kollmann TR, Levy O, Montgomery RR, Goriely S. Innate immune function by Tolllike receptors: distinct responses in newborns and the elderly. Immunity 2012; 37:77183.

35. Holt PG, Jones CA. The development of the immune system during pregnancy and early life. Allergy 2000; 55:688-97.

36. Sjogren YM, Tomicic S, Lundberg A, Bottcher MF, Bjorksten B, SverremarkEkstrom E, et al. Influence of early gut microbiota on the maturation of childhood mucosal and systemic immune responses. Clinical and experimental allergy : journal of the British Society for Allergy and Clinical Immunology 2009; 39:1842-51.

37. Renz H, Brandtzaeg P, Hornef M. The impact of perinatal immune development on mucosal homeostasis and chronic inflammation. Nat Rev Immunol 2012; 12:9-23.

38. Jakobsson HE, Abrahamsson TR, Jenmalm MC, Harris K, Quince C, Jernberg C, et al. Decreased gut microbiota diversity, delayed Bacteroidetes colonisation and reduced Th1 responses in infants delivered by caesarean section. Gut 2014; 63:559-66.

39. Sjogren YM, Jenmalm MC, Bottcher MF, Bjorksten B, Sverremark-Ekstrom E. Altered early infant gut microbiota in children developing allergy up to 5 years of age. Clinical and experimental allergy : journal of the British Society for Allergy and Clinical Immunology 2009; 39:518-26.

40. Sollid LM, Jabri B. Triggers and drivers of autoimmunity: lessons from coeliac disease. Nat Rev Immunol 2013; 13:294-302.

41. Villanacci V, Ceppa P, Tavani E, Vindigni C, Volta U. Coeliac disease: the histology report. Dig Liver Dis 2011; 43 Suppl 4:S385-95. 
42. van Berge-Henegouwen GP, Mulder CJ. Pioneer in the gluten free diet: Willem-Karel Dicke 1905-1962, over 50 years of gluten free diet. Gut 1993; 34:1473-5.

43. Meresse B, Malamut G, Cerf-Bensussan N. Celiac disease: an immunological jigsaw. Immunity 2012; 36:907-19.

44. Ciclitira PJ, Johnson MW, Dewar DH, Ellis HJ. The pathogenesis of coeliac disease. Mol Aspects Med 2005; 26:421-58.

45. Anderson CM. Histological changes in the duodenal mucosa in coeliac disease. Reversibility during treatment with a wheat gluten free diet. Arch Dis Child 1960; 35:419-27.

46. Sollid LM, Markussen G, Ek J, Gjerde H, Vartdal F, Thorsby E. Evidence for a primary association of celiac disease to a particular HLA-DQ alpha/beta heterodimer. J Exp Med 1989; 169:345-50.

47. Trier JS. Celiac sprue. N Engl J Med 1991; 325:1709-19.

48. Fasano A, Catassi C. Clinical practice. Celiac disease. N Engl J Med 2012; 367:241926.

49. Sollid LM, Lie BA. Celiac disease genetics: current concepts and practical applications. Clin Gastroenterol Hepatol 2005; 3:843-51.

50. Karell K, Louka AS, Moodie SJ, Ascher H, Clot F, Greco L, et al. HLA types in celiac disease patients not carrying the DQA1*05-DQB1*02 (DQ2) heterodimer: results from the European Genetics Cluster on Celiac Disease. Hum Immunol 2003; 64:46977.

51. Abadie V, Sollid LM, Barreiro LB, Jabri B. Integration of genetic and immunological insights into a model of celiac disease pathogenesis. Annu Rev Immunol 2011; 29:493-525.

52. Mearin ML, Biemond I, Pena AS, Polanco I, Vazquez C, Schreuder GT, et al. HLADR phenotypes in Spanish coeliac children: their contribution to the understanding of the genetics of the disease. Gut 1983; 24:532-7.

53. Vader W, Stepniak D, Kooy Y, Mearin L, Thompson A, van Rood JJ, et al. The HLADQ2 gene dose effect in celiac disease is directly related to the magnitude and breadth of gluten-specific T cell responses. Proc Natl Acad Sci U S A 2003; 100:12390-5.

54. Bevan S, Popat S, Braegger CP, Busch A, O'Donoghue D, Falth-Magnusson K, et al. Contribution of the MHC region to the familial risk of coeliac disease. J Med Genet 1999; 36:687-90.

55. Gupta R, Reddy DN, Makharia GK, Sood A, Ramakrishna BS, Yachha SK, et al. Indian task force for celiac disease: current status. World J Gastroenterol 2009; 15:6028-33.

56. Trynka G, Hunt KA, Bockett NA, Romanos J, Mistry V, Szperl A, et al. Dense genotyping identifies and localizes multiple common and rare variant association signals in celiac disease. Nat Genet 2011; 43:1193-201.

57. Brophy K, Ryan AW, Turner G, Trimble V, Patel KD, O'Morain C, et al. Evaluation of 6 candidate genes on chromosome 11q23 for coeliac disease susceptibility: a case control study. BMC Med Genet 2010; 11:76.

58. Zhernakova A, Eerligh P, Barrera P, Wesoly JZ, Huizinga TW, Roep BO, et al. CTLA4 is differentially associated with autoimmune diseases in the Dutch population. Hum Genet 2005; 118:58-66.

59. Barker JM. Clinical review: Type 1 diabetes-associated autoimmunity: natural history, genetic associations, and screening. J Clin Endocrinol Metab 2006; 91:1210-7.

60. Brophy K, Ryan AW, Thornton JM, Abuzakouk M, Fitzgerald AP, McLoughlin RM, et al. Haplotypes in the CTLA4 region are associated with coeliac disease in the Irish population. Genes Immun 2006; 7:19-26. 
61. Bjornvold M, Undlien DE, Joner G, Dahl-Jorgensen K, Njolstad PR, Akselsen HE, et al. Joint effects of HLA, INS, PTPN22 and CTLA4 genes on the risk of type 1 diabetes. Diabetologia 2008; 51:589-96.

62. Smyth DJ, Cooper JD, Howson JM, Walker NM, Plagnol V, Stevens H, et al. PTPN22 Trp620 explains the association of chromosome 1p13 with type 1 diabetes and shows a statistical interaction with HLA class II genotypes. Diabetes 2008; 57:1730-7.

63. Santin I, Castellanos-Rubio A, Aransay AM, Castano L, Vitoria JC, Bilbao JR. The functional R620W variant of the PTPN22 gene is associated with celiac disease. Tissue Antigens 2008; 71:247-9.

64. Branski D, Fasano A, Troncone R. Latest developments in the pathogenesis and treatment of celiac disease. J Pediatr 2006; 149:295-300.

65. Hernell O, Forsberg G, Hammarstrom ML, Hammarstrom S, Ivarsson A. Celiac disease: effect of weaning on disease risk. Nestle Nutr Workshop Ser Pediatr Program 2005; 56:27-38; discussion -42 .

66. Falth-Magnusson K, Franzen L, Jansson G, Laurin P, Stenhammar L. Infant feeding history shows distinct differences between Swedish celiac and reference children. Pediatr Allergy Immunol 1996; 7:1-5.

67. Ivarsson A, Hernell O, Stenlund H, Persson LA. Breast-feeding protects against celiac disease. Am J Clin Nutr 2002; 75:914-21.

68. Norris JM, Barriga K, Hoffenberg EJ, Taki I, Miao D, Haas JE, et al. Risk of celiac disease autoimmunity and timing of gluten introduction in the diet of infants at increased risk of disease. JAMA 2005; 293:2343-51.

69. Stepniak D, Koning F. Celiac disease--sandwiched between innate and adaptive immunity. Hum Immunol 2006; 67:460-8.

70. Troncone R, Auricchio S. Rotavirus and celiac disease: clues to the pathogenesis and perspectives on prevention. J Pediatr Gastroenterol Nutr 2007; 44:527-8.

71. Stene LC, Honeyman MC, Hoffenberg EJ, Haas JE, Sokol RJ, Emery L, et al. Rotavirus infection frequency and risk of celiac disease autoimmunity in early childhood: a longitudinal study. Am J Gastroenterol 2006; 101:2333-40.

72. Zanoni G, Navone R, Lunardi C, Tridente G, Bason C, Sivori S, et al. In celiac disease, a subset of autoantibodies against transglutaminase binds toll-like receptor 4 and induces activation of monocytes. PLoS Med 2006; 3:e358.

73. Kagnoff MF. Overview and pathogenesis of celiac disease. Gastroenterology 2005; 128:S10-8.

74. Devendra D, Eisenbarth GS. Interferon alpha--a potential link in the pathogenesis of viral-induced type 1 diabetes and autoimmunity. Clin Immunol 2004; 111:225-33.

75. Forsberg G, Fahlgren A, Horstedt P, Hammarstrom S, Hernell O, Hammarstrom ML. Presence of bacteria and innate immunity of intestinal epithelium in childhood celiac disease. Am J Gastroenterol 2004; 99:894-904.

76. Tjellstrom B, Stenhammar L, Hogberg L, Falth-Magnusson K, Magnusson KE, Midtvedt T, et al. Gut microflora associated characteristics in children with celiac disease. Am J Gastroenterol 2005; 100:2784-8.

77. Sanz Y, Sanchez E, Marzotto M, Calabuig M, Torriani S, Dellaglio F. Differences in faecal bacterial communities in coeliac and healthy children as detected by PCR and denaturing gradient gel electrophoresis. FEMS Immunol Med Microbiol 2007; 51:562-8.

78. Di Cagno R, De Angelis M, De Pasquale I, Ndagijimana M, Vernocchi P, Ricciuti P, et al. Duodenal and faecal microbiota of celiac children: molecular, phenotype and metabolome characterization. BMC Microbiol 2011; 11:219. 
79. Green PH. The many faces of celiac disease: clinical presentation of celiac disease in the adult population. Gastroenterology 2005; 128:S74-8.

80. Fasano A. Clinical presentation of celiac disease in the pediatric population. Gastroenterology 2005; 128:S68-73.

81. Ravikumara M, Tuthill DP, Jenkins HR. The changing clinical presentation of coeliac disease. Arch Dis Child 2006; 91:969-71.

82. Ivarsson A, Persson LA, Juto P, Peltonen M, Suhr O, Hernell O. High prevalence of undiagnosed coeliac disease in adults: a Swedish population-based study. J Intern Med 1999; 245:63-8.

83. Fasano A, Catassi C. Current approaches to diagnosis and treatment of celiac disease: an evolving spectrum. Gastroenterology 2001; 120:636-51.

84. Catassi C, Fabiani E. The spectrum of coeliac disease in children. Baillieres Clin Gastroenterol 1997; 11:485-507.

85. Green PH, Cellier C. Celiac disease. N Engl J Med 2007; 357:1731-43.

86. Cellier C, Flobert C, Cormier C, Roux C, Schmitz J. Severe osteopenia in symptomfree adults with a childhood diagnosis of coeliac disease. Lancet 2000; 355:806.

87. Mustalahti K, Collin P, Sievanen H, Salmi J, Maki M. Osteopenia in patients with clinically silent coeliac disease warrants screening. Lancet 1999; 354:744-5.

88. Siniscalchi M, Iovino P, Tortora R, Forestiero S, Somma A, Capuano L, et al. Fatigue in adult coeliac disease. Aliment Pharmacol Ther 2005; 22:489-94.

89. Ciacci C, Iavarone A, Mazzacca G, De Rosa A. Depressive symptoms in adult coeliac disease. Scand J Gastroenterol 1998; 33:247-50.

90. Fasano A, Catassi C. Coeliac disease in children. Best Pract Res Clin Gastroenterol 2005; 19:467-78.

91. Goldstein NS. Proximal small-bowel mucosal villous intraepithelial lymphocytes. Histopathology 2004; 44:199-205.

92. Marsh MN, Crowe PT. Morphology of the mucosal lesion in gluten sensitivity. Baillieres Clin Gastroenterol 1995; 9:273-93.

93. Reunala T, Kosnai I, Karpati S, Kuitunen P, Torok E, Savilahti E. Dermatitis herpetiformis: jejunal findings and skin response to gluten free diet. Arch Dis Child 1984; 59:517-22.

94. Maki M, Collin P. Coeliac disease. Lancet 1997; 349:1755-9.

95. Lagerqvist C, Ivarsson A, Juto P, Persson LA, Hernell O. Screening for adult coeliac disease - which serological marker(s) to use? J Intern Med 2001; 250:241-8.

96. Catassi C, Ratsch IM, Fabiani E, Rossini M, Bordicchia F, Candela F, et al. Coeliac disease in the year 2000: exploring the iceberg. Lancet 1994; 343:200-3.

97. Mooney PD, Hadjivassiliou M, Sanders DS. Coeliac disease. Bmj 2014; 348:g1561.

98. Hopper AD, Hadjivassiliou M, Butt S, Sanders DS. Adult coeliac disease. BMJ 2007; 335:558-62.

99. Ludvigsson JF, Leffler DA, Bai JC, Biagi F, Fasano A, Green PH, et al. The Oslo definitions for coeliac disease and related terms. Gut 2013; 62:43-52.

100. Maki M, Holm K, Collin P, Savilahti E. Increase in gamma/delta T cell receptor bearing lymphocytes in normal small bowel mucosa in latent coeliac disease. Gut 1991; 32:1412-4.

101. Savilahti E, Arato A, Verkasalo M. Intestinal gamma/delta receptor-bearing T lymphocytes in celiac disease and inflammatory bowel diseases in children. Constant increase in celiac disease. Pediatr Res 1990; 28:579-81.

102. Holm K, Savilahti E, Koskimies S, Lipsanen V, Maki M. Immunohistochemical changes in the jejunum in first degree relatives of patients with coeliac disease and the 
coeliac disease marker DQ genes. HLA class II antigen expression, interleukin-2 receptor positive cells and dividing crypt cells. Gut 1994; 35:55-60.

103. Tosco A, Salvati VM, Auricchio R, Maglio M, Borrelli M, Coruzzo A, et al. Natural history of potential celiac disease in children. Clin Gastroenterol Hepatol 2011; 9:3205; quiz e36.

104. Biagi F, Trotta L, Alfano C, Balduzzi D, Staffieri V, Bianchi PI, et al. Prevalence and natural history of potential celiac disease in adult patients. Scand J Gastroenterol 2013; 48:537-42.

105. Auricchio R, Tosco A, Piccolo E, Galatola M, Izzo V, Maglio M, et al. Potential celiac children: 9-year follow-up on a gluten-containing diet. The American journal of gastroenterology 2014; 109:913-21.

106. Husby S, Koletzko S, Korponay-Szabo IR, Mearin ML, Phillips A, Shamir R, et al. European Society for Pediatric Gastroenterology, Hepatology, and Nutrition guidelines for the diagnosis of coeliac disease. J Pediatr Gastroenterol Nutr 2012; 54:136-60.

107. Hogberg L, Nordwall M, Stenhammar L. One thousand small-bowel biopsies in children. A single-port versus a double-port capsule. Scand J Gastroenterol 2001; 36:1230-2.

108. Bonamico M, Mariani P, Thanasi E, Ferri M, Nenna R, Tiberti C, et al. Patchy villous atrophy of the duodenum in childhood celiac disease. J Pediatr Gastroenterol Nutr 2004; 38:204-7.

109. Scott BB, Losowsky MS. Patchiness and duodenal-jejunal variation of the mucosal abnormality in coeliac disease and dermatitis herpetiformis. Gut 1976; 17:984-92.

110. Marsh MN, Bjarnason I, Shaw J, Ellis A, Baker R, Peters TJ. Studies of intestinal lymphoid tissue. XIV--HLA status, mucosal morphology, permeability and epithelial lymphocyte populations in first degree relatives of patients with coeliac disease. Gut 1990; 31:32-6.

111. Lionetti P. The enteropathy of celiac disease. J Pediatr Gastroenterol Nutr 2002; 34 Suppl 1:S18-21.

112. Wahab PJ, Meijer JW, Mulder CJ. Histologic follow-up of people with celiac disease on a gluten-free diet: slow and incomplete recovery. Am J Clin Pathol 2002; 118:45963.

113. Halstensen TS, Brandtzaeg P. Activated T lymphocytes in the celiac lesion: nonproliferative activation (CD25) of CD4+ alpha/beta cells in the lamina propria but proliferation (Ki-67) of alpha/beta and gamma/delta cells in the epithelium. Eur $\mathbf{J}$ Immunol 1993; 23:505-10.

114. Sollid LM. Molecular basis of celiac disease. Annu Rev Immunol 2000; 18:53-81.

115. Halstensen TS, Farstad IN, Scott H, Fausa O, Brandtzaeg P. Intraepithelial TcR alpha/beta+ lymphocytes express CD45RO more often than the TcR gamma/delta+ counterparts in coeliac disease. Immunology 1990; 71:460-6.

116. Ferguson A, Murray D. Quantitation of intraepithelial lymphocytes in human jejunum. Gut 1971; 12:988-94.

117. Kutlu T, Brousse N, Rambaud C, Le Deist F, Schmitz J, Cerf-Bensussan N. Numbers of $\mathrm{T}$ cell receptor (TCR) alpha beta+ but not of TcR gamma delta+ intraepithelial lymphocytes correlate with the grade of villous atrophy in coeliac patients on a long term normal diet. Gut 1993; 34:208-14.

118. Marsh MN. Grains of truth: evolutionary changes in small intestinal mucosa in response to environmental antigen challenge. Gut 1990; 31:111-4.

119. Oberhuber G. Histopathology of celiac disease. Biomed Pharmacother 2000; 54:36872 . 
120. Ciclitira PJ, King AL, Fraser JS. AGA technical review on Celiac Sprue. American Gastroenterological Association. Gastroenterology 2001; 120:1526-40.

121. Cataldo F, Marino V, Ventura A, Bottaro G, Corazza GR. Prevalence and clinical features of selective immunoglobulin A deficiency in coeliac disease: an Italian multicentre study. Italian Society of Paediatric Gastroenterology and Hepatology (SIGEP) and "Club del Tenue" Working Groups on Coeliac Disease. Gut 1998; 42:362-5.

122. Cataldo F, Lio D, Marino V, Picarelli A, Ventura A, Corazza GR. IgG(1) antiendomysium and IgG antitissue transglutaminase (anti-tTG) antibodies in coeliac patients with selective IgA deficiency. Working Groups on Celiac Disease of SIGEP and Club del Tenue. Gut 2000; 47:366-9.

123. Schuppan D, Zimmer KP. The diagnosis and treatment of celiac disease. Dtsch Arztebl Int 2013; 110:835-46.

124. O'Farrelly C, Kelly J, Hekkens W, Bradley B, Thompson A, Feighery C, et al. Alpha gliadin antibody levels: a serological test for coeliac disease. BMJ 1983; 286:2007-10.

125. Burgin-Wolff A, Gaze H, Hadziselimovic F, Huber H, Lentze MJ, Nussle D, et al. Antigliadin and antiendomysium antibody determination for coeliac disease. Arch Dis Child 1991; 66:941-7.

126. Ladinser B, Rossipal E, Pittschieler K. Endomysium antibodies in coeliac disease: an improved method. Gut 1994; 35:776-8.

127. Burgin-Wolff A, Dahlbom I, Hadziselimovic F, Petersson CJ. Antibodies against human tissue transglutaminase and endomysium in diagnosing and monitoring coeliac disease. Scand J Gastroenterol 2002; 37:685-91.

128. Kwiecien J, Karczewska K, Lukasik M, Kasner J, Dyduch A, Zabka A, et al. Negative results of antiendomysial antibodies: long term follow up. Arch Dis Child 2005; 90:41-2.

129. Rostami K, Kerckhaert J, Tiemessen R, von Blomberg BM, Meijer JW, Mulder CJ. Sensitivity of antiendomysium and antigliadin antibodies in untreated celiac disease: disappointing in clinical practice. Am J Gastroenterol 1999; 94:888-94.

130. Dieterich W, Ehnis T, Bauer M, Donner P, Volta U, Riecken EO, et al. Identification of tissue transglutaminase as the autoantigen of celiac disease. Nat Med 1997; 3:797801.

131. Wolters V, Vooijs-Moulaert AF, Burger H, Brooimans R, De Schryver J, Rijkers G, et al. Human tissue transglutaminase enzyme linked immunosorbent assay outperforms both the guinea pig based tissue transglutaminase assay and anti-endomysium antibodies when screening for coeliac disease. Eur J Pediatr 2002; 161:284-7.

132. Sblattero D, Berti I, Trevisiol C, Marzari R, Tommasini A, Bradbury A, et al. Human recombinant tissue transglutaminase ELISA: an innovative diagnostic assay for celiac disease. Am J Gastroenterol 2000; 95:1253-7.

133. Hansson T, Dahlbom I, Hall J, Holtz A, Elfman L, Dannaeus A, et al. Antibody reactivity against human and guinea pig tissue transglutaminase in children with celiac disease. J Pediatr Gastroenterol Nutr 2000; 30:379-84.

134. Lewis NR, Scott BB. Systematic review: the use of serology to exclude or diagnose coeliac disease (a comparison of the endomysial and tissue transglutaminase antibody tests). Aliment Pharmacol Ther 2006; 24:47-54.

135. Donaldson MR, Firth SD, Wimpee H, Leiferman KM, Zone JJ, Horsley W, et al. Correlation of duodenal histology with tissue transglutaminase and endomysial antibody levels in pediatric celiac disease. Clin Gastroenterol Hepatol 2007; 5:567-73. 
136. Dalgic B, Sari S, Basturk B, Ensari A, Egritas O, Bukulmez A, et al. Prevalence of celiac disease in healthy Turkish school children. Am J Gastroenterol 2011; 106:15127.

137. Green PH, Rostami K, Marsh MN. Diagnosis of coeliac disease. Best Pract Res Clin Gastroenterol 2005; 19:389-400.

138. Wolters VM, Wijmenga C. Genetic background of celiac disease and its clinical implications. Am J Gastroenterol 2008; 103:190-5.

139. Lohi S, Mustalahti K, Kaukinen K, Laurila K, Collin P, Rissanen H, et al. Increasing prevalence of coeliac disease over time. Aliment Pharmacol Ther 2007; 26:1217-25.

140. Reilly NR, Green PH. Epidemiology and clinical presentations of celiac disease. Semin Immunopathol 2012; 34:473-8.

141. Fasano A, Berti I, Gerarduzzi T, Not T, Colletti RB, Drago S, et al. Prevalence of celiac disease in at-risk and not-at-risk groups in the United States: a large multicenter study. Arch Intern Med 2003; 163:286-92.

142. Maki M, Mustalahti K, Kokkonen J, Kulmala P, Haapalahti M, Karttunen T, et al. Prevalence of Celiac disease among children in Finland. N Engl J Med 2003; 348:2517-24.

143. West J, Logan RF, Hill PG, Lloyd A, Lewis S, Hubbard R, et al. Seroprevalence, correlates, and characteristics of undetected coeliac disease in England. Gut 2003; 52:960-5.

144. Castano L, Blarduni E, Ortiz L, Nunez J, Bilbao JR, Rica I, et al. Prospective population screening for celiac disease: high prevalence in the first 3 years of life. $\mathrm{J}$ Pediatr Gastroenterol Nutr 2004; 39:80-4.

145. Biagi F, Klersy C, Balduzzi D, Corazza GR. Are we not over-estimating the prevalence of coeliac disease in the general population? Ann Med 2010; 42:557-61.

146. Mustalahti K, Catassi C, Reunanen A, Fabiani E, Heier M, McMillan S, et al. The prevalence of celiac disease in Europe: results of a centralized, international mass screening project. Ann Med 2010; 42:587-95.

147. Alarida K, Harown J, Ahmaida A, Marinelli L, Venturini C, Kodermaz G, et al. Coeliac disease in Libyan children: a screening study based on the rapid determination of anti-transglutaminase antibodies. Dig Liver Dis 2011; 43:688-91.

148. Wang XQ, Liu W, Xu CD, Mei H, Gao Y, Peng HM, et al. Celiac disease in children with diarrhea in 4 cities in China. J Pediatr Gastroenterol Nutr 2011; 53:368-70.

149. Catassi C, Ratsch IM, Gandolfi L, Pratesi R, Fabiani E, El Asmar R, et al. Why is coeliac disease endemic in the people of the Sahara? Lancet 1999; 354:647-8.

150. Greco L, Romino R, Coto I, Di Cosmo N, Percopo S, Maglio M, et al. The first large population based twin study of coeliac disease. Gut 2002; 50:624-8.

151. Rubio-Tapia A, Van Dyke CT, Lahr BD, Zinsmeister AR, El-Youssef M, Moore SB, et al. Predictors of family risk for celiac disease: a population-based study. Clin Gastroenterol Hepatol 2008; 6:983-7.

152. Ivarsson A, Persson LA, Nystrom L, Hernell O. The Swedish coeliac disease epidemic with a prevailing twofold higher risk in girls compared to boys may reflect gender specific risk factors. Eur J Epidemiol 2003; 18:677-84.

153. Ivarsson A, Hernell O, Nystrom L, Persson LA. Children born in the summer have increased risk for coeliac disease. J Epidemiol Community Health 2003; 57:36-9.

154. Wingren CJ, Agardh D, Merlo J. Sex differences in coeliac disease risk: a Swedish sibling design study. Digestive and liver disease : official journal of the Italian Society of Gastroenterology and the Italian Association for the Study of the Liver 2012; 44:909-13. 
155. Muenchhoff M, Goulder PJ. Sex differences in pediatric infectious diseases. The Journal of infectious diseases 2014; 209 Suppl 3:S120-6.

156. Chen W, Mempel M, Schober W, Behrendt H, Ring J. Gender difference, sex hormones, and immediate type hypersensitivity reactions. Allergy 2008; 63:1418-27.

157. Carlsson AK, Axelsson IE, Borulf SK, Bredberg AC, Ivarsson SA. Serological screening for celiac disease in healthy 2.5-year-old children in Sweden. Pediatrics 2001; 107:42-5.

158. Tommasini A, Not T, Kiren V, Baldas V, Santon D, Trevisiol C, et al. Mass screening for coeliac disease using antihuman transglutaminase antibody assay. Arch Dis Child 2004; 89:512-5.

159. Csizmadia CG, Mearin ML, von Blomberg BM, Brand R, Verloove-Vanhorick SP. An iceberg of childhood coeliac disease in the Netherlands. Lancet 1999; 353:813-4.

160. Meloni G, Dore A, Fanciulli G, Tanda F, Bottazzo GF. Subclinical coeliac disease in schoolchildren from northern Sardinia. Lancet 1999; 353:37.

161. Korponay-Szabo IR, Kovacs JB, Czinner A, Goracz G, Vamos A, Szabo T. High prevalence of silent celiac disease in preschool children screened with $\mathrm{IgA} / \operatorname{IgG}$ antiendomysium antibodies. J Pediatr Gastroenterol Nutr 1999; 28:26-30.

162. Bjorck S, Brundin C, Lorinc E, Lynch KF, Agardh D. Screening detects a high proportion of celiac disease in young HLA-genotyped children. J Pediatr Gastroenterol Nutr 2010; 50:49-53.

163. Agardh D, Nilsson A, Tuomi T, Lindberg B, Carlsson AK, Lernmark A, et al. Prediction of silent celiac disease at diagnosis of childhood type 1 diabetes by tissue transglutaminase autoantibodies and HLA. Pediatr Diabetes 2001; 2:58-65.

164. Ivarsson A, Persson LA, Nystrom L, Ascher H, Cavell B, Danielsson L, et al. Epidemic of coeliac disease in Swedish children. Acta Paediatr 2000; 89:165-71.

165. Myleus A, Ivarsson A, Webb C, Danielsson L, Hernell O, Hogberg L, et al. Celiac disease revealed in $3 \%$ of Swedish 12-year-olds born during an epidemic. J Pediatr Gastroenterol Nutr 2009; 49:170-6.

166. Ivarsson A, Myleus A, Norstrom F, van der Pals M, Rosen A, Hogberg L, et al. Prevalence of childhood celiac disease and changes in infant feeding. Pediatrics 2013; 131:e687-94.

167. Green PH, Jabri B. Coeliac disease. Lancet 2003; 362:383-91.

168. Marietta EV, David CS, Murray JA. Important lessons derived from animal models of celiac disease. Int Rev Immunol 2011; 30:197-206.

169. Catassi C, Kryszak D, Bhatti B, Sturgeon C, Helzlsouer K, Clipp SL, et al. Natural history of celiac disease autoimmunity in a USA cohort followed since 1974. Ann Med 2010; 42:530-8.

170. Lionetti E, Catassi C. New clues in celiac disease epidemiology, pathogenesis, clinical manifestations, and treatment. Int Rev Immunol 2011; 30:219-31.

171. Fasano A. Zonulin and its regulation of intestinal barrier function: the biological door to inflammation, autoimmunity, and cancer. Physiol Rev 2011; 91:151-75.

172. Dieterich W, Esslinger B, Schuppan D. Pathomechanisms in celiac disease. Int Arch Allergy Immunol 2003; 132:98-108.

173. Schuppan D. Current concepts of celiac disease pathogenesis. Gastroenterology 2000; 119:234-42.

174. van de Wal Y, Kooy Y, van Veelen P, Pena S, Mearin L, Papadopoulos G, et al. Selective deamidation by tissue transglutaminase strongly enhances gliadin-specific $\mathrm{T}$ cell reactivity. J Immunol 1998; 161:1585-8. 
175. Forsberg G, Hernell O, Hammarstrom S, Hammarstrom ML. Concomitant increase of IL-10 and pro-inflammatory cytokines in intraepithelial lymphocyte subsets in celiac disease. Int Immunol 2007; 19:993-1001.

176. Iltanen S, Holm K, Ashorn M, Ruuska T, Laippala P, Maki M. Changing jejunal gamma delta $\mathrm{T}$ cell receptor (TCR)-bearing intraepithelial lymphocyte density in coeliac disease. Clin Exp Immunol 1999; 117:51-5.

177. Jabri B, de Serre NP, Cellier C, Evans K, Gache C, Carvalho C, et al. Selective expansion of intraepithelial lymphocytes expressing the HLA-E-specific natural killer receptor CD94 in celiac disease. Gastroenterology 2000; 118:867-79.

178. Halstensen TS, Scott H, Fausa O, Brandtzaeg P. Gluten stimulation of coeliac mucosa in vitro induces activation (CD25) of lamina propria CD4+ T cells and macrophages but no crypt-cell hyperplasia. Scand J Immunol 1993; 38:581-90.

179. Forsberg G, Hernell O, Melgar S, Israelsson A, Hammarstrom S, Hammarstrom ML. Paradoxical coexpression of proinflammatory and down-regulatory cytokines in intestinal T cells in childhood celiac disease. Gastroenterology 2002; 123:667-78.

180. Mention JJ, Ben Ahmed M, Begue B, Barbe U, Verkarre V, Asnafi V, et al. Interleukin 15: a key to disrupted intraepithelial lymphocyte homeostasis and lymphomagenesis in celiac disease. Gastroenterology 2003; 125:730-45.

181. Tiittanen M, Westerholm-Ormio M, Verkasalo M, Savilahti E, Vaarala O. Infiltration of forkhead box P3-expressing cells in small intestinal mucosa in coeliac disease but not in type 1 diabetes. Clin Exp Immunol 2008; 152:498-507.

182. Salvati VM, MacDonald TT, Bajaj-Elliott M, Borrelli M, Staiano A, Auricchio S, et al. Interleukin 18 and associated markers of T helper cell type 1 activity in coeliac disease. Gut 2002; 50:186-90.

183. Westerholm-Ormio M, Garioch J, Ketola I, Savilahti E. Inflammatory cytokines in small intestinal mucosa of patients with potential coeliac disease. Clin Exp Immunol 2002; 128:94-101.

184. Monteleone I, Sarra M, Del Vecchio Blanco G, Paoluzi OA, Franze E, Fina D, et al. Characterization of IL-17A-producing cells in celiac disease mucosa. J Immunol 2010; 184:2211-8.

185. Monteleone I, Monteleone G, Del Vecchio Blanco G, Vavassori P, Cucchiara S, MacDonald TT, et al. Regulation of the T helper cell type 1 transcription factor T-bet in coeliac disease mucosa. Gut 2004; 53:1090-5.

186. Castellanos-Rubio A, Santin I, Irastorza I, Castano L, Carlos Vitoria J, Ramon Bilbao J. TH17 (and TH1) signatures of intestinal biopsies of CD patients in response to gliadin. Autoimmunity 2009; 42:69-73.

187. Ciccocioppo R, Di Sabatino A, Bauer M, Della Riccia DN, Bizzini F, Biagi F, et al. Matrix metalloproteinase pattern in celiac duodenal mucosa. Lab Invest 2005; 85:397407.

188. Kontakou M, Sturgess RP, Przemioslo RT, Limb GA, Nelufer JM, Ciclitira PJ. Detection of interferon gamma mRNA in the mucosa of patients with coeliac disease by in situ hybridisation. Gut 1994; 35:1037-41.

189. Nilsen EM, Jahnsen FL, Lundin KE, Johansen FE, Fausa O, Sollid LM, et al. Gluten induces an intestinal cytokine response strongly dominated by interferon gamma in patients with celiac disease. Gastroenterology 1998; 115:551-63.

190. Adams RB, Planchon SM, Roche JK. IFN-gamma modulation of epithelial barrier function. Time course, reversibility, and site of cytokine binding. J Immunol 1993; 150:2356-63. 
191. Bruewer M, Luegering A, Kucharzik T, Parkos CA, Madara JL, Hopkins AM, et al. Proinflammatory cytokines disrupt epithelial barrier function by apoptosisindependent mechanisms. J Immunol 2003; 171:6164-72.

192. Przemioslo RT, Lundin KE, Sollid LM, Nelufer J, Ciclitira PJ. Histological changes in small bowel mucosa induced by gliadin sensitive T lymphocytes can be blocked by anti-interferon gamma antibody. Gut 1995; 36:874-9.

193. Monteleone G, Pender SL, Alstead E, Hauer AC, Lionetti P, McKenzie C, et al. Role of interferon alpha in promoting $\mathrm{T}$ helper cell type 1 responses in the small intestine in coeliac disease. Gut 2001; 48:425-9.

194. Przemioslo RT, Kontakou M, Nobili V, Ciclitira PJ. Raised pro-inflammatory cytokines interleukin 6 and tumour necrosis factor alpha in coeliac disease mucosa detected by immunohistochemistry. Gut 1994; 35:1398-403.

195. Maiuri L, Ciacci C, Auricchio S, Brown V, Quaratino S, Londei M. Interleukin 15 mediates epithelial changes in celiac disease. Gastroenterology 2000; 119:996-1006.

196. Brazowski E, Cohen S, Yaron A, Filip I, Eisenthal A. FOXP3 expression in duodenal mucosa in pediatric patients with celiac disease. Pathobiology 2010; 77:328-34.

197. Vorobjova T, Uibo O, Heilman K, Rago T, Honkanen J, Vaarala O, et al. Increased FOXP3 expression in small-bowel mucosa of children with coeliac disease and type I diabetes mellitus. Scand J Gastroenterol 2009; 44:422-30.

198. Sapone A, Lammers KM, Mazzarella G, Mikhailenko I, Carteni M, Casolaro V, et al. Differential mucosal IL-17 expression in two gliadin-induced disorders: gluten sensitivity and the autoimmune enteropathy celiac disease. Int Arch Allergy Immunol 2010; 152:75-80.

199. Fina D, Sarra M, Caruso R, Del Vecchio Blanco G, Pallone F, MacDonald TT, et al. Interleukin 21 contributes to the mucosal $\mathrm{T}$ helper cell type 1 response in coeliac disease. Gut 2008; 57:887-92.

200. Leon AJ, Garrote JA, Blanco-Quiros A, Calvo C, Fernandez-Salazar L, Del Villar A, et al. Interleukin 18 maintains a long-standing inflammation in coeliac disease patients. Clin Exp Immunol 2006; 146:479-85.

201. Beckett CG, Dell'Olio D, Kontakou M, Przemioslo RT, Rosen-Bronson S, Ciclitira PJ. Analysis of interleukin-4 and interleukin-10 and their association with the lymphocytic infiltrate in the small intestine of patients with coeliac disease. Gut 1996; 39:818-23.

202. Midhagen G, Aberg AK, Olcen P, Jarnerot G, Valdimarsson T, Dahlbom I, et al. Antibody levels in adult patients with coeliac disease during gluten-free diet: a rapid initial decrease of clinical importance. J Intern Med 2004; 256:519-24.

203. Vader LW, Stepniak DT, Bunnik EM, Kooy YM, de Haan W, Drijfhout JW, et al. Characterization of cereal toxicity for celiac disease patients based on protein homology in grains. Gastroenterology 2003; 125:1105-13.

204. Storsrud S, Olsson M, Arvidsson Lenner R, Nilsson LA, Nilsson O, Kilander A. Adult coeliac patients do tolerate large amounts of oats. Eur J Clin Nutr 2003; 57:163-9.

205. Hogberg L, Laurin P, Falth-Magnusson K, Grant C, Grodzinsky E, Jansson G, et al. Oats to children with newly diagnosed coeliac disease: a randomised double blind study. Gut 2004; 53:649-54.

206. Zilli T, Boudreau C, Doucet R, Alizadeh M, Lambert C, van Nguyen T, et al. Bone marrow-sparing intensity-modulated radiation therapy for Stage I seminoma. Acta Oncol 2011; 50:555-62.

207. Janatuinen EK, Kemppainen TA, Julkunen RJ, Kosma VM, Maki M, Heikkinen M, et al. No harm from five year ingestion of oats in coeliac disease. Gut 2002; 50:332-5. 
208. Hollen E, Holmgren Peterson K, Sundqvist T, Grodzinsky E, Hogberg L, Laurin P, et al. Coeliac children on a gluten-free diet with or without oats display equal anti-avenin antibody titres. Scand J Gastroenterol 2006; 41:42-7.

209. Hallert C, Olsson M, Storsrud S, Lenner RA, Kilander A, Stenhammar L. [Oats can be included in gluten-free diet]. Lakartidningen 1999; 96:3339-40.

210. Tapsas D, Falth-Magnusson K, Hogberg L, Hammersjo JA, Hollen E. Swedish children with celiac disease comply well with a gluten-free diet, and most include oats without reporting any adverse effects: a long-term follow-up study. Nutrition research 2014; 34:436-41.

211. Sjoberg V, Hollen E, Pietz G, Magnusson KE, Falth-Magnusson K, Sundstrom M, et al. Noncontaminated dietary oats may hamper normalization of the intestinal immune status in childhood celiac disease. Clin Transl Gastroenterol 2014; 5:e58.

212. Tjellstrom B, Stenhammar L, Sundqvist T, Falth-Magnusson K, Hollen E, Magnusson $\mathrm{KE}$, et al. The effects of oats on the function of gut microflora in children with coeliac disease. Alimentary pharmacology \& therapeutics 2014.

213. Holm K, Maki M, Vuolteenaho N, Mustalahti K, Ashorn M, Ruuska T, et al. Oats in the treatment of childhood coeliac disease: a 2-year controlled trial and a long-term clinical follow-up study. Aliment Pharmacol Ther 2006; 23:1463-72.

214. Wouters J, Weijerman ME, van Furth AM, Schreurs MW, Crusius JB, von Blomberg $\mathrm{BM}$, et al. Prospective human leukocyte antigen, endomysium immunoglobulin A antibodies, and transglutaminase antibodies testing for celiac disease in children with Down syndrome. J Pediatr 2009; 154:239-42.

215. Cosnes J, Cellier C, Viola S, Colombel JF, Michaud L, Sarles J, et al. Incidence of autoimmune diseases in celiac disease: protective effect of the gluten-free diet. Clin Gastroenterol Hepatol 2008; 6:753-8.

216. Hansen D, Bennedbaek FN, Hansen LK, Hoier-Madsen M, Hegedu LS, Jacobsen BB, et al. High prevalence of coeliac disease in Danish children with type I diabetes mellitus. Acta Paediatr 2001; 90:1238-43.

217. Sud S, Marcon M, Assor E, Palmert MR, Daneman D, Mahmud FH. Celiac disease and pediatric type 1 diabetes: diagnostic and treatment dilemmas. Int $\mathbf{J}$ Pediatr Endocrinol 2010; 2010:161285.

218. Csizmadia CG, Mearin ML, Oren A, Kromhout A, Crusius JB, von Blomberg BM, et al. Accuracy and cost-effectiveness of a new strategy to screen for celiac disease in children with Down syndrome. J Pediatr 2000; 137:756-61.

219. Mackey J, Treem WR, Worley G, Boney A, Hart P, Kishnani PS. Frequency of celiac disease in individuals with Down syndrome in the United States. Clin Pediatr 2001; 40:249-52.

220. Sheldon W. Prognosis in early adult life of coeliac children treated with a gluten-free diet. BMJ 1969; 2:401-4.

221. Holmes GK, Prior P, Lane MR, Pope D, Allan RN. Malignancy in coeliac disease-effect of a gluten free diet. Gut 1989; 30:333-8.

222. West J, Logan RF, Smith CJ, Hubbard RB, Card TR. Malignancy and mortality in people with coeliac disease: population based cohort study. BMJ 2004; 329:716-9.

223. Peters U, Askling J, Gridley G, Ekbom A, Linet M. Causes of death in patients with celiac disease in a population-based Swedish cohort. Arch Intern Med 2003; 163:1566-72.

224. Ludvigsson JF, Montgomery SM, Ekbom A, Brandt L, Granath F. Small-intestinal histopathology and mortality risk in celiac disease. JAMA 2009; 302:1171-8. 
225. Malamut G, Afchain P, Verkarre V, Lecomte T, Amiot A, Damotte D, et al. Presentation and long-term follow-up of refractory celiac disease: comparison of type I with type II. Gastroenterology 2009; 136:81-90.

226. Rubio-Tapia A, Murray JA. Classification and management of refractory coeliac disease. Gut 2010; 59:547-57.

227. Krauss N, Schuppan D. Monitoring nonresponsive patients who have celiac disease. Gastrointest Endosc Clin N Am 2006; 16:317-27.

228. Howdle PD, Jalal PK, Holmes GK, Houlston RS. Primary small-bowel malignancy in the UK and its association with coeliac disease. QJM 2003; 96:345-53.

229. ADA. Diagnosis and classification of diabetes mellitus. Diabetes Care 2008; 31 Suppl 1:S55-60.

230. Pugliese A. The multiple origins of Type 1 diabetes. Diabet Med 2013; 30:135-46.

231. Ludvigsson J. Why diabetes incidence increases--a unifying theory. Ann N Y Acad Sci 2006; 1079:374-82.

232. Yoon JW, Austin M, Onodera T, Notkins AL. Isolation of a virus from the pancreas of a child with diabetic ketoacidosis. The New England journal of medicine 1979; 300:1173-9.

233. Lonnrot M, Korpela K, Knip M, Ilonen J, Simell O, Korhonen S, et al. Enterovirus infection as a risk factor for beta-cell autoimmunity in a prospectively observed birth cohort: the Finnish Diabetes Prediction and Prevention Study. Diabetes 2000; 49:1314-8.

234. Honeyman MC, Coulson BS, Stone NL, Gellert SA, Goldwater PN, Steele CE, et al. Association between rotavirus infection and pancreatic islet autoimmunity in children at risk of developing type 1 diabetes. Diabetes 2000; 49:1319-24.

235. Hyoty H, Hiltunen M, Knip M, Laakkonen M, Vahasalo P, Karjalainen J, et al. A prospective study of the role of coxsackie $\mathrm{B}$ and other enterovirus infections in the pathogenesis of IDDM. Childhood Diabetes in Finland (DiMe) Study Group. Diabetes 1995; 44:652-7.

236. Salminen K, Sadeharju K, Lonnrot M, Vahasalo P, Kupila A, Korhonen S, et al. Enterovirus infections are associated with the induction of beta-cell autoimmunity in a prospective birth cohort study. J Med Virol 2003; 69:91-8.

237. Moya-Suri V, Schlosser M, Zimmermann K, Rjasanowski I, Gurtler L, Mentel R. Enterovirus RNA sequences in sera of schoolchildren in the general population and their association with type 1-diabetes-associated autoantibodies. J Med Microbiol 2005; 54:879-83.

238. Holt PG, McMenamin C. IgE and mucosal immunity: studies on the role of intraepithelial Ia + dendritic cells and gamma/delta T-lymphocytes in regulation of Tcell activation in the lung. Clin Exp Allergy 1991; 21 Suppl 1:148-52.

239. Isolauri E. Intestinal involvement in atopic disease. J R Soc Med 1997; 90 Suppl 30:15-20.

240. Savilahti E, Saukkonen TT, Virtala ET, Tuomilehto J, Akerblom HK. Increased levels of cow's milk and beta-lactoglobulin antibodies in young children with newly diagnosed IDDM. The Childhood Diabetes in Finland Study Group. Diabetes Care 1993; 16:984-9.

241. Saukkonen T, Savilahti E, Vaarala O, Virtala ET, Tuomilehto J, Akerblom HK. Children with newly diagnosed IDDM have increased levels of antibodies to bovine serum albumin but not to ovalbumin. Childhood Diabetes in Finland Study Group. Diabetes Care 1994; 17:970-6. 
242. Luopajarvi K, Savilahti E, Virtanen SM, Ilonen J, Knip M, Akerblom HK, et al. Enhanced levels of cow's milk antibodies in infancy in children who develop type 1 diabetes later in childhood. Pediatric diabetes 2008; 9:434-41.

243. Vaarala O, Klemetti P, Savilahti E, Reijonen H, Ilonen J, Akerblom HK. Cellular immune response to cow's milk beta-lactoglobulin in patients with newly diagnosed IDDM. Diabetes 1996; 45:178-82.

244. Akerblom HK, Knip M. Putative environmental factors in Type 1 diabetes. Diabetes Metab Rev 1998; 14:31-67.

245. Ventura A, Magazzu G, Greco L. Duration of exposure to gluten and risk for autoimmune disorders in patients with celiac disease. SIGEP Study Group for Autoimmune Disorders in Celiac Disease. Gastroenterology 1999; 117:297-303.

246. Vaarala O. Intestinal immunity and type 1 diabetes. J Pediatr Gastroenterol Nutr 2004; 39 Suppl 3:S732-3.

247. Wahlberg J, Vaarala O, Ludvigsson J. Dietary risk factors for the emergence of type 1 diabetes-related autoantibodies in 21/2 year-old Swedish children. Br J Nutr 2006; 95:603-8.

248. Ziegler AG, Schmid S, Huber D, Hummel M, Bonifacio E. Early infant feeding and risk of developing type 1 diabetes-associated autoantibodies. Jama 2003; 290:1721-8.

249. Antvorskov JC, Josefsen K, Engkilde K, Funda DP, Buschard K. Dietary gluten and the development of type 1 diabetes. Diabetologia 2014.

250. Vaarala O, Paronen J, Otonkoski T, Akerblom HK. Cow milk feeding induces antibodies to insulin in children--a link between cow milk and insulin-dependent diabetes mellitus? Scand J Immunol 1998; 47:131-5.

251. Vaarala O, Atkinson MA, Neu J. The "perfect storm" for type 1 diabetes: the complex interplay between intestinal microbiota, gut permeability, and mucosal immunity. Diabetes 2008; 57:2555-62.

252. Klemetti P, Savilahti E, Ilonen J, Akerblom HK, Vaarala O. T-cell reactivity to wheat gluten in patients with insulin-dependent diabetes mellitus. Scand J Immunol 1998; 47:48-53.

253. Troncone R, Franzese A, Mazzarella G, Paparo F, Auricchio R, Coto I, et al. Gluten sensitivity in a subset of children with insulin dependent diabetes mellitus. Am J Gastroenterol 2003; 98:590-5.

254. Savilahti E, Ormala T, Saukkonen T, Sandini-Pohjavuori U, Kantele JM, Arato A, et al. Jejuna of patients with insulin-dependent diabetes mellitus (IDDM) show signs of immune activation. Clin Exp Immunol 1999; 116:70-7.

255. Vaarala O. Gut and the induction of immune tolerance in type 1 diabetes. Diabetes Metab Res Rev 1999; 15:353-61.

256. Vaarala O, Klemetti P, Juhela S, Simell O, Hyoty H, Ilonen J. Effect of coincident enterovirus infection and cows' milk exposure on immunisation to insulin in early infancy. Diabetologia 2002; 45:531-4.

257. Westerholm-Ormio M, Vaarala O, Pihkala P, Ilonen J, Savilahti E. Immunologic activity in the small intestinal mucosa of pediatric patients with type 1 diabetes. Diabetes 2003; 52:2287-95.

258. Virtanen SM, Rasanen L, Ylonen K, Aro A, Clayton D, Langholz B, et al. Early introduction of dairy products associated with increased risk of IDDM in Finnish children. The Childhood in Diabetes in Finland Study Group. Diabetes 1993; 42:178690 .

259. Virtanen SM, Knip M. Nutritional risk predictors of beta cell autoimmunity and type 1 diabetes at a young age. Am J Clin Nutr 2003; 78:1053-67. 
260. Kimpimaki T, Erkkola M, Korhonen S, Kupila A, Virtanen SM, Ilonen J, et al. Shortterm exclusive breastfeeding predisposes young children with increased genetic risk of Type I diabetes to progressive beta-cell autoimmunity. Diabetologia 2001; 44:63-9.

261. Holmberg H, Wahlberg J, Vaarala O, Ludvigsson J. Short duration of breast-feeding as a risk-factor for beta-cell autoantibodies in 5-year-old children from the general population. Br J Nutr 2007; 97:111-6.

262. Johansson C, Samuelsson U, Ludvigsson J. A high weight gain early in life is associated with an increased risk of type 1 (insulin-dependent) diabetes mellitus. Diabetologia 1994; 37:91-4.

263. Group TESS. Vitamin D supplement in early childhood and risk for Type I (insulindependent) diabetes mellitus. The EURODIAB Substudy 2 Study Group. Diabetologia 1999; 42:51-4.

264. Scott FW, Cloutier HE, Kleemann R, Woerz-Pagenstert U, Rowsell P, Modler HW, et al. Potential mechanisms by which certain foods promote or inhibit the development of spontaneous diabetes in BB rats: dose, timing, early effect on islet area, and switch in infiltrate from Th1 to Th2 cells. Diabetes 1997; 46:589-98.

265. Scott FW, Rowsell P, Wang GS, Burghardt K, Kolb H, Flohe S. Oral exposure to diabetes-promoting food or immunomodulators in neonates alters gut cytokines and diabetes. Diabetes 2002; 51:73-8.

266. Sapone A, de Magistris L, Pietzak M, Clemente MG, Tripathi A, Cucca F, et al. Zonulin upregulation is associated with increased gut permeability in subjects with type 1 diabetes and their relatives. Diabetes 2006; 55:1443-9.

267. Kuitunen M, Saukkonen T, Ilonen J, Akerblom HK, Savilahti E. Intestinal permeability to mannitol and lactulose in children with type 1 diabetes with the HLADQB $1 * 02$ allele. Autoimmunity 2002; 35:365-8.

268. Secondulfo M, Iafusco D, Carratu R, deMagistris L, Sapone A, Generoso M, et al. Ultrastructural mucosal alterations and increased intestinal permeability in non-celiac, type I diabetic patients. Dig Liver Dis 2004; 36:35-45.

269. Bosi E, Molteni L, Radaelli MG, Folini L, Fermo I, Bazzigaluppi E, et al. Increased intestinal permeability precedes clinical onset of type 1 diabetes. Diabetologia 2006; 49:2824-7.

270. Paronen J, Klemetti P, Kantele JM, Savilahti E, Perheentupa J, Akerblom HK, et al. Glutamate decarboxylase-reactive peripheral blood lymphocytes from patients with IDDM express gut-specific homing receptor alpha4beta7-integrin. Diabetes 1997; 46:583-8.

271. Isolauri E, Majamaa H, Arvola T, Rantala I, Virtanen E, Arvilommi H. Lactobacillus casei strain GG reverses increased intestinal permeability induced by cow milk in suckling rats. Gastroenterology 1993; 105:1643-50.

272. Salminen S, von Wright A, Morelli L, Marteau P, Brassart D, de Vos WM, et al. Demonstration of safety of probiotics -- a review. Int J Food Microbiol 1998; 44:93106.

273. Kaila M, Isolauri E, Soppi E, Virtanen E, Laine S, Arvilommi H. Enhancement of the circulating antibody secreting cell response in human diarrhea by a human Lactobacillus strain. Pediatr Res 1992; 32:141-4.

274. Majamaa H, Isolauri E. Probiotics: a novel approach in the management of food allergy. J Allergy Clin Immunol 1997; 99:179-85.

275. Miettinen M, Lehtonen A, Julkunen I, Matikainen S. Lactobacilli and Streptococci activate NF-kappa B and STAT signaling pathways in human macrophages. J Immunol 2000; 164:3733-40. 
276. Coombes JL, Powrie F. Dendritic cells in intestinal immune regulation. Nat Rev Immunol 2008; 8:435-46.

277. Pozzilli P, Signore A, Williams AJ, Beales PE. NOD mouse colonies around the world--recent facts and figures. Immunol Today 1993; 14:193-6.

278. Delovitch TL, Singh B. The nonobese diabetic mouse as a model of autoimmune diabetes: immune dysregulation gets the NOD. Immunity 1997; 7:727-38.

279. Lernmark A. Immune intervention yes, but for what reason, for whom, when and how? Diabetologia 1992; 35:1096-8.

280. Bach JF. Insulin-dependent diabetes mellitus as an autoimmune disease. Endocr Rev 1994; 15:516-42.

281. Rolandsson O, Hagg E, Hampe C, Sullivan EP, Jr., Nilsson M, Jansson G, et al. Glutamate decarboxylase (GAD65) and tyrosine phosphatase-like protein (IA-2) autoantibodies index in a regional population is related to glucose intolerance and body mass index. Diabetologia 1999; 42:555-9.

282. Leslie RD, Atkinson MA, Notkins AL. Autoantigens IA-2 and GAD in Type I (insulin-dependent) diabetes. Diabetologia 1999; 42:3-14.

283. Verge CF, Gianani R, Kawasaki E, Yu L, Pietropaolo M, Chase HP, et al. Number of autoantibodies (against insulin, GAD or ICA512/IA2) rather than particular autoantibody specificities determines risk of type I diabetes. J Autoimmun 1996; 9:379-83.

284. Vardi P, Ziegler AG, Mathews JH, Dib S, Keller RJ, Ricker AT, et al. Concentration of insulin autoantibodies at onset of type I diabetes. Inverse log-linear correlation with age. Diabetes Care 1988; 11:736-9.

285. Ziegler AG, Hummel M, Schenker M, Bonifacio E. Autoantibody appearance and risk for development of childhood diabetes in offspring of parents with type 1 diabetes: the 2-year analysis of the German BABYDIAB Study. Diabetes 1999; 48:460-8.

286. Sabbah E, Savola K, Kulmala P, Reijonen H, Veijola R, Vahasalo P, et al. Diseaseassociated autoantibodies and HLA-DQB1 genotypes in children with newly diagnosed insulin-dependent diabetes mellitus (IDDM). The Childhood Diabetes in Finland Study Group. Clin Exp Immunol 1999; 116:78-83.

287. Holmberg H, Vaarala O, Sadauskaite-Kuehne V, Ilonen J, Padaiga Z, Ludvigsson J. Higher prevalence of autoantibodies to insulin and GAD65 in Swedish compared to Lithuanian children with type 1 diabetes. Diabetes Res Clin Pract 2006; 72:308-14.

288. Winter WE, Harris N, Schatz D. Type 1 diabetes islet autoantibody markers. Diabetes Technol Ther 2002; 4:817-39.

289. Strebelow M, Schlosser M, Ziegler B, Rjasanowski I, Ziegler M. Karlsburg Type I diabetes risk study of a general population: frequencies and interactions of the four major Type I diabetes-associated autoantibodies studied in 9419 schoolchildren. Diabetologia 1999; 42:661-70.

290. Atkinson MA, Maclaren NK. The pathogenesis of insulin-dependent diabetes mellitus. N Engl J Med 1994; 331:1428-36.

291. Zimmet PZ, Tuomi T, Mackay IR, Rowley MJ, Knowles W, Cohen M, et al. Latent autoimmune diabetes mellitus in adults (LADA): the role of antibodies to glutamic acid decarboxylase in diagnosis and prediction of insulin dependency. Diabet Med 1994; 11:299-303.

292. Bingley PJ, Christie MR, Bonifacio E, Bonfanti R, Shattock M, Fonte MT, et al. Combined analysis of autoantibodies improves prediction of IDDM in islet cell antibody-positive relatives. Diabetes 1994; 43:1304-10. 
293. Christie MR, Genovese S, Cassidy D, Bosi E, Brown TJ, Lai M, et al. Antibodies to islet $37 \mathrm{k}$ antigen, but not to glutamate decarboxylase, discriminate rapid progression to IDDM in endocrine autoimmunity. Diabetes 1994; 43:1254-9.

294. Kulmala P, Savola K, Petersen JS, Vahasalo P, Karjalainen J, Lopponen T, et al. Prediction of insulin-dependent diabetes mellitus in siblings of children with diabetes. A population-based study. The Childhood Diabetes in Finland Study Group. J Clin Invest 1998; 101:327-36.

295. Bonifacio E, Ziegler AG. Advances in the prediction and natural history of type 1 diabetes. Endocrinol Metab Clin North Am 2010; 39:513-25.

296. Achenbach P, Warncke K, Reiter J, Naserke HE, Williams AJ, Bingley PJ, et al. Stratification of type 1 diabetes risk on the basis of islet autoantibody characteristics. Diabetes 2004; 53:384-92.

297. Borg H, Gottsater A, Fernlund P, Sundkvist G. A 12-year prospective study of the relationship between islet antibodies and beta-cell function at and after the diagnosis in patients with adult-onset diabetes. Diabetes 2002; 51:1754-62.

298. Wenzlau JM, Juhl K, Yu L, Moua O, Sarkar SA, Gottlieb P, et al. The cation efflux transporter ZnT8 (Slc30A8) is a major autoantigen in human type 1 diabetes. Proc Natl Acad Sci U S A 2007; 104:17040-5.

299. Bingley PJ, Bonifacio E, Williams AJ, Genovese S, Bottazzo GF, Gale EA. Prediction of IDDM in the general population: strategies based on combinations of autoantibody markers. Diabetes 1997; 46:1701-10.

300. Gale EA. The rise of childhood type 1 diabetes in the 20th century. Diabetes 2002; 51:3353-61.

301. Dahlquist G, Mustonen L. Analysis of 20 years of prospective registration of childhood onset diabetes time trends and birth cohort effects. Swedish Childhood Diabetes Study Group. Acta Paediatr 2000; 89:1231-7.

302. Berhan Y, Waernbaum I, Lind T, Mollsten A, Dahlquist G. Thirty years of prospective nationwide incidence of childhood type 1 diabetes: the accelerating increase by time tends to level off in Sweden. Diabetes 2011; 60:577-81.

303. Rawshani A, Landin-Olsson M, Svensson AM, Nystrom L, Arnqvist HJ, Bolinder J, et al. The incidence of diabetes among 0-34 year olds in Sweden: new data and better methods. Diabetologia 2014; 57:1375-81.

304. Atkinson MA, Eisenbarth GS. Type 1 diabetes: new perspectives on disease pathogenesis and treatment. Lancet 2001; 358:221-9.

305. Rabinovitch A, Suarez-Pinzon WL, Sorensen O, Bleackley RC, Power RF. IFNgamma gene expression in pancreatic islet-infiltrating mononuclear cells correlates with autoimmune diabetes in nonobese diabetic mice. J Immunol 1995; 154:4874-82.

306. Pearl-Yafe M, Kaminitz A, Yolcu ES, Yaniv I, Stein J, Askenasy N. Pancreatic islets under attack: cellular and molecular effectors. Curr Pharm Des 2007; 13:749-60.

307. Yoon JW, Jun HS, Santamaria P. Cellular and molecular mechanisms for the initiation and progression of beta cell destruction resulting from the collaboration between macrophages and T cells. Autoimmunity 1998; 27:109-22.

308. Moriwaki M, Itoh N, Miyagawa J, Yamamoto K, Imagawa A, Yamagata K, et al. Fas and Fas ligand expression in inflamed islets in pancreas sections of patients with recent-onset Type I diabetes mellitus. Diabetologia 1999; 42:1332-40.

309. Rabinovitch A, Suarez-Pinzon WL. Cytokines and their roles in pancreatic islet betacell destruction and insulin-dependent diabetes mellitus. Biochem Pharmacol 1998; 55:1139-49.

310. Liblau RS, Singer SM, McDevitt HO. Th1 and Th2 CD4+ T cells in the pathogenesis of organ-specific autoimmune diseases. Immunol Today 1995; 16:34-8. 
311. Kallmann BA, Huther M, Tubes M, Feldkamp J, Bertrams J, Gries FA, et al. Systemic bias of cytokine production toward cell-mediated immune regulation in IDDM and toward humoral immunity in Graves' disease. Diabetes 1997; 46:237-43.

312. Berman MA, Sandborg CI, Wang Z, Imfeld KL, Zaldivar F, Jr., Dadufalza V, et al. Decreased IL-4 production in new onset type I insulin-dependent diabetes mellitus. J Immunol 1996; 157:4690-6.

313. Honkanen J, Nieminen JK, Gao R, Luopajarvi K, Salo HM, Ilonen J, et al. IL-17 immunity in human type 1 diabetes. J Immunol 2010; 185:1959-67.

314. Marwaha AK, Crome SQ, Panagiotopoulos C, Berg KB, Qin H, Ouyang Q, et al. Cutting edge: Increased IL-17-secreting T cells in children with new-onset type 1 diabetes. J Immunol 2010; 185:3814-8.

315. Ryba-Stanislawowska M, Skrzypkowska M, Mysliwska J, Mysliwiec M. The serum IL-6 profile and Treg/Th17 peripheral cell populations in patients with type 1 diabetes. Mediators Inflamm 2013; 2013:205284.

316. Ryba-Stanislawowska M, Skrzypkowska M, Mysliwiec M, Mysliwska J. Loss of the balance between CD4(+)Foxp3(+) regulatory T cells and CD4(+)IL17A(+) Th17 cells in patients with type 1 diabetes. Hum Immunol 2013; 74:701-7.

317. Lindley S, Dayan CM, Bishop A, Roep BO, Peakman M, Tree TI. Defective suppressor function in CD4(+)CD25(+) T-cells from patients with type 1 diabetes. Diabetes 2005; 54:92-9.

318. Brusko T, Wasserfall C, McGrail K, Schatz R, Viener HL, Schatz D, et al. No alterations in the frequency of FOXP3+ regulatory T-cells in type 1 diabetes. Diabetes 2007; 56:604-12.

319. Wallden J, Honkanen J, Ilonen J, Ludvigsson J, Vaarala O. No evidence for activation of $\mathrm{T}(\mathrm{H}) 1$ or $\mathrm{T}(\mathrm{H}) 17$ pathways in unstimulated peripheral blood mononuclear cells from children with beta-cell autoimmunity or T1D. J Inflamm Res 2008; 1:11-7.

320. Malik FS, Taplin CE. Insulin therapy in children and adolescents with type 1 diabetes. Paediatr Drugs 2014; 16:141-50.

321. Sundberg F, Sand P, Forsander G. Health-related quality of life in preschool children with Type 1 diabetes. Diabetic medicine : a journal of the British Diabetic Association 2014.

322. Hanberger L, Ludvigsson J, Nordfeldt S. Health-related quality of life in intensively treated young patients with type 1 diabetes. Pediatric diabetes 2009; 10:374-81.

323. Mahmud FH, Murray JA, Kudva YC, Zinsmeister AR, Dierkhising RA, Lahr BD, et al. Celiac disease in type 1 diabetes mellitus in a North American community: prevalence, serologic screening, and clinical features. Mayo Clin Proc 2005; 80:142934.

324. Bybrant MC, Ortqvist E, Lantz S, Grahnquist L. High prevalence of celiac disease in Swedish children and adolescents with type 1 diabetes and the relation to the Swedish epidemic of celiac disease: a cohort study. Scand J Gastroenterol 2013.

325. Scaramuzza AE, Mantegazza C, Bosetti A, Zuccotti GV. Type 1 diabetes and celiac disease: The effects of gluten free diet on metabolic control. World J Diabetes 2013; 4:130-4.

326. Waernbaum I, Blohme G, Ostman J, Sundkvist G, Eriksson JW, Arnqvist HJ, et al. Excess mortality in incident cases of diabetes mellitus aged 15 to 34 years at diagnosis: a population-based study (DISS) in Sweden. Diabetologia 2006; 49:653-9.

327. Secrest AM, Becker DJ, Kelsey SF, LaPorte RE, Orchard TJ. All-cause mortality trends in a large population-based cohort with long-standing childhood-onset type 1 diabetes: the Allegheny County type 1 diabetes registry. Diabetes Care 2010; 33:25739. 
328. Secrest AM, Becker DJ, Kelsey SF, Laporte RE, Orchard TJ. Cause-specific mortality trends in a large population-based cohort with long-standing childhood-onset type 1 diabetes. Diabetes 2010; 59:3216-22.

329. Weiderpass E, Gridley G, Nyren O, Pennello G, Landstrom AS, Ekbom A. Causespecific mortality in a cohort of patients with diabetes mellitus: a population-based study in Sweden. J Clin Epidemiol 2001; 54:802-9.

330. Webb RT, Lichtenstein P, Dahlin M, Kapur N, Ludvigsson JF, Runeson B. Unnatural deaths in a national cohort of people diagnosed with diabetes. Diabetes Care 2014; 37:2276-83.

331. DCCT. The effect of intensive treatment of diabetes on the development and progression of long-term complications in insulin-dependent diabetes mellitus. The Diabetes Control and Complications Trial Research Group. The New England journal of medicine 1993; 329:977-86.

332. Bojestig M, Arnqvist HJ, Hermansson G, Karlberg BE, Ludvigsson J. Declining incidence of nephropathy in insulin-dependent diabetes mellitus. The New England journal of medicine 1994; 330:15-8.

333. Nordwall M, Bojestig M, Arnqvist HJ, Ludvigsson J. Declining incidence of severe retinopathy and persisting decrease of nephropathy in an unselected population of Type 1 diabetes-the Linkoping Diabetes Complications Study. Diabetologia 2004; 47:1266-72.

334. Ludvigsson J, Heding L, Lieden G, Marner B, Lernmark A. Plasmapheresis in the initial treatment of insulin-dependent diabetes mellitus in children. British medical journal 1983; 286:176-8.

335. Stiller CR, Dupre J, Gent M, Jenner MR, Keown PA, Laupacis A, et al. Effects of cyclosporine immunosuppression in insulin-dependent diabetes mellitus of recent onset. Science 1984; 223:1362-7.

336. Sherry N, Hagopian W, Ludvigsson J, Jain SM, Wahlen J, Ferry RJ, Jr., et al. Teplizumab for treatment of type 1 diabetes (Protege study): 1-year results from a randomised, placebo-controlled trial. Lancet 2011; 378:487-97.

337. Hagopian W, Ferry RJ, Jr., Sherry N, Carlin D, Bonvini E, Johnson S, et al. Teplizumab preserves C-peptide in recent-onset type 1 diabetes: two-year results from the randomized, placebo-controlled Protege trial. Diabetes 2013; 62:3901-8.

338. Ludvigsson J, Krisky D, Casas R, Battelino T, Castano L, Greening J, et al. GAD65 antigen therapy in recently diagnosed type 1 diabetes mellitus. The New England journal of medicine 2012; 366:433-42.

339. Ludvigsson J, Faresjo M, Hjorth M, Axelsson S, Cheramy M, Pihl M, et al. GAD treatment and insulin secretion in recent-onset type 1 diabetes. N Engl J Med 2008; 359:1909-20.

340. DPT-1. Effects of insulin in relatives of patients with type 1 diabetes mellitus. The New England journal of medicine 2002; 346:1685-91.

341. Skyler JS, Krischer JP, Wolfsdorf J, Cowie C, Palmer JP, Greenbaum C, et al. Effects of oral insulin in relatives of patients with type 1 diabetes: The Diabetes Prevention Trial--Type 1. Diabetes Care 2005; 28:1068-76.

342. Nanto-Salonen K, Kupila A, Simell S, Siljander H, Salonsaari T, Hekkala A, et al. Nasal insulin to prevent type 1 diabetes in children with HLA genotypes and autoantibodies conferring increased risk of disease: a double-blind, randomised controlled trial. Lancet 2008; 372:1746-55.

343. Knip M, Akerblom HK, Becker D, Dosch HM, Dupre J, Fraser W, et al. Hydrolyzed infant formula and early beta-cell autoimmunity: a randomized clinical trial. JAMA : the journal of the American Medical Association 2014; 311:2279-87. 
344. Gale EA, Bingley PJ, Emmett CL, Collier T. European Nicotinamide Diabetes Intervention Trial (ENDIT): a randomised controlled trial of intervention before the onset of type 1 diabetes. Lancet 2004; 363:925-31.

345. Ljungberg M, Korpela R, Ilonen J, Ludvigsson J, Vaarala O. Probiotics for the prevention of beta cell autoimmunity in children at genetic risk of type 1 diabetes--the PRODIA study. Ann N Y Acad Sci 2006; 1079:360-4.

346. Calcinaro F, Dionisi S, Marinaro M, Candeloro P, Bonato V, Marzotti S, et al. Oral probiotic administration induces interleukin-10 production and prevents spontaneous autoimmune diabetes in the non-obese diabetic mouse. Diabetologia 2005; 48:156575.

347. Matsuzaki T, Nagata Y, Kado S, Uchida K, Kato I, Hashimoto S, et al. Prevention of onset in an insulin-dependent diabetes mellitus model, NOD mice, by oral feeding of Lactobacillus casei. APMIS 1997; 105:643-9.

348. Troncone R, Bhatnagar S, Butzner D, Cameron D, Hill I, Hoffenberg E, et al. Celiac disease and other immunologically mediated disorders of the gastrointestinal tract: Working Group report of the second World Congress of Pediatric Gastroenterology, Hepatology, and Nutrition. J Pediatr Gastroenterol Nutr 2004; 39 Suppl 2:S601-10.

349. Tamayo P, Slonim D, Mesirov J, Zhu Q, Kitareewan S, Dmitrovsky E, et al. Interpreting patterns of gene expression with self-organizing maps: methods and application to hematopoietic differentiation. Proc Natl Acad Sci U S A 1999; 96:290712.

350. Arikawa E, Sun Y, Wang J, Zhou Q, Ning B, Dial SL, et al. Cross-platform comparison of SYBR Green real-time PCR with TaqMan PCR, microarrays and other gene expression measurement technologies evaluated in the MicroArray Quality Control (MAQC) study. BMC Genomics 2008; 9:328.

351. Bender R, Lange S. Multiple test procedures other than Bonferroni's deserve wider use. BMJ 1999; 318:600-1.

352. Bland JM, Altman DG. Multiple significance tests: the Bonferroni method. BMJ 1995; 310: 170 .

353. Raychaudhuri S, Sutphin PD, Chang JT, Altman RB. Basic microarray analysis: grouping and feature reduction. Trends Biotechnol 2001; 19:189-93.

354. Gerling IC, Singh S, Lenchik NI, Marshall DR, Wu J. New data analysis and mining approaches identify unique proteome and transcriptome markers of susceptibility to autoimmune diabetes. Mol Cell Proteomics 2006; 5:293-305.

355. Wu J, Lenchik NI, Gerling IC. Approaches to reduce false positives and false negatives in the analysis of microarray data: applications in type 1 diabetes research. BMC Genomics 2008; 9 Suppl 2:S12.

356. Verhoeckx KC, Gaspari M, Bijlsma S, van der Greef J, Witkamp RF, Doornbos RP, et al. In search of secreted protein biomarkers for the anti-inflammatory effect of beta2adrenergic receptor agonists: application of DIGE technology in combination with multivariate and univariate data analysis tools. J Proteome Res 2005; 4:2015-23.

357. Raychaudhuri S, Stuart JM, Altman RB. Principal components analysis to summarize microarray experiments: application to sporulation time series. Pac Symp Biocomput 2000:455-66.

358. Toronen P, Kolehmainen M, Wong G, Castren E. Analysis of gene expression data using self-organizing maps. FEBS Lett 1999; 451:142-6.

359. Bragde H, Jansson U, Jarlsfelt I, Soderman J. Gene expression profiling of duodenal biopsies discriminates celiac disease mucosa from normal mucosa. Pediatr Res 2011; 69:530-7. 
360. Tjellstrom B, Hogberg L, Stenhammar L, Falth-Magnusson K, Magnusson KE, Norin $\mathrm{E}$, et al. Faecal short-chain fatty acid pattern in childhood coeliac disease is normalised after more than one year's gluten-free diet. Microb Ecol Health Dis 2013; 24.

361. Wapenaar MC, van Belzen MJ, Fransen JH, Sarasqueta AF, Houwen RH, Meijer JW, et al. The interferon gamma gene in celiac disease: augmented expression correlates with tissue damage but no evidence for genetic susceptibility. J Autoimmun 2004; 23:183-90.

362. Walsh SV, Hopkins AM, Nusrat A. Modulation of tight junction structure and function by cytokines. Adv Drug Deliv Rev 2000; 41:303-13.

363. Youakim A, Ahdieh M. Interferon-gamma decreases barrier function in T84 cells by reducing ZO-1 levels and disrupting apical actin. The American journal of physiology 1999; 276:G1279-88.

364. Vorobjova T, Uibo O, Ojakivi I, Teesalu K, Panarina M, Heilman K, et al. Lower Expression of Tight Junction Protein 1 Gene and Increased FOXP3 Expression in the Small Bowel Mucosa in Coeliac Disease and Associated Type 1 Diabetes Mellitus. Int Arch Allergy Immunol 2011; 156:451-61.

365. Pizzuti D, Bortolami M, Mazzon E, Buda A, Guariso G, D'Odorico A, et al. Transcriptional downregulation of tight junction protein $\mathrm{ZO}-1$ in active coeliac disease is reversed after a gluten-free diet. Digestive and liver disease : official journal of the Italian Society of Gastroenterology and the Italian Association for the Study of the Liver 2004; 36:337-41.

366. Schulzke JD, Bentzel CJ, Schulzke I, Riecken EO, Fromm M. Epithelial tight junction structure in the jejunum of children with acute and treated celiac sprue. Pediatric research 1998; 43:435-41.

367. Sjoberg V, Sandstrom O, Hedberg M, Hammarstrom S, Hernell O, Hammarstrom ML. Intestinal T-cell responses in celiac disease - impact of celiac disease associated bacteria. PLoS One 2013; 8:e53414.

368. Ayyoub M, Deknuydt F, Raimbaud I, Dousset C, Leveque L, Bioley G, et al. Human memory FOXP3+ Tregs secrete IL-17 ex vivo and constitutively express the T(H)17 lineage-specific transcription factor RORgamma t. Proc Natl Acad Sci U S A 2009; 106:8635-40.

369. Komatsu N, Mariotti-Ferrandiz ME, Wang Y, Malissen B, Waldmann H, Hori S. Heterogeneity of natural Foxp3+ T cells: a committed regulatory T-cell lineage and an uncommitted minor population retaining plasticity. Proc Natl Acad Sci U S A 2009; 106: $1903-8$.

370. Zhou X, Bailey-Bucktrout SL, Jeker LT, Penaranda C, Martinez-Llordella M, Ashby $\mathrm{M}$, et al. Instability of the transcription factor Foxp3 leads to the generation of pathogenic memory T cells in vivo. Nat Immunol 2009; 10:1000-7.

371. Beriou G, Costantino CM, Ashley CW, Yang L, Kuchroo VK, Baecher-Allan C, et al. IL-17-producing human peripheral regulatory $\mathrm{T}$ cells retain suppressive function. Blood 2009; 113:4240-9.

372. Ye J, Su X, Hsueh EC, Zhang Y, Koenig JM, Hoft DF, et al. Human tumor-infiltrating Th17 cells have the capacity to differentiate into IFN-gamma+ and FOXP3+ T cells with potent suppressive function. Eur J Immunol 2011; 41:936-51.

373. Sperandeo MP, Tosco A, Izzo V, Tucci F, Troncone R, Auricchio R, et al. Potential celiac patients: a model of celiac disease pathogenesis. PLoS One 2011; 6:e21281.

374. Blaschitz C, Raffatellu M. Th17 cytokines and the gut mucosal barrier. J Clin Immunol 2010; 30:196-203.

375. Daum S, Bauer U, Foss HD, Schuppan D, Stein H, Riecken EO, et al. Increased expression of mRNA for matrix metalloproteinases-1 and -3 and tissue inhibitor of 
metalloproteinases-1 in intestinal biopsy specimens from patients with coeliac disease. Gut 1999; 44:17-25.

376. Salmela MT, Pender SL, Reunala T, MacDonald T, Saarialho-Kere U. Parallel expression of macrophage metalloelastase (MMP-12) in duodenal and skin lesions of patients with dermatitis herpetiformis. Gut 2001; 48:496-502.

377. Mohamed BM, Feighery C, Kelly J, Coates C, O'Shea U, Barnes L, et al. Increased protein expression of matrix metalloproteinases $-1,-3$, and -9 and TIMP-1 in patients with gluten-sensitive enteropathy. Dig Dis Sci 2006; 51:1862-8.

378. Goetzl EJ, Banda MJ, Leppert D. Matrix metalloproteinases in immunity. J Immunol 1996; 156:1-4.

379. Bamba S, Andoh A, Yasui H, Araki Y, Bamba T, Fujiyama Y. Matrix metalloproteinase-3 secretion from human colonic subepithelial myofibroblasts: role of interleukin-17. J Gastroenterol 2003; 38:548-54.

380. Diosdado B, van Oort E, Wijmenga C. "Coelionomics": towards understanding the molecular pathology of coeliac disease. Clin Chem Lab Med 2005; 43:685-95.

381. Pender SL, Tickle SP, Docherty AJ, Howie D, Wathen NC, MacDonald TT. A major role for matrix metalloproteinases in T cell injury in the gut. J Immunol 1997; 158:1582-90.

382. Mesturini R, Nicola S, Chiocchetti A, Bernardone IS, Castelli L, Bensi T, et al. ICOS cooperates with CD28, IL-2, and IFN-gamma and modulates activation of human naive CD4+ T cells. Eur J Immunol 2006; 36:2601-12.

383. Haimila K, Smedberg T, Mustalahti K, Maki M, Partanen J, Holopainen P. Genetic association of coeliac disease susceptibility to polymorphisms in the ICOS gene on chromosome 2q33. Genes Immun 2004; 5:85-92.

384. Lundholm M, Mayans S, Motta V, Lofgren-Burstrom A, Danska J, Holmberg D. Variation in the $\mathrm{Cd} 3$ zeta $(\mathrm{Cd} 247)$ gene correlates with altered $\mathrm{T}$ cell activation and is associated with autoimmune diabetes. J Immunol 2010; 184:5537-44.

385. Gorman CL, Russell AI, Zhang Z, Cunninghame Graham D, Cope AP, Vyse TJ. Polymorphisms in the CD3Z gene influence TCRzeta expression in systemic lupus erythematosus patients and healthy controls. J Immunol 2008; 180:1060-70.

386. Berg L, Ronnelid J, Klareskog L, Bucht A. Down-regulation of the T cell receptor CD3 zeta chain in rheumatoid arthritis (RA) and its influence on $\mathrm{T}$ cell responsiveness. Clin Exp Immunol 2000; 120:174-82.

387. Tjon JM, Verbeek WH, Kooy-Winkelaar YM, Nguyen BH, van der Slik AR, Thompson A, et al. Defective synthesis or association of T-cell receptor chains underlies loss of surface T-cell receptor-CD3 expression in enteropathy-associated Tcell lymphoma. Blood 2008; 112:5103-10.

388. Weigmann B, Lehr HA, Yancopoulos G, Valenzuela D, Murphy A, Stevens S, et al. The transcription factor NFATc2 controls IL-6-dependent T cell activation in experimental colitis. J Exp Med 2008; 205:2099-110.

389. Wing K, Onishi Y, Prieto-Martin P, Yamaguchi T, Miyara M, Fehervari Z, et al. CTLA-4 control over Foxp3+ regulatory T cell function. Science 2008; 322:271-5.

390. Uibo R, Panarina M, Teesalu K, Talja I, Sepp E, Utt M, et al. Celiac disease in patients with type 1 diabetes: a condition with distinct changes in intestinal immunity? Cell Mol Immunol 2011; 8:150-6.

391. Andoh A, Takaya H, Makino J, Sato H, Bamba S, Araki Y, et al. Cooperation of interleukin-17 and interferon-gamma on chemokine secretion in human fetal intestinal epithelial cells. Clin Exp Immunol 2001; 125:56-63. 
392. Tack GJ, van Wanrooij RL, Von Blomberg BM, Amini H, Coupe VM, Bonnet P, et al. Serum parameters in the spectrum of coeliac disease: beyond standard antibody testing--a cohort study. BMC Gastroenterol 2012; 12:159.

393. Santangelo C, Scipioni A, Marselli L, Marchetti P, Dotta F. Suppressor of cytokine signaling gene expression in human pancreatic islets: modulation by cytokines. Eur $\mathrm{J}$ Endocrinol 2005; 152:485-9.

394. Mori H, Shichita T, Yu Q, Yoshida R, Hashimoto M, Okamoto F, et al. Suppression of SOCS3 expression in the pancreatic beta-cell leads to resistance to type 1 diabetes. Biochem Biophys Res Commun 2007; 359:952-8.

395. Arif S, Moore F, Marks K, Bouckenooghe T, Dayan CM, Planas R, et al. Peripheral and Islet Interleukin-17 Pathway Activation Characterizes Human Autoimmune Diabetes and Promotes Cytokine-Mediated \{beta\}-Cell Death. Diabetes 2011; 60:2112-9.

396. Frisullo G, Nociti V, Iorio R, Patanella AK, Plantone D, Bianco A, et al. T-bet and pSTAT-1 expression in PBMC from coeliac disease patients: new markers of disease activity. Clin Exp Immunol 2009; 158:106-14.

397. Lettesjo H, Hansson T, Bergqvist A, Gronlund J, Dannaeus A. Enhanced interleukin18 levels in the peripheral blood of children with coeliac disease. Clin Exp Immunol 2005; 139:138-43.

398. Benahmed M, Meresse B, Arnulf B, Barbe U, Mention JJ, Verkarre V, et al. Inhibition of TGF-beta signaling by IL-15: a new role for IL-15 in the loss of immune homeostasis in celiac disease. Gastroenterology 2007; 132:994-1008.

399. Di Sabatino A, D'Alo S, Millimaggi D, Ciccocioppo R, Parroni R, Sciarra G, et al. Apoptosis and peripheral blood lymphocyte depletion in coeliac disease. Immunology 2001; 103:435-40.

400. Siljander HT, Simell S, Hekkala A, Lahde J, Simell T, Vahasalo P, et al. Predictive characteristics of diabetes-associated autoantibodies among children with HLAconferred disease susceptibility in the general population. Diabetes 2009; 58:2835-42.

401. Wolk K, Docke WD, von Baehr V, Volk HD, Sabat R. Impaired antigen presentation by human monocytes during endotoxin tolerance. Blood 2000; 96:218-23.

402. Lightfoot YL, Mohamadzadeh M. Tailoring gut immune responses with lipoteichoic acid-deficient Lactobacillus acidophilus. Frontiers in immunology 2013; 4:25.

403. Marschan E, Kuitunen M, Kukkonen K, Poussa T, Sarnesto A, Haahtela T, et al. Probiotics in infancy induce protective immune profiles that are characteristic for chronic low-grade inflammation. Clinical and experimental allergy : journal of the British Society for Allergy and Clinical Immunology 2008; 38:611-8. 



\section{Papers}

The articles associated with this thesis have been removed for copyright reasons. For more details about these see:

http://urn.kb.se/resolve?urn=urn:nbn:se:liu:diva- 110687 